\title{
An exploration of issues of primary health services for Taranaki Te Atiawa children based on the expectations and perceptions of their female caregivers
}

By

Patricia Helen Adams-Smith

A thesis submitted to Victoria University of Wellington in fulfilment of the requirements for the degree of

Master of Arts

In

Nursing.

Victoria University of Wellington 


\section{Contents}

Title page

Abstract

Acknowledgements

Glossary

Chapter One: Introduction to the thesis 1

Introduction to the research project 1

Reflections on the beginning of the project 3

Conclusion to chapter one 5

Chapter Two: Research context and focus 6

Introduction to chapter two 6

The journey 6

Cultural safety $\quad 11$

Consultation 16

Reflections on the journey $\quad 17$

Summary of the journey 20

Background to this project $\quad 22$

The history of Maori health in New Zealand
before colonisation

Maori and health 26

Maori models of health $\quad 29$

Summary of the background to this project 29

$\begin{array}{ll}\text { The Treaty of Waitangi } & 31\end{array}$

Maori tribal society 31

The Declaration of Independence $\quad 32$

Te Tiriti o Waitangi $\quad 33$

Principles of the Treaty 38

The place of the Treaty of Waitangi in present day New Zealand 39

The Treaty of Waitangi and health 41

Conclusion to chapter two 44

Chapter Three: Literature review $\quad 45$

Introduction to chapter three $\quad 45$

Primary health care $\quad 46$

Barriers to primary health care $\quad 47$

Access to Primary Health Care 49

Socio-economic contexts 51

The New Zealand experience $\quad 52$

The Indigenous experience 54

The Maori experience $\quad 55$

Conclusion to chapter three 58 
Chapter Four: Theoretical and philosophical position 60

Introduction to chapter four $\quad 60$

Critical Social Theory $\quad 60$

Basic design of the Critical Social Science/Theory
paradigm

Rigour, trustworthiness and limitations of Critical
Social Theory

Relevance to this research $\quad 66$

Critical Social Theory, power relations and empowerment in the New Zealand
context

Nursing and Critical Social Theory $\quad 70$

$\begin{array}{ll}\text { Reflections and Relexivity } & 74\end{array}$

Reflective practice in nursing $\quad 75$

Deep down and personal $\quad 77$

$\begin{array}{ll}\text { Participatory research } & 79\end{array}$

The emergence of participatory research $\quad 79$

The method of participatory research $\quad 81$

The process of participatory research 85

Validity and reliability of qualitative data collected

Participatory Research and health care 93

Conclusion to chapter four $\quad 94$

Chapter Five: The research design 96

Introduction to chapter five $\quad 96$

Aims of the research 96

Consent 96

Participant selection $\quad 97$

The focus group method in qualitative research 101

Advantages and limitations of the focus group 103

The interviews 103

One-to-one interviews 106

Trialing the focus group / interview guiding questions 107

Data analysis $\quad 110$

Ethical issues $\quad 111$

Summary of the research process utilised in this project 115

$\begin{array}{ll}\text { Conclusion to chapter five } & 115\end{array}$

Chapter Six: Findings from the research 116

Introduction to Chapter Six 116

Question One 117

Question Two 121

Question Three 124

Question Four $\quad 129$

Cost 130

Lack of availability of preferred choice $\quad 130$

Lack of reliable transport $\quad 131$

Issues of cultural safety $\quad 131$ 
Question Five

Issues of cultural safety 133

Preferred choice 134

Community based / environment 134

Someone to phone 135

Support 135

After hours / house calls $\quad 136$

Parenting course 136

Quality of doctors 137

Budget and nutrition advice $\quad 137$

Well child checks $\quad 137$

Information 137

$\begin{array}{ll}\text { Continuity } & 137\end{array}$

Addiction 138

Confidentiality 138

Conclusion to chapter six 139

Chapter Seven: Discussion of the findings 141

Introduction to chapter seven $\quad 141$

First theme 141

Second theme 146

Issues specific to this research project, concerning non-Maori doing research with Maori 148

Summary of the discussion $\quad 152$

Conclusion to chapter seven 154

Chapter Eight: Conclusion to the research and recommendations 156

Introduction to chapter eight $\quad 156$

Recommendations 157

Recommendation one $\quad 157$

Recommendation two 157

Recommendation three $\quad 157$

Recommendation four $\quad 158$

Recommendation five 158

Recommendation six 159

Recommendation seven $\quad 159$

Recommendation eight 159

Benefits of the research process for myself and the participants $\quad 160$

Limitations of the research project 161

Dissemination of the findings and feedback to the
participants

Conclusion to chapter eight $\quad 162$

Concluding statement of the Thesis 162

Appendices

One: The Treaty of Waitangi

A: Maori version

B: English translation of the Maori version

C: English text / 'Official' version

Two: Ethical Approval 
Three: Interview Questions

Four: Information Sheet

Five: Consent Form

\section{References}




\section{Acknowledgments}

First I would like to acknowledge and thank all the women who willingly gave up their time and energy to meet and talk to me about their expectations and perceptions of primary health services for Te Atiawa children. To the people of Te Atiawa in Taranaki, thank you for your support and approval in going ahead with this project.

I also extend my heartfelt thanks to all those who assisted the direction and completion of this project. A special thanks goes to Mina Timutimu for your consistent support and guidance throughout this project.

To my original supervisor Margaret Southwick, and to Rose McEldowney, who took over most of the supervision of the project, thank you both so much for your time and input. Rose, your unwavering support and encouragement have been inspiring. Thanks also to Joy Bickley for getting me through the last bit.

To my family and friends who put up with my behaviour and let me get on with it, especially Shane. To my boys Te Riu and Ropata for helping me to keep a healthy perspective.

A special acknowledgment goes to Kura Taylor, who acted as my personal and 'critical friend' and provided unique insights into this project, and without whom this project might never have happened. Thank you so much. Your input has been invaluable.

To the Health Research Council and the Nurses Education Research Fund, thank you for supporting this project and enabling it to proceed. 


\begin{abstract}
The debate about Maori child health in New Zealand continues perennially. The intention of this research is, through collaborative discussion and selective conversations, to explore female caregivers' expectations and perceptions of primary health services for some Te Atiawa Maori children. The research process was developed in a partnership between the Maori women participants and myself. In addition, two local kuia actively participated in and supported the process. It is hoped, through this study, to contribute new knowledge to the discussion, as I found no published research on this topic. If female caregivers choose when to access primary health services for their children, it seemed to me that they should be asked what is important to them in terms of their children's health and access they have.
\end{abstract}

Emancipatory critical social theory underpins and informs the project. Power relationships between the researcher and the participants can be overtly explored within this theoretical framework. In terms of this particular exploratory study, participatory research appeared to be applicable. The participants are female caregivers of Te Atiawa children. Data collection was done using group interactions and semi-structured interviews in the winter of the year 2000. A thematic analysis of the data was used, in which common themes were identified, compared and discussed. From the analysis of the data of the participants' conversations, I identified some key ideas. The major findings have been identified within two main themes. These are: a concept of health is not the same for Pakeha as for Maori, and access issues are still problematic for the participants in this study. Many quotes from the interview participants are included in order to keep the focus of the project on the voices of the women interviewed.

In terms of the significant contribution of this research, this study aims to allow voices of female caregivers of Te Atiawa Maori children to be heard. Individual and collaborative interactions offer insights into what is important to them in terms of Maori child health. Clearly, the primary health initiatives 
promoted by the New Zealand government are not reaching at least some of the people for whom they are intended. The research participants offered their ideas as to how these deficits could be remedied in their community. 


\section{Glossary of Maori terms used in this Thesis}

Note: Some Maori words have many different meanings. The definitions included here are congruent with the meanings of the Maori words used in the text. In some publications, Maori words may have macrons over some vowels. Instead of this, I have placed two of the same vowels together to create the same sound. For example: Whare Tapa Whaa.

\begin{tabular}{|c|c|}
\hline Aotearoa & New Zealand \\
\hline Ariki & Chiefly; leader \\
\hline Aroha & Love, compassion \\
\hline Awhi & Help, support \\
\hline Hapu & Section of a large tribe or clan; secondary tribe \\
\hline Hauora & Health, well being \\
\hline Hokianga & An area on the west coast of Northland \\
\hline Hui & Congregate; come together; meeting \\
\hline Iwi & Nation, people, tribe \\
\hline Kai & Food \\
\hline Kainga & Home, residence, village, settlement \\
\hline Karakia & Charm, incantation; prayer (modern useage) \\
\hline Kawa & Protocol \\
\hline Kawa Whakaruruhau & Cultural safety \\
\hline Kawakawa & A shrub \\
\hline Kawanatanga & Governorship \\
\hline Kaumatua & $\begin{array}{l}\text { An old man or woman; an older person with seniority in } \\
\text { the community }\end{array}$ \\
\hline Kaupapa Maori & Maori plan or proposal; underlying Maori philosophy \\
\hline Koha & Present or gift \\
\hline
\end{tabular}


Kohanga Reo

Kuia

Kumarahou

Kura

Mana

Maoritanga

Marae

Mirimiri

Mo

Mokopuna

Mokos

Nga Puna Ora o Te Atiawa

Trust

Ngaa Puutake

Pa

Pakeha

Puha

Roopu

Runanga

Tainui

Tamariki Ora

Tangata whenua

Tapu

Taranaki
Maori language nest; typically for pre-school age

Old woman; perceived to be wise, and with seniority in the community

A shrub

Place of learning, school

Authority, control, influence, prestige, power

Maori perspective, Maori culture

Enclosed space in front of a house, Maori courtyard or village common

Rub, soothe, smear

For

Grandchild / grandchildren

Plural of mokopuna

A local Maori health provider

The foundations; the ancestors

Stockade; fortified place

A person of predominantly European descent born in New Zealand; foreign

A plant

Company of persons; a group

Group (with a common purpose)

Ancestral canoe of Waikato; major Waikato tribe

Well child health

People of the land; original indigenous occupants

Under religious or superstitious restriction

Area in the west of the North Island. Name of the only mountain in this province. Name of a local tribe. 
Te

Te Atiawa

Te Maunga Hauora

Te Reo

Te Tiriti o Waitangi

Te Whare Punanga Korero 'The house where the chiefs talk'.

Te Wheke

Tiaki

Tikanga

Tino Rangatiratanga

Tuhoe

Wairua

Waitangi

Waka

Whakairotoi

Whakapapa

Whanau

Whanaungatanga

Whangai

Whare tapa whaa
The

A Taranaki tribe.

A Taranaki health organisation.

The Maori language

The Treaty of Waitangi

The octopus

Guard or keep safe

Customs, meaning, obligations, criterion.

Absolute sovereignty.

A tribe based in the center and on the east coast of New Zealand

Spirit

Historic settlement in Northland where the Treaty of Waitangi was signed.

Canoe

Maori carving, engraving.

Genealogy, family, cultural identity.

Offspring; family group generally comprising both nuclear and extended family

Relationship, kinship and the support inherent in these ties

Feed, nourish, bring up

A four-sided house 


\section{Chapter One Introduction to the research project}

\section{Introduction to chapter one}

Maori child health needs in New Zealand (NZ) are not being adequately met, in spite of efforts to remedy this, according to the literature (see Chapter three) and to anecdotal evidence (Malcolm, 1996; Parata \& Durie, 1993; Pomare, 1995; Te Puni Kokiri, 1998; The Maori Health Commission [MHC], 1998). The research project on which this thesis is based planned to explore the veracity of this statement for Maori children in a local community.

This thesis is the academic presentation of a research project about issues of primary health services for Taranaki Te Atiawa children. The full project title is: "An exploration of issues of primary health services for Taranaki Te Atiawa children, based on the expectations and perceptions of their female caregivers".

I am aware that the audience for this work is likely to be a varied group, including the Maori whanau who were involved in this research, and the Maori roopu who supported the project. This work is likely to be of interest to local Maori health workers and Maori health providers in Taranaki, Maori researchers and academics, and non-Maori researchers and academics, both in New Zealand and overseas. It may be that members of this audience take a different view to what is presented here. However, it is my fervent hope that the voices of the participants resonate throughout this work, which, after all, belongs to them and their community.

The participants' personal demographics, such as the annual amount a family earns, have not been included in this project. The rationale for this is twofold. Firstly, I felt that asking about demographics in a noted 'poor' community might be felt to be intrusive, and might put off potential participants (Statistics NZ, 1996). Secondly, I did not think such data would add to the knowledge sought and gained in this study. Many of the things 
the women discuss do pertain to demographics, albeit indirectly. The importance is in their experiences, beliefs and needs, which the women speak of in conversations and stories.

However, some demographics about the researched community may be usefully included here. Maori women are generally responsible for enhancing and maintaining family health (Ministry Of Health $[\mathrm{MOH}]$, 1998a), though caring for children has traditionally been a family responsibility for Maori (Durie, 1998a; Pihama, 1993). It is estimated that single Maori women head at least $43 \%$ of Maori families with dependent children in New Zealand (Statistics NZ, 1996). In the community in which the research took place, there are at least 186 single Maori mothers (Statistics NZ).

In considering whom to seek as participants it was decided to include caregivers of more than one child, as their experiences with child health were likely to be richer. It was anticipated that the female caregivers involved in this exploratory study might be Te Atiawa, and this turned out to be true in some cases. That is, it was important that the children identify as Te Atiawa, and the fact that some of the female caregivers do is serendipitous. All the women who chose to take part identify as Maori.

This was an exploratory study, which aimed through collaborative and explicitly interactive discussion and selective conversations to:

1. Provide insights into Maori child health through the voices of female caregivers.

2. Allow the voices of local women to define what is important to them in terms of Maori child health.

3. Contribute new knowledge to the discussion on Maori child health.

This thesis is organised into chapters that deal with various aspects of the project. Chapter one introduces the project and my reflections on this beginning. Chapter two deals with the research focus and context, including sections about the journey of the research, some background to the project, 
cultural safety and consultation issues, and the Treaty of Waitangi. Chapter three contains a review of the relevant international and national literature. Chapter four discusses the theoretical and philosophical underpinnings of the project - Critical Social Theory. The methodology used and explained is Participatory Research. This chapter also includes a section on the use of reflexivity in nursing. Chapter five explains the research design, including the method, participant selection, data collection and analysis, and there is a section on ethical issues. Chapter six explicates the research findings, while a discussion of the findings is found in Chapter seven. Chapter eight contains recommendations based on the findings and the conclusion to the thesis. There are appendices with a glossary of Maori terms and three versions of the Treaty of Waitangi. Included in the appendices are copies of the Ethical Approval and the list of interview questions used. Examples of both the information sheet given to the participants, and the consent form that they signed can be found here. A reference section ends the thesis. My own reflections appear throughout the text.

\section{Reflections on the beginning of the project}

In my inexperience as a new researcher, I assumed that a research process went along one stage at a time, as if following the contents page of a thesis in a linear fashion. I should have known better. Nothing in my life has ever proceeded one step at a time, and this project was no different. I had heaps of ideas rolling around in my brain. I thought that perhaps I could incorporate a nursing and social anthropology project together, since I have undergraduate degrees in both these disciplines. I hoped to do research with women at the Kohanga Reo that my children attended. My children have a Maori father, and are being raised bilingually and biculturally. A Maori colleague at the time told me that to consider such research was inappropriate for me as a Pakeha. However, I was encouraged by a Te Atiawa health worker to continue. So I dropped in to a local community Maori health office and had a chat with the Te Atiawa nurse there, henceforth referred to as Auntie T. Auntie T is a kuia in the community where I undertook the research. That is, she has seniority in the community, 
carries a great deal of mana and is well known by, and related to, many local Maori. She offered to be a partner in this project. We sat down and had a chat about the worries we had about the local Maori children, and what we perceived to be barriers to primary health services for them. Auntie T and I have worked together on child health projects in our local community before, so it seemed a really good idea to work together. I was aware that with Auntie T supporting the project, community approval would be much easier. I explained that five mothers of children at the Kohanga Reo that my children attended had spoken of barriers to health care for their children. Together Auntie T and I wondered if there was a way in which to discover whether the New Zealand health reforms of the 1990s had had any effect on our local community. Thus was this project born.

One day at a hui facilitated by Auntie T, I was lucky enough to find myself sitting beside a well known Te Atiawa academic who is a cousin of Auntie T. Henceforth referred to as $\mathrm{M}$, she kindly took me under her wing and became my 'critical friend' through the process of this project. Both $\mathrm{M}$ and Auntie $\mathrm{T}$ have commented on various parts of the project, and assisted me to make changes. They have walked beside me the whole way, and have ensured that what I wrote about Maori was accurate and acceptable. They have loaned me resources I could not have sourced elsewhere. They have encouraged me to keep going and reminded me how important the knowledge gained from this project will be for our local community. Because they are tangata whenua, this project could not proceed without their approval, and they have been involved at every stage. Their input has certainly improved this research project, and has also taught me a great deal. We have brought our various skills together, and created something of use to all the people involved. To me, this is an example of how the partnership spoken of in the Treaty of Waitangi can work in practice. It has been an incredibly enriching experience.

Originally, I had been advised that the appropriate methodology for this research project was Kaupapa Maori. I understand that Kaupapa Maori research is by, with and for Maori, and is about regaining control over Maori 
knowledge and Maori resources (Keefe, Cram, Ormsby \& Ormsby, 1999). As I am not Maori, I felt very uncomfortable trying to understand my position in Kaupapa Maori methodology, where I strongly felt I did not belong. So the project instead is underpinned by critical social theory and a participatory research process, which shares power between researcher and participants is used. I consider this fits with the principle of partnership described in the Treaty of Waitangi. This is discussed further in Chapter two.

\section{Conclusion to chapter one}

This chapter has introduced the title and intent of this research thesis. It explains the organisation of the work and includes my reflections on the beginning of the project.

The next chapter is about the research focus and context. It contains sections about my journey throughout the research process, a background to the research and the position of the Treaty of Waitangi in relation to this project. 


\section{Chapter Two Research context and focus}

\section{Introduction to chapter two}

This chapter comprises three sections: the journey, background to the project, and the Treaty of Waitangi. In this section I will describe parts of the research journey that led me to believe I might be able to be involved in this particular research project. I will provide comments about my understanding of what it means to be Pakeha and working with Maori. This part of the chapter also contains comments on cultural safety, consultation and my reflections on the research process.

\section{The journey}

I am a third generation New Zealander of European origin, a Pakeha, but my family travelled around the world until I was in my twenties. As a young person, I was educated in England and the United States of America, and also lived in the Middle East, so I have had involvement with cultures other than my own. While in the Middle East, my family lived as a minority culture, though we were materially well off. Having to follow the social rules of a culture in which I was a minority, where the language was strange to me, and the religion had a powerful influence on the way people lived, was challenging and fortuitous for my future work.

I came back to New Zealand for my sixth form school year at age seventeen, and that is when I began to learn something about New Zealand, but I did not know much about Maori or New Zealand history.

I knew I wanted to study nursing before I finished high school and I went to Auckland to train. I finished my general and obstetric nurse training in 1982, and worked in a variety of clinical settings before working in paediatric nursing. I worked in the paediatric infectious diseases ward, where children of various cultures and ethnicity came through the doors. I loved working with children so much that in 1985 I went to London, England to train as a sick children's nurse. After finishing this training, and adding a paediatric 
intensive care course to my repertoire, I went to work in a children's hospital in the East End of London, where many Asian and Middle Eastern families lived. I also spent time working at a children's hospital in central London, to which children from all over the world were referred. Many came from Arabic speaking countries, and my knowledge of the language and culture was helpful. I found that my ability to communicate a few words of Arabic led to an immediate change in the parent's body language. Often they would speak to me very quickly in Arabic, so then I had to explain that I didn't understand. By this process of taking communication to the parent as much as I could, we discovered some mutual ground. My understanding of the culture meant that I knew about the difference in gender roles in Arabic and English society. For example, Arabic women tend to be most uncomfortable speaking to a man outside their immediate family circle. Traditionally, a male family member would always be present. However, in the English hospital, if this wasn't possible, having a European nurse present helped to support the Arabic women. Also, Arabic women have different ways of performing personal hygiene. Most of them stayed on the ward with their children, and they needed plastic jugs in the toilets. These were provided for them, and they were welcome in the kitchen in the evenings where they often gathered to chat, as is traditional in their society. The establishment of a rapport between the Arabic women and myself helped in the care of their children. I recall some amusing conversations I had with some of the women as I tried to explain a medical procedure. Drawing pictures was a really useful tool. A group of Arabic women squatting in a circle in the ward kitchen one night kindly offered to remove my body hair. They meant ALL my body hair. I crossed my legs in horror and politely refused, to their vast amusement. I felt as though I was looking through a window into their world and it was fascinating.

In 1991 I came back to settle in New Zealand. I went to live near my parents in a community where more than $40 \%$ of the population identify as Maori (Statistics NZ, 1996). I began studying for a Bachelor of Nursing degree combined with Social Anthropology. I found the combination of these two disciplines enhanced my studies in each. I married a man from Te 
Atiawa iwi, and we have two children. My husband had not been brought up in a way that fostered his knowledge of, and interest in, his Maori heritage.

That changed as I began studying towards a university degree. One of the social anthropology papers I studied was a Maori studies paper, and I learned something about Maori history in New Zealand. I had to explore a whakapapa, so I asked my husband if he was interested in exploring his Maori heritage. We were both fascinated by what we found, and the study of Maoritanga, Te Reo, and whakairotoi have become ongoing sources of great interest and self-esteem to my husband.

Our children attend the Maori immersion unit at the local primary school, and are both learning to read and write in Maori before they learn English. Before they started school, they were enrolled at the local Kohanga Reo where I learned my first Maori language. I also learned something of the culture of local Maori by being a whanau member of the Kohanga Reo. I come from a culture where extended family links have often been forgotten. This is certainly not true amongst Maori in the local community. I saw the way Maori processes were used to run the Kohanga Reo by a whanau group. Collective agreement was important, and everyone got a chance to present their opinion, taking as much time as they needed to. Each day at the Kohanga Reo and each hui there were opened by karakia. Only Maori was spoken in the main room where the children were. English was occasionally whispered, or spoken in the kitchen. The women there cared for and taught the children, and organised their days in ways that suited the whanau. Again, for me it was fascinating to be part of this culture on a daily basis.

Before my children were born I worked as a volunteer for a few years with the local Women's Refuge. I saw an advertisement in the local paper for volunteers needed, and undertook the training. The Women's Refuge movement in New Zealand was started in 1973 by a group of women in Christchurch to support battered women. The New Zealand National Collective of Independent Women's Refuges describes Women's Refuge as:

"a woman based organisation which has, as its guiding principles, a policy of creating a violence-free environment and community, of 
providing support and ensuring empowerment for all women and children, the establishment of parallel Refuge facilities for and by Maori women, and the development of culturally appropriate and complementary services within Refuge's own structures for women of different cultures [Parallel development is a partnership between cultures which enables each to develop services which are both culturally appropriate and complementary]. The National Collective of Independent Women's Refuges recognises and accepts Tino rangatiratanga mo te Iwi Maori” (1990).

My social conscience was horrified by the powerlessness of some of the women who phoned for advice and came to the safe house. My nursing training focusing on care and advocacy combined with my personal feminist beliefs bolstered me in the work I did with Refuge.

As well as offering safe temporary accommodation, the Women's Refuge offers practical telephone advice and support and programs for both women and children, and can refer women and children to counselling along appropriate cultural lines, social workers and other social and financial support, lawyers, legal aid, legal advocates. Maori women and children are statistically over-represented as clients of Women's Refuge, compared to their percentage of the general population.

Volunteers and paid workers at Women's Refuge, both Maori and non-Maori have to undertake a comprehensive training program before they start work. After that the training is on going and based on the principles of The Treaty of Waitangi. While there, I undertook training that involved increasing my understanding of the Treaty of Waitangi, biculturalism, parallel development, issues of power and control and homophobia. These workshops were the catalyst that began to change my perception of the society in which I was living. At 'Refuge', as we called it, I worked alongside many empowered Maori women, as well as Pakeha women who understood and accepted the principles of partnership, protection and participation, elucidated in the Treaty of Waitangi. I learned about Maori and New Zealand history, and myself, 
from the women who worked at Refuge. It was the first time that I had really seen the racism that runs through the Pakeha culture. I could see that by the actions of the Crown in not ever honouring the Treaty of Waitangi, there was no chance of an equal partnership between Maori and Pakeha in New Zealand. An unequal state of affairs means that someone has more power than someone else does. Perhaps because I had the majority of my schooling outside NZ, I was able to look at NZ racist issues from an 'outsider' focus. It seemed that the scales fell from my eyes, and the continuing struggle of NZ's indigenous people for equity and fairness in our society persists everywhere I look. Ironically, at Refuge we all worked with women and children who were powerless in some way, and who sought the help of Women's Refuge.

As I studied towards a Bachelor of Arts degree in Nursing and Social Anthropology, I learned about health in New Zealand, and about how to research areas of interest. I met Maori health workers with whom I would later forge links in the community. While I studied, I also worked as a sick children's nurse in the local hospital, and saw that there were a lot of Maori children who were admitted with illness that I believed could have been addressed at a primary health care level in the community.

The hospital system was clearly not set up to meet the needs of extended families. As the family structure is an important facet of Maori culture, this created problems for the families of sick children in hospital. Often, the people who wanted to stay with the child were not able to do so because of lack of space. There were many other issues as well, such as the use of medical language and attitudes of the health professionals towards clients whose values differed from their own. I slowly began to understand how knowledge of history and politics was important to nursing practice. In my studies I learned about the things that define a culture such as: language, customs, gender roles, the importance of and use of land, systems of economics and justice, education, food, clothing, rituals, the place of myths and legends, housing structures, lifestyles and how people of different ages fit into their society. I started to reflect on the effect that colonisation has had on the Maori population in New Zealand, and how that might be explained. 
Health statistics show that Maori children still suffer comparatively from more illnesses and hospital admissions than Pakeha children do (Te Puni Kokiri, 2000).

My reflections on these experiences together with a desire to make a difference to nursing students led me to leave my hospital job to teach for a year at the local Polytechnic in the Nursing department. I was asked to teach Kawa Whakaruruhau (cultural safety) in partnership with a Maori colleague.

\section{Cultural safety}

The notion of cultural safety in nursing in New Zealand arose out of the recognition that cultural difference is an issue for nursing practice, and should be addressed. Maori nurses suggested that we go one step further and have cultural safety in nursing (Wood \& Schwass, 1993). The concept of cultural safety was developed in NZ in the late 1980s by a group of Maori nurses (Hui Piri ki nga Tangaora, 1989). They felt that there was a need to analyse nursing practice from the perspective of the tangata whenua - the indigenous minority of NZ (Polaschek, 1998). The vision and model of cultural safety have been developed and defined by Irihapeti Ramsden, a Maori nurse educator along with other Maori nurses.

Cultural safety is defined by the Nursing Council of New Zealand [NCNZ] (1995, p.19) as: "The effective nursing of a person / family from another culture by a nurse who has undertaken a process of reflection on [their] own cultural identity and recognises the impact of the nurse's culture on [their] own nursing practice." Conversely, unsafe cultural practice is "any action which diminishes, demeans or disempowers the cultural identity and wellbeing of an individual" (NZNC, 1995,p. 19). The model of cultural safety in nursing is that of a negotiated and equal partnership in nursing education used both in New Zealand and, more lately, in some other countries. The principles of cultural safety can be applied to all cultures (Coup, 1996; Wood \& Schwass, 1993). In New Zealand / Aotearoa, the principles of cultural safety must be first demonstrated in the provision of culturally safe care for Maori, the tangata whenua (Wood \& Schwass). "Cultural safety ensures non- 
violation of all those attitudes, values and actions which implement the obligations of Te Tiriti o Waitangi and the practice of tino rangatiratanga" (Hui Piri ki nga Tangaroa, 1989, p. 10). The Nursing Council of New Zealand, which adopted the principles of cultural safety in 1992, describes the expectations for cultural safety in education as a process that "by its very nature should not place the culture of others at risk.... The process of education towards cultural safety should be examining, challenging, enlightening and ultimately, behaviour changing" (Nursing Council of New Zealand, 1992, p. 6). Research and literature on cultural safety continues to develop.

The concept of cultural safety is not the same as that of transcultural nursing, which is based on an anthropological perspective developed by Madeleine Leininger. The similarities and differences between the two approaches have been argued comprehensively by their proponents since the pathway of cultural safety in nursing was chosen for New Zealand (Cooney, 1994; Coup, 1996; Leininger, 1996). Coup (1996) believes that Leininger's approach contains elements that may be culturally inappropriate and unsafe for Maori. She suggests that it is unrealistic to expect nurses to learn "a lot of ethnographic detail" about many cultures, and that it appears the educational objectives for cultural safety in nursing are achievable and applicable for all cultures, be they minority or dominant (1996, p. 10).

The importance of cultural factors in influencing health status and health and illness behaviour is recognised in both models. However, in New Zealand, Maori nursing students identified the harmful effects of an ethnocentric nursing education system on Maori nursing students. They voiced their concerns about the effect that an ethnocentric health care system was having on the health of Maori people in general (Coup, 1996).

One of the most exciting discoveries I made was the work of Irihapeti Ramsden, in the field of Kawa Whakaruruhau specific to nursing. Ramsden (1992) believes that all people should be nursed 'regardful' of all the things that make them unique, as opposed to nursing people regardless of their race 
or religion. It is Ramsden's view that cultural safety is based in attitude change and that if safe attitudes are held by nurse practitioners, they will be able to work with "the continuum of Maori people from traditional practitioners of the culture to those who have been denied any information about our Maoritanga" (Ramsden, 1992, p. 22).

The major foci for non-Maori nursing students in striving towards culturally safe practice are racism awareness training and exploration of European cultural heritage. They learn about issues of power and inequality, and revisionist colonial history since 1840 when the Treaty of Waitangi was signed. Training in Treaty of Waitangi issues of the past, present and future is an important component of cultural safety for non-Maori nursing students (Coup, 1996). The educational curriculum framework for these nursing students was formulated through a partnership, negotiated process with Maori and non-Maori together (Coup).

For me, it was a baptism by fire. I had to learn and understand what the principles of partnership, participation and protection, which underlie the Treaty of Waitangi mean to nursing practice and education. I had to learn the history of New Zealand fast enough to keep up with the students' questions. I was fortunate that New Zealand history is not a mandatory part of the national secondary school curriculum, so most of the students came to learn kawa whakaruruhau with less knowledge, but perhaps more assumptions and erroneous beliefs than I had. I did not teach the Maori students; their issues about cultural safety were different, and they worked through their learning with the Maori tutor.

To start at the beginning and encourage the students to think about what a culture is, I designed an exercise planned to stimulate their imaginations. On the whiteboard, I drew a large square divided into various sized smaller blocks. I asked the students to get up and name a box with one aspect of any culture, their own included. The ensuing class discussion led to most of the boxes being named fairly quickly as: justice, language, health, food, land use, gender roles and family relationships, among others. Once we had 
constructed a society, we then pondered the consequences of deconstructing a society in the way that has happened to many indigenous people under the impact of colonisation. For some students, this was the first time they had ever considered the balance of power in NZ society.

The students and I grappled together with the concepts of cultural safety in nursing. We debated whether a bicultural model for nursing such as Ramsden's model, or a multicultural approach such as Madeline Leininger's transcultural nursing model, is more appropriate for professional nursing practice in New Zealand. It was agreed that Ramsden's model is more appropriate, as her bicultural model is based on the principles of the Treaty of Waitangi, which is the founding document of bicultural relations unique to New Zealand. We thought that nursing people 'regardful' of their culture, in a country where people of many cultures live, was more realistic than trying to become 'cultural ambassadors' of many cultures. The attitude shift required by the students and myself was not so easy to measure. I believe that an essay cannot measure the attitude shift needed in order for nurses to practice in cultural safety, but must be evaluated by the clients for whom they care. A huge shift in thinking is required for some nurses who have been educated and practiced in an ethnocentric way for years, and I think this shift may take some years to achieve, and should be supported by on going cultural safety work with these nurses.

The political aspect of teaching Kawa Whakaruruhau became frighteningly apparent to me as I struggled to take on board concepts and issues that I had only begun to understand. An example of this was the approach that was taken by a Pakeha staff nurse to a Maori student nurse who was caring for an older Maori man in one of the hospital wards. I was responsible for working with the student on the ward. The student struggled to support this man and his family, in the way that would best aid his discharge from hospital, in spite of fierce resistance from some of the permanent nursing staff who were used to treating every 'patient' in the same way. My position of power compared to that of the student and her patient meant that I was successful in buffering most of the negative comments made to the student and myself about her 
perceived care of this man by the non-Maori nursing staff. I began to spend more time with this man when the student was busy with other 'patients', and from him I learned a lot about his expectations of his illness, the hospital system, and what future he could expect. This experience allowed me to have some insight into a Maori experience of powerlessness as a hospital 'patient'. (I have continued to keep in contact with this man's family as they live near to me.) The student and I were able to discuss issues to do with inequity of power in the health system that she had felt for years, and I was just beginning to understand, though from a Pakeha perspective in support of Maori.

I progressed to Master's level study at a time when I was becoming more immersed in a community where many of the Maori were, and are poor in terms of available finances. The Maori families I met through the Kohanga Reo and the school my children attended offered insights into the Maori way of living that had previously been unknown to me.

This research project started with a kernel of an idea. I decided that for my Masters thesis I wanted to look at Maori child health, taking a local focus. I found that Maori child health has typically been presented as poor, compared to that of Pakeha children. Numerous government documents have focused on statistics supporting contentions that Maori child health statistics are still very poor when compared with Pakeha child health statistics (Maori Health Commission, 1998; Ministry of Health, 1998a, 1998b, 2001a, 2001b; National Health Committee, 1998; Te Kete Hauora, 1995; Te Puni Kokiri, 1993, 1998).

As I spoke to Auntie T one day, I wondered aloud if the parents or caregivers of Maori children had been asked for their opinions on this issue. Out of our subsequent conversations, this research project was born. Initially, an idea for this research was discussed with a local Te Atiawa nurse based at a local Maori health clinic, and with the Te Atiawa chief executive officer and one of his staff members, a Te Atiawa nurse from a regional Maori health provider. Neither of these nurses was in a position to undertake such research, but 
recognised the potential usefulness of such a project, and encouraged me to continue. Informal discussions were held with these health providers around the direction this project would take, and my suitability to embark on the planned project. The methodology and method of data collection were also discussed at length, as was the size and composition of the research sample. The rights of the research participants were considered by all to be of the utmost importance.

\section{Consultation}

A hui was held with the local branch of The Maori Women's Welfare League (Te Roopu Wahine Maori Toko I Te Ora). At this hui a summary of the proposed study was presented by Auntie $\mathrm{T}$ and myself, from which positive feedback was received.

As a consequence of this hui I undertook extensive consultation with community groups before I was able to gain access to the research participants. This consultation included Te Maunga Hauora, Tui Ora Limited (a Taranaki based Maori health provider), the local branch of Te Roopu Wahine Toko I Te Ora, the Te Atiawa Iwi Health Forum and Te Whare Punanga Korero. Because I am Pakeha it was important that my research partner, who is a Te Atiawa kuia, was present in her own right and to support the research.

Both groups asked questions of both of us about ethical issues, particularly in terms of safety of the participants in a community that had been researched extensively in the past. Also discussed were the planned methodology, intellectual property rights for the participants and the community, and how dissemination of the information would take place. There was some debate about myself as a non-Maori researcher working with Maori in the project. I was told by one of the local kaumatua that, because he knew me and had worked with me before, he was satisfied that I was genuine in my endeavours, and that he would therefore recommend that his group support the project. 
Eventually both groups approved the project subject to more evidence of working together between my Maori partner and myself. One of the kaumatua explained in Maori and then in English that he would support the project as long as I as Pakeha was the waka, and my Maori partner paddled it. Each group requested that they be provided with a copy of a report of the research when it was completed.

Auntie $\mathrm{T}$ was present with me for our meeting with the nationally accredited Taranaki Ethics Committee, which had some challenging questions for us, particularly from the Maori members. The feedback I had from this ethics committee was very useful. They approved the project and were able to supply me with contact people at all the Maori research units in New Zealand, and asked that I send a copy of the research to each of them. It was necessary for Auntie T and I to gain approval from the Maori community groups before the Taranaki Ethics Committee would approve the research. Once this was approval was granted, notification was sent to the Victoria University Human Ethics Committee, as part of the university's research approval process.

All the people with whom we consulted agreed that the project was a timely and useful one, and were very interested in what the participants had to say. They were particularly interested in considering issues of access to primary health services for Maori in rural communities, which is where the research took place.

\section{Reflections on the journey}

Like many of my journeys, this one has not been smooth. Many potential barriers have confronted me, and the process has at times been extremely challenging. Once the project got started, it gathered momentum and seemed to take on a life of its own. I believe this may be a characteristic of a cooperative, qualitative research project.

I am Pakeha working with Maori, and thus there was a necessity for me to work in partnership with Maori in this project from the beginning. I continue to be grateful for the trust I have had placed in me and the patience shown me 
when I took ages to grasp a simple concept that the aunties continued to explain to me until they knew I understood.

Many different things have risen out of this project. For example, it became clear early on that processes that might work for Western based research would not work for this project. My participants decided for themselves if they were in or not, and they chose themselves. The interviews were quite informal, with some people who had said they would come not turning up, and other people joining in at the last minute. It felt as though I had made dozens of presentations to potential participants, only to find no fast way forward. Once I let go of the anxiety I felt, everything began to fall into place.

Auntie $\mathrm{T}$ and a group of local kuia found the groups of grandmothers who participated, and I spoke to mothers I knew who fitted the criteria. It interested me that the 'nannies' were often found in groups, whereas the 'mums' had to be found singly. This led me to wonder about how Maori female networks work for the different generations. The older women had networks such as the Maori Women's Welfare League and various kaumatua organisations, whereas the younger generation had less formal networks.

One of the tensions that I grappled with throughout the project was whether I should be there at all. Some Maori believe that there is a place for non-Maori researchers in Maori health research, but not as observers (Ramsden, 1996). The Treaty guarantee of tino rangatiratanga should ensure that Maori participate in research design and methodology, and that outcomes are meaningful to Maori (Ramsden). Being non-Maori has its advantages. This was pointed out to me more than once both by research participants and by others supporting the project in other ways. For example, in spite of my marital and community links with local Maori, I am Pakeha, so did not have any issues with various iwi links to participants. The partnership for this research project is between Maori iwi and a Pakeha researcher. The knowledge of the Maori partner is respected in defining local iwi boundaries to geographically locate this research. Te Awekotuku (1991) speaks about 
the need for intellectual property rights from research with Maori to remain with Maori. She reminds us that the realities of participants cannot be assumed to fit a certain ethnic stereotype. I am mindful that dissemination of the research must be done in a way that is culturally safe for the community.

I was offered a job as a well child health nurse in the community in which the research took place and I accepted. I wondered if some of the research participants might be clients, and this proved to be the case. Indeed, some of the women who participated told me that they had signed up with the service because they knew me through research interviews and word of mouth. Some of the issues that concerned them I have been able to address with them in my role as a nurse. In the research interviews, we did discuss various strategies to deal with problems they were having in terms of the access to health care that they wanted for their children. It has been valuable for me professionally and personally to support or further advise these women.

I was aware when I started the project that there is an expectation of reciprocity of information between researcher and participants when the research is informed by critical social theory, as this project is. By definition, participatory inquiry infers input by both parties involved in the research (Lather, 1991). I found the conversations I had with the women during the research interviews helped us both. For the women, they gained information they were seeking. For myself, our dialogue reinforced the personal relationships I had with these women outside the research process. The participants knew me as a local health professional, a mother of Maori children, and then as a researcher. This was not a problem for me, as filling different roles at the same time is a reality for many women in their daily lives. In fact, it felt comfortable for me to be able to change roles, as I do in my daily life, and not trying to squeeze myself into an unnatural 'researcher' role. I am sure if I had tried to do this, the interviews would not have generated the rich data that they did. The group of kuia with whom I trialed the interview questions controlled the process themselves, with guiding questions leading the focus of the conversations. Being a part of all the research interviews conducted for this research has made me aware that in 
different interview situations, a researcher needs to be aware that their position may need to be multi-faceted and involved, depending on what the participants want.

Women who participated in the research have telephoned me at home with queries they have about their children's health. There have been discussions as to how the local community can better meet the needs of Maori in accessing primary health care for their children, and I have been invited to be actively involved in these discussions. I have been asked by two nursing students to critique nursing work that they are doing. These sessions have certainly stretched my mental processes, and the students tell me that they have found them enormously beneficial.

Unfortunately, one of the women who participated in the research, and whose grandchildren were also clients of mine, misunderstood some of the issues of confidentiality inherent in the research process. She was initially reluctant to use the well child health service for her grandchildren once I took the nursing job with the service. She saw me involved in two different roles with personal knowledge about her that she thought I might divulge. This issue has now been resolved, but it took some time and a lot of explanation. I had to regain her trust. It seems that this is one of the pitfalls of living, working and researching within the same community.

\section{Summary of the journey}

So far, this is the journey of the research project. I recognise that the beginnings happened long ago, both on the part of the participants, and for myself. For the Maori women, the journey began before the colonists arrived in New Zealand. I have partly described my journey here. Understanding the history of the participants as well as myself is the only way to situate this project in a meaningful way in the present. The completion of this thesis will not be the end of my journey with the women who participated in the research, though. I believe that journey will be on going. 
In the next section, the background to this project is explored. I have included a section on Maori health in New Zealand before outsiders arrived on these shores. The purpose of this is to inform the reader of the facts, so that a comparison can be made with 'then' and 'now'. 


\section{Background to this project}

In this section, I begin by situating Maori child health needs in NZ in the present day. Then there is a section about Maori health in NZ before colonisation began. This is followed by a brief description of five Maori models of health. The primary health services referred to in this research project are those that are funded in some way by the government in New Zealand. They are typically those of a General Medical Practitioner (GP), Accident and Medical Centre/Clinic, Plunket / Well Child Health Nurse, Midwife, Independent Nurse Practitioner, Family Planning Clinic, Pharmacist, Optometrist, Dentist and Complementary Therapist (Women's Health Action Trust, 1999). These services are mainly community based, and so should theoretically be accessible to all sectors of the community. In the researched community, the only primary health services not available are those of an accident and medical centre, independent nurse practitioner and a family planning clinic. These three services are all provided in the nearest city, which is about thirty minutes drive away.

The New Zealand Government's principal Maori health objective remains current (MOH, 1998b), though it was formulated in 1992. It states: "The Crown will seek to improve Maori health status so in the future Maori will have the same opportunity to enjoy at least the same level of health as nonMaori" (Parata \& Durie, 1993, p. 4). It is worth asking if, in the ten years since this objective was published, the Crown initiatives have been successful? Have the social and economic gaps between Maori and Pakeha closed? A critical part in asking about the success of any Crown initiatives must surely include comprehensive comments from the recipients of the services. This is what my thesis sets out to do.

Maori child health needs in New Zealand are still not being adequately met, according to the literature (Malcolm, 1996; Parata \& Durie, 1993; Pomare, 1995; Te Puni Kokiri, 2000; The Maori Health Commission [MHC], 1998). Maori children still need a greater amount of treatment in hospitals and are under-represented at a primary health level (Durie, 1998a; Ministry of Health 
[MOH] 1998a; Pomare, 1995). The term 'closing the gaps', which was once used to refer to the social and economic disparity between various groups in New Zealand society, has fallen out of favour. That does not mean that the gaps have closed; the disparity in the health status of Maori and European/Pakeha children remains as wide as ever (Te Puni Kokiri, 2000).

Pomare (1995) explains how Maori are grossly disadvantaged socially, economically and culturally. This is evidenced by high levels of unemployment, low earning capacity, poorer educational attainment, low home ownership, over-representation in prison, and high rates of physical and mental ill-health and accidents. Less than adequate access to health care relates to both cost and cultural factors (Pomare).

In order to improve Maori standards of health in any substantial way, jobs are required and access to health care needs to be improved. In the longer term, the most substantial benefits will occur by reducing lifestyle risk-taking and accidents, and by improving the status of Maori socially, economically and culturally (Pomare, 1995).

The next section presents an historical perspective of Maori health prior to the settling of New Zealand by Europeans. It may be used as a way to measure the inequities for Maori in the current NZ environment. It may help to explain some of the traditional beliefs that are still held today.

History has been defined as "the total accumulation of past events, especially relating to human affairs or to the accumulation of developments connected with a particular nation, person, thing, etc.” (Tulloch, 1996, p. 708). I believe that history, as a study of the past, informs the present in the same way that present events shape the future. The relevance of considering history is that without examining Maori health beliefs, realities, practices and expectations of the past, situating Maori health in the present is impossible. Many ideas about health that informed the culture of the 'old time Maori' (before any European contact) underpin the beliefs about health held by modern day Maori. 


\section{The history of Maori health in NZ before colonisation}

I believe that every culture has its own definition of what it means to be healthy. The concept of health is as integral to any culture as are concepts such as justice, gender roles, language, economics, customs, religious practices and ways of explaining their people's past and history.

The old time Maori considered themselves to be numerous, healthy and long lived, though they had their share of maladies and diseases (Buck, 1910; Lange, 1999). Buck describes as minor their complaints such as headaches, coughs, abdominal pains, papules and enlarged glands. The average life span for those who survived to adulthood, however, was only thirty years, and it was rare for Maori to reach the age of fifty (Lange).

Sir Peter Buck (1910) describes public health and sanitation of Maori in preEuropean times. Each pa had at least one toilet, and offal and rubbish were carefully disposed of. Captain Cook is said to have remarked that the sanitation of Maori villages was of a much higher standard than many of the European cities of the time. However, ventilation in the dwelling huts was not good, and Buck identifies this as a weak point that affected health. The close environment was made worse by the practice of keeping fires burning while the houses were occupied. There are many stories of people who had violent headaches or a deep sleep in which the body became rigid; these conditions resolved once the sufferer was dragged into the open air. The effects of foul air were recognised by Maori, and explained through the use of myths and legends. Differing myths and legends for the same phenomena were developed in order to encompass the circumstances and environments of various iwi (Buck).

Buck explains that the spirit of a person is the wairua. In severe illness, it was thought to leave the sufferer, and in fatal cases, it never returned. Any disease, to the old time Maori, was supernatural and had no natural cause. Accidents also were attributed to supernatural causes. The notion of tapu (loosely translated as a prohibition) was a very powerful one to the old time Maori. Breaking or transgressing tapu were blamed for accidents, disease, 
misfortune and death. For the old time Maori, illness was regarded as supernaturally caused and likely to end in death unless something was done (Buck, 1910; Lange, 1999).

With the arrival of the European came foreign diseases, whose impact on the Maori population was devastating, especially between the years of 1769-1840 (Lange, 1999). The enormous Maori depopulation was a disaster from which Maori are still recovering. The situation was worsened by the social and economic changes happening at the time, which Lange describes as giving Maori a new susceptibility to illness. Traditional methods were of no use in dealing with European diseases, and, though society continued to function, uncertainties and social confusion were rife (Lange). The Pakeha brought with them alcohol, leading to many problems amongst the Maori who were not used to it. They also brought gonorrhoea, measles, influenza, smallpox and tuberculosis (Walker, 1990).

Lange (1999) describes how standards of health dropped seriously from 1840 and the signing of the Treaty of Waitangi, as Maori were dislocated from their traditional environment. This varied in intensity from region to region and happened in some places before others. Loss of traditional tribal lands led to some temporary villages being occupied permanently, though they were sometimes situated in places that became wet, cold and sunless through the winter. Pollution of local rivers and streams, changes in clothing habits and diet are all thought to have contributed to the decline in Maori health standards, especially in the areas of personal and community health. The style of communal living, a basic feature of traditional Maori society, facilitated the spread of disease. Alcohol abuse became another symptom of the Maori struggle to cope with huge social adjustments they faced for survival at this time (Lange).

There is plenty of documented evidence describing in detail the effect that European exposure and colonisation practices had on the health of the Maori population (Dow, 1999; Fox, 1997; Ritchie, 1992; Te Puni Kokiri, 2000; Walker, 1990), and of the current socio-economic climate in New Zealand 
that continues to promote lower health standards for Maori (Durie, 1998a; Ellison-Loschmann, 1997; Waldegrave \& Coventry, 1987; Walker, 1990).

For example, pre-European Maori had no resistance to the influenza, measles and whooping cough. King (2001) describes how epidemics of these diseases decimated the Maori population. The appearance of venereal disease and tuberculosis increased levels of ill health in the population and led to a marked decrease in fertility. Typhoid and dysentery also swept through Maori settlements in epidemic proportions. Some Maori died from wounds, especially from gunshots inflicted in the land wars. Alcohol abuse was common in villages without a sound economic base (King).

Maori health and welfare were ignored in the early 1900s, unless there were concerns for the Pakeha population. A Maori family traditionally had several dwelling places located near different resources, such as the sea and inland forest. They moved between them through the seasons of the year (Metge, 1995). Alienation from their traditional lands led to changes in living conditions. In many Maori communities, people lived close to starvation. Most of their good land had been bought or taken from them, and they were denied access to the government assistance given to Pakeha farmers for land development (King, 2001). The legacy of the effect of colonisation on Maori is still evident in the twenty-first Century. In the next section Maori and health are considered within the New Zealand context.

\section{Maori and health}

Traditionally in New Zealand, documents about health have been based on a Western medical model, which is the dominant health model in New Zealand. They have tended to consider health only in terms of statistics, health indicators and health outcomes, which measure physical conditions (Durie, 1998a; The Public Health Commission [PHC], 1995; Shipley, 1995). Health outcomes measured in this way have tended to measure Maori health issues in a negative way, compared with non-Maori (Pomare, 1995). Child health issues, including those of Maori child health, have been dealt with in the same way (Midland Health, 1995; PHC, 1995). For example, various reports to the 
Government discuss child health in terms of disparities in key indicators between Maori and non-Maori (MOH, 1998b; 2001; Te Puni Kokiri, 2000).

There is a growing recognition of the importance of the link between health and culture. It has been shown conclusively that, for Maori, health cannot be separated from other social and economic considerations. Socio-economic factors such as income, employment, housing and education have been found to be strongly related to health (NHC, 1998; Pomare et al., 1995; Te Puni Kokiri, 2000).

More recently, there has been some recognition by national health agencies and the NZ government that the concept of health cannot be defined in a socio-economic vacuum (MOH, 1998b; NHC, 1998; Stephens, Frater \& Waldegrave, 2000). For instance, the NCH Report (1998, p. 3) states: “...social, cultural and economic factors are the main determinants of health".

Dr. Mason Durie has written seminal works about Maori and health in New Zealand. Some of his ideas, along with several Maori models of health, are included here. Durie states that "people and groups are best able to articulate their own positions, values and beliefs" (1995, p. 465). This assumption is totally at odds with imposed stereotypes of a Western culture, which create misleading expectations of preferred outcomes. It is my belief in Durie's assumption that informs this research project.

Maori elders and a variety of health professionals consistently highlight the health of children as an important health problem currently affecting Maori (Durie, 1983). For Maori, the whanau is where health status is determined; one of the main roles of the whanau is to nurture and protect the young (Metge, 1995; Pihama, 1993). This is why the participants in this study are caregivers of Maori children; specifically of Te Atiawa children who live in Taranaki.

Maori health experts have described the concept of health as having many different aspects, which, woven together, help to define a person, their family 
and their community (Durie; 1998a; Pere, 1997; Pomare, 1995; Rimene, Hassan \& Broughton, 1998; Te Whaiti, McCarthy \& Durie, 1997). These aspects of health are described by Maori health models that embrace traditional Maori approaches to health, as well as depicting a view of health that accords with contemporary Maori thinking (Durie, 1998a).

In terms of diversity, Durie recognises that Maori individuals are not members of an homogenous group. Maori individuals live in a number of cultural and socio-economic realities, and have a variety of cultural characteristics. Also, all Maori do not find the same relevance in so-called traditional values, and they may not define their Maori identity in terms of classical constructs. There are distinctions between members of different iwi, and because each tribe has its distinguishing cultural and historical associations, cultural homogeneity cannot be assumed to occur across the range of iwi.

The dynamic changes in Maori society are typical of New Zealand society generally, and are accompanied by changes in cultural beliefs and practices. The multiple social and cultural affiliations of Maori, in terms of both individual and group memberships, vary over time and depend on competing claims, such as cultural expectations, financial barriers, opportunities and personal preferences. The position of contemporary Maori acknowledges their diversity, dynamic change, multiple affiliations and self-identification (Durie, 1995).

A number of frameworks have been developed as a way of conceptualising and locating Maori individuals according to characteristics of Maori identity, culture, well-being and knowledge. These frameworks endeavour to describe Maori according to certain key aspects, and to differentiate Maori experience and realities from those of non-Maori. I include brief descriptions of three of these frameworks in the next section to explicate the reader's understanding that widely differing views are held regarding Maori identity, culture, well being and knowledge. The broad holistic focus of these models may be contrasted with traditional Western models, and the differences considered. 


\section{Maori models of health}

\section{Whare Tapa Whaa}

In 1985 Mason Durie introduced a widely quoted health framework, Whare Tapa Whaa (Durie, 1998a). In this model, four Maori health dimensions are compared to the four sides of a house: taha wairua signifies spirituality, taha hinengaro denotes thoughts and feelings, taha tinana stands for physical health, and taha whanau is about family. Though there has been uncertainty about appropriate measures for taha wairua and taha hinengaro, this model offers a construction of health that is based on Maori understandings. Clearly, this is a model based on much more than just that of Western medicine.

\section{Te Wheke}

Pere's model of health, Te Wheke (1997), uses the analogy of the eight tentacles of the octopus to illustrate particular aspects of health. The head and body of the creature symbolise the family unit as a whole. The aspects of health that she identified are: wairuatanga (spirituality), tinana (physical), hinengaro (mental), whanaungatanga (family), manaake (uniqueness), mauri (vitality), haa-a-koro-maa-a-kui-maa (inspiration from ancestors), whatumanawa (emotions), and waiora (health).

\section{Ngaa Puutake}

The foundations for good Maori mental health comprise three institutions (Durie, 1995). They are whenua (land), whanau (family), and Te Reo (Maori language/communication). Poor mental health may develop if access to any of these foundations is blocked or eroded.

\section{Summary of the background to this project}

These three Maori health models all include a wide focus, with reference to the importance of spirituality, the environment, social relationships and traditional practices. The importance of family and family cohesion is a common thread in all of these models. They give an optimum comparative view against which to consider a traditional Western model of health. Serendipitously, all the participants in this research are Maori. As I 
progressed through the study, it became clear to me that the participants clearly situated their concepts of health in a broader context than the Western model. This is discussed further in Chapters six and seven.

The Treaty of Waitangi has also been identified as a useful model for Maori health (Ramsden, 1992). The main principles of the Treaty are those of partnership, participation and protection. These are the principles on which the research process described in my thesis is based. The next section of this chapter takes a broad look at the Treaty of Waitangi, and its relevance to Maori health. 


\section{The Treaty of Waitangi}

The Treaty of Waitangi is the founding document for bicultural relations in New Zealand (Orange, 1987). The following section has been included with an international readership in mind.

I believe that to have some understanding of the dialectic relationship between Maori and Pakeha in New Zealand, it is necessary to have some knowledge of the Treaty of Waitangi. In order to contextualise the Treaty in both colonial and modern times, I have included the following section about Maori tribal society.

\section{Maori tribal society}

In this section, I have briefly described how Maori society worked prior to European influence. I believe that this will illuminate somewhat the expectations that Maori had on behalf of their people when the chiefs signed the Treaty of Waitangi (also referred to as the Treaty). I have borrowed heavily from Makereti's book The Old Time Maori (1938).

A Maori iwi consists of all the descendants of the ancestors who arrived in New Zealand in a particular canoe. When the waka arrived in New Zealand, the occupants typically claimed some land and settled in the surrounding country. Many chiefs settled on the coasts, though some made their way inland. Families grew and settled a few miles apart from each other. Once a family group had increased to the size of one hundred and fifty or more families, they formed a hapu, taking the name of a famous ancestor. Hapu spread through intermarriage with the descendants of other canoes and settled in many parts of New Zealand. Maori identify themselves through genealogy and links to the land (Makereti, 1938).

Maori life was communal and every member of the community joined in the work to be done. In each village there could usually be found several families, each a self-controlling unit, but all members of the same hapu. The main division of labour was between men and women. Each family in the pa 
or kainga had their own piece of ground for sleeping and cooking houses. The chiefs of the various families dealt with any matters of great importance concerning the hapu. The whanau was considered to be more important than any individual. If anyone was in conflict with another member of the same whanau, their differences would be set aside if the whanau was threatened by anyone from another hapu or iwi. The individual's personal feelings would be set aside for the sake of his whanau, hapu or iwi, depending on the threat (Makereti, 1938).

Outsiders to the iwi would be welcomed only as guests, with great ceremony and hospitality. No one from outside could ever become part of the iwi or hapu, even by marriage, so could not inherit any land from a husband or wife's tribe. Genealogy descent in Maori society was and is bilinear; that is Maori may inherit land from both the mother's and the father's families (Makereti, 1938).

Maori society still works in many ways according to tribal traditions (King, 2001). Ritchie (1992) describes tribes as being generational, with a sense of heritage comprising what their ancestors passed down to them, and what they are creating for their grandchildren.

\section{The Declaration of Independence}

In 1835, five years before the Treaty of Waitangi was signed, a Maori Declaration of Independence, recognised by the British, laid the groundwork for the Treaty that followed. This declaration has been referred to as "the Magna Carta of New Zealand" (Orange, 1987, p. 22). In 1830 thirteen leading Maori chiefs from the North of New Zealand, with missionary support, petitioned the King of England for some form of control of British nationals in New Zealand, and for protection from other possible foreign intervention (Walker, 1990). In particular, the behaviour of a small number of British ex-convicts and ship-jumpers at Kororareka (now Russell) was of great concern to the Maori and missionaries of this region. Drinking and prostitution were rife, causing problems for the inhabitants of this region (Walker, 1990). 
The British rationale behind the Declaration was to promote the interests of Britain by establishing the independence of the country under the protection of the British government. The threat from De Thierry's power base of wider French settlement in the Hokianga caused the British to act quickly in securing the dependency of New Zealand on the British Empire (Orange, 1987).

The Declaration proposed a Maori legislature and a Parliament made up of chiefs. This would enable the new nation to join the international community as an independent state. Maori values, practices and aspirations would determine future directions. Maori self-determination would be firmly tied to collective Maori sovereignty (Durie, 1998b). The eventual possibility of the development of a Maori nation under the Declaration was usurped by the Treaty, which assumed that the Maori tribes in New Zealand constituted a Maori nation (Ritchie, 1992). In fact, this was not so, as each iwi retained its unique character (Durie, 1998b).

\section{Te Tiriti o Waitangi (The Treaty of Waitangi)}

The Treaty of Waitangi is described by the Royal Commission on Social Policy [RCSP] (1988, p. 19) as "an established foundation of New Zealand's society and economy...". Coates, (in Coates \& McHugh, 1998, p. 19) describes the Treaty as a defining document that dominates the country's inter-cultural political landscape, and is central to New Zealand's attempts to "address its past and define its future". The New Zealand government has acknowledged the Treaty of Waitangi as the country's constitutional foundation stone (Kelsey \& O’Brien, 1995).

It is impossible to explain the significance of the Treaty of Waitangi to New Zealand in the past, present and future, without contextualising it to some degree. The Treaty is embedded in the history of New Zealand, even though it was marginalised up until the 1980s (personal communication, Kura Taylor, November $27^{\text {th }}, 2001$ ). What follows is a brief outline of how the Treaty came to be, which is drawn from the writing of Kawharu (1989), 
Orange (1987) and Walker (1990). Copies of three versions of the Treaty can be found in Appendix One.

The British colonisation of various countries of the world was characterised by British assumptions of racial, religious, cultural and technological superiority (Walker, 1990). Treaties with indigenous peoples were a common part of British colonial expansion. These treaties were primarily designed to acquire indigenous land wanted for settlement, but these treaties were generally deliberately pushed aside by the dominant British (Coates, in Coates \& McHugh, 1998). New Zealand is an exception, in that the Treaty of Waitangi remains a central and contentious issue in New Zealand's political climate.

The Treaty is considered to be an international agreement, which was signed at Waitangi in 1840 by a Crown representative and over 500 Maori chiefs (Orange, 1987). The Treaty consists of a preamble, three articles and a concluding paragraph. The version described here was translated by $\mathrm{Mr}$. T. E. Young (of the Native Department) from the Maori original. The majority of chiefs signed the Maori version of the Treaty (Orange, 1987, p. 265).

The Preamble describes the actions planned by Queen Victoria in her response to requests from both Pakeha and Maori for some sort of protection for New Zealand's inhabitants, and for some form of law and order. Regardful of the concerns expressed by both, she sent a negotiator to ask that Maori consent to the government by the Queen of all parts of New Zealand, because many of her people had settled here and more were coming to look for land for settlement.

Article One addresses the Crown's position and its right to rule. It gives the Crown governorship of Maori land forever. The Chiefs who signed, and those who did not, were included here by the British. However, this is where there is a misunderstanding about the concepts of 'sovereignty' and 'kawanatanga', which is not the nearest Maori equivalent for the word 
sovereignty. It is suggested that 'mana' would more appropriately be used instead (RCSP, 1988).

Article Two guarantees Maori 'tino rangatiratanga', that is chieftainship over their lands, villages and all their treasures. Provision was made for land to be sold by Maori to the Crown at an agreed price, if both parties were willing.

Article Three concerns the democratic rights granted to all New Zealanders, be they Maori or Pakeha.

The final paragraph of the Treaty implies an understanding by Maori; therefore they consented to sign.

The Maori version of the Treaty supports the claim to rangatiratanga under the sovereignty of the Crown. Maori see the Treaty as an express recognition by the Crown of the incorporation of rangatiratanga into the fabric of NZ society (McHugh in Kawharu, 1989).

Maori expected that their natural rights as tangata whenua would be upheld and respected, in exchange for settlement rights. Pakeha expected that they could settle peacefully in New Zealand under the British flag.

Claudia Orange's book The Treaty of Waitangi (1987) describes in great detail the colonist thinking of the time that led to the Treaty of Waitangi being signed in 1840. Hobson, the British Crown's representative in New Zealand at this time, was given the task of securing sovereignty over New Zealand for Britain, by treaty if possible in a peaceful fashion. Three critical factors to be considered from the British perspective were: the legal status of the country; humanitarian concern for Maori welfare; and the need to convince Maori to accept the inevitable continuing tide of British colonialists to New Zealand. Attempting to address all these concerns at the same time led to confused negotiations, with British Crown interests paramount. Crown interests were played down because it was important to the Crown that Maori 
be persuaded to sign the Treaty so that peaceful colonisation could continue (Orange).

Orange (1987) describes the ways in which Maori suspicions were lulled. Maori independence was to be officially recognised, albeit under British sovereignty. The Crown led Maori to understand that their agreement was required before the increasingly troublesome presence of lawless Europeans around Kororareka could be legally and effectively controlled. Finally, the benefits to be gained from the treaty were touted, and the inevitable restrictions to Maori ignored.

The Treaty of Waitangi of 1840 was drafted first in English, and then hurriedly translated into Maori the night before the signing was to take place. The Maori text version of the Treaty was the one signed by almost all the chiefs throughout New Zealand. After the Treaty was signed at Waitangi, versions were taken around New Zealand where many other chiefs signed on behalf of their people, though Tuhoe and Tainui and some other ariki never signed (Orange, 1987).

The Treaty was understood by some Maori as guaranteeing the Maori way of life with the added benefits that the Pakeha presence could bring. This understanding describes a simple concept of tino rangatiratanga (Kelsey, 1990).

The Crown usually refers to the English version of the Treaty, despite international law and the rule of 'contra preferentum' meaning that the indigenous text takes precedence $(\mathrm{MOH}, 1995)$. There were translation and interpretation difficulties inherent in the Treaty from its conception. In any language, there are meanings for words that are not directly translatable into another language, and the Maori and English languages are no exception. Due to cultural illiteracy of the times and language manipulation, the concepts of rangatiratanga and kawanatanga were not adequately translated into English (Orange, 1987). The English version of the Treaty used the word 'sovereignty' instead, though the meaning for this English concept was not 
explained to Maori in terms that they understood (Orange). There are other examples which suggest that the spirit and intent of the Maori and English versions of the Treaty were quite different (Kelsey, 1990; Kelsey \& O'Brien, 1995; King, 2001; RCSP, 1988; Williams in Kawharu, 1989).

This is clear when comparing the English version with a more literal English translation of the Maori text version that was signed by the chiefs (see Orange, 1987, p. 262). It goes a long way towards explaining why the Treaty has been debated so hotly from 1840 until the present day, and why Pakeha have marginalised it and been reluctant to discuss it for so many years. Maori grievances can be directly traced back to the conflicting understandings and expectations that the Crown and Maori had of "New Zealand's founding document" (New Zealand, 1990). Difficulties of interpretation and implementation have meant that conflict over land, power and authority, in particular, has continued to be debated as bitterly as ever. The Treaty only gave Britain partial entitlement to New Zealand, though it did give them the right to govern (King, 2001).

Matters were not helped by the fact that not every Maori chief signed the Treaty. There continues to be on going debate about whether the Treaty applied to those Maori iwi who had not signed.

Ritchie (1992) believes that a reasonably detailed knowledge of the Treaty is imperative for all New Zealanders, but more so with anyone working with those who identify as being Maori. I concur with this, as for so long the Treaty has been denigrated and forgotten by those recognised as the Crown partners. If the Treaty is considered the basis for bicultural agreement in New Zealand, then it makes sense for the Pakeha partners to understand it as well as do Maori.

Ramsden (1996) identifies the Treaty as the tool for negotiation, which has remained constant throughout the colonial history of New Zealand. She explains that the guarantees of Crown protection of Maori property rights and citizenship rights have remained meaningful to Maori, and more recently, to 
increasing numbers of non-Maori. Pomare (1995) feels the Treaty can be used as the basis for forward planning in health, with the aim that all New Zealanders can enjoy equal opportunities for good health.

\section{Principles of the Treaty}

Various groups have endeavoured to list the principles enshrined in the Treaty of Waitangi. For example, the NZ Labour government in 1989 (Ritchie, 1992) published an official list of the ten implied principles of Waitangi. These principles are not necessarily agreed to by all parties, but serve more as guidelines for interpretation where Statutes refer to the Treaty. The ten principles defined by the New Zealand Maori Council take a different focus. In 1986, the Department of Health described the Treaty as having special significance, and recommended that its principles be integrated into the health services (RCSP, 1988).

Pomare (1995) recommends that the principles of the Treaty of Waitangi be incorporated into the constitutions and terms of reference of all groups and organisations involved in health care. He believes that this would enable Maori to be more effectivelv involved in health care nlannino and deliverv 
Land issues continue to be a major grievance. Maori had never believed that land was a commodity to be bought and sold (Makereti, 1938), but they soon found that by a valid sale to a Pakeha, they had permanently disposed of both their land and of any rights to it. The Maori chiefs who signed the Treaty had not understood that this would happen, but it was necessary for successful colonisation to continue. As more and more settlers poured in, private land sales went ahead, despite Maori resistance (Orange).

A land dispute in Waitara, Taranaki led to Taranaki Maori taking up arms against the British. Thus began the New Zealand Land Wars in 1860. Kelsey (1990) disputes that these wars were fought over property rights to land. She believes they were a struggle for tino rangatiratanga versus sovereignty.

As the settler presence grew, so did settler racial prejudice and the quest for land. For the Pakeha, land that wasn't currently being 'lived on' constituted 'waste-land', and Pakeha confiscated much of this so-called 'waste land'. The Maori owners of such land might return from a seasonal visit to their tribal ocean side territory, to find that in their absence, someone had moved into their other dwelling place. Legislation was passed that continued to erode Maori rights to their land and their traditional ways of life. Efforts to subjugate Maori escalated through the 1860 s, with a policy of suppression and confiscation of Maori land for perceived wrong doings. From the 1870s, the Pakeha population outnumbered the Maori population, and the settlers had no interest in the Treaty; nor did the government want to resurrect it. The Land Court was busy investigating disputes throughout this period. However, as Ritchie points out (1992), it is only through the Treaty that non-Maori can claim any right to be in New Zealand.

\section{The place of the Treaty of Waitangi in present day New Zealand}

The Treaty is a defining document that is central to New Zealand's attempts to address its past and define its future; it has a positive and enduring role (Coates \& McHugh, 1998). The Treaty has become the focus for Maori in seeking the sovereignty promised in 1840, and in seeking redress from the wrongs of the past. It is generally agreed that the grievances of the past must 
be resolved before Maori / Pakeha relationships can move forward (Durie, 1998b; Orange, 1987; Ritchie, 1992; Walker, 1990). These grievances relate to resource issues, questions of representation and political voice and cultural self-determination. Kelsey (1990) describes more than one hundred and fifty years of destruction of Maori economic, spiritual, political and cultural autonomy that had been guaranteed in the Treaty.

Coates (Coates \& McHugh, 1998) summarises the developments of the last fifty years. There has been increased attention to indigenous rights, bringing the issue into the international political spotlight. Much has been written, and many achievements claimed on paper. The Draft Declaration on the Rights of Indigenous People was published in 1993, yet there is still a fundamental cultural gap between the indigenous people of New Zealand - the Maori, and the newcomers - the Pakeha. In the last half century there has been continuing occupation of Maori lands and extreme social, economic and cultural distress amongst Maori communities. Resource developments have flown in the face of Maori ecological practices. Maori owners have lost the ownership and control of their resources, leaving them poor and powerless. Maori communities have struggled to cope with serious socio-economic deprivation, which has been compounded by drug and alcohol problems and high unemployment. Maori have continued to be challenged by unfriendly legal and political systems. Conditions that remain unchanged for Maori in the face of achievements claimed on paper suggest that this matter has become urgent (Coates \& McHugh).

References to the Treaty have begun to be included in legislation since the Treaty of Waitangi Act of 1975, enabling the courts and the Waitangi Tribunal (set up to deal with Treaty claims) to define the principles of the Treaty. However, without changes in behaviour and attitudes on the part of the Crown and Pakeha New Zealand, it appears clear that the bicultural partnership once anticipated for New Zealand cannot fulfil its potential.

The systematic solution that Maori are seeking depends on more than goodwill and political patronage (Durie, 1998b). As equal partners in the 
Treaty, Maori can reasonably expect to participate fully in New Zealand society, and to share equitably in its benefits in areas such as health, education and housing. Durie suggests that Maori should also expect to be able to exercise their preferences for political organisation, cultural expression and relationships with the environment. Unless the central issue of tino rangatiratanga is addressed, Maori resistance to the status quo seems likely to increase (Kelsey, 1990).

The crucial issue in honouring the Treaty has always been, and remains, the recognition of Maori sovereignty (Kelsey \& O'Brien, 1995). One of the problems the Crown has encountered when trying to prescribe Treaty settlement strategy is that no one is clear on exactly what is being settled. Durie and Mansfield (in Coates \& McHugh, 1998) agree that the Treaty is about the future. Put simplistically, it seems that until the wrongs of the past have been addressed in a manner satisfactory to Maori, the relationship between Maori and other New Zealanders, prescribed by the Treaty, has nowhere to go.

\section{The Treaty of Waitangi and health}

Many Maori health workers have identified The Treaty of Waitangi as a suitable framework within which to consider health, especially in regard to the relationship between Maori and the Crown as Treaty partners. (Durie, 1998a; Pomare, 1995). There are a number of opinions that give the reasons why it is a suitable framework.

Pomare (1995) explains how the Treaty has special relevance in health, by virtue of the partnership agreement between Maori and the Crown guaranteeing equity. The wellbeing of the residents of NZ, especially Maori, was an intention of the Treaty, and Maori have continued to contribute to the development of the health sector.

Durie (1998a) describes how concerns about the effect of colonisation on Maori health were recognised in the 1830s. Part of the motivation for the Treaty placed a burden on the Crown of ensuring that Maori were not unfairly 
marginalised by British settlement. Policies of positive protection, linking economic and social objectives were promoted.

The right to sovereignty over health and wellbeing for Maori, and to have whanau, hapu and iwi involved in decisions about them is guaranteed by the Treaty (Ratima, Allan, Durie, Edwards, Gillies, Kingi, \& Waldon, 1996). Maori aspirations for increased autonomy and the demand for culturally safe health services have been illustrated by Maori efforts within the framework of general health services and the health budget to provide and manage health services by and for Maori (Pomare, 1995). In these terms, health services for Maori children and their families seem to be most logically considered within the concept of Tino Rangatiratanga.

The twentieth century implications of the Treaty objectives in health have been outlined by Timutimu (2001) as follows. Article One describes Parliament's right and authority to govern, Article Two recognises oritetanga (equity) and the tribal right to exercise tino rangatiratanga. Article Three relates to Maori individual rights to expect a fair share of society's benefits.

Maori have been seeking tino rangatiratanga in health since the mid-1980s. Maori especially want to be actively involved in the formulation of health policy, health service planning and purchasing, and health service delivery (Kiro, 1999).

Hauora (health) has important determinants besides physical well being, such as mana. Loss of mana may lead to low self-esteem with the associated lifestyle risk-taking behaviour. Loss of land, marae, language, family relationships and a clean environment are all examples of loss of mana (Durie, 1998a).

The current health of Maori as a people is incontestably bound up with income, education and housing status (RCSP, 1988). Kiro (1999) postulates that the common experiences of oppression, poverty, social exclusion and environmental damage shape the health, and therefore the lives of indigenous 
people. Health determinants, socioeconomic and cultural determinants are important in any discussion about indigenous health because of the way they focus on the relationship between government policy, medical practice, the wider social environment and health outcomes (Kiro, 1999).

Delayed visits to the doctor are one recurring feature of poverty, from which Maori families are more likely to suffer than Pakeha families. Maori women who are sole parents are likely to be poorer than other groups (Kelsey \& O'Brien, 1995). As has been established, Maori women are the primary guardians of their children's health. Because children are often unable to access the health care they need without adult support, Maori children are more likely than any other group to have their health needs unmet.

The Nursing Council of New Zealand (NCNZ) has been working towards developing strategies to work with Maori. The concept of cultural safety in the New Zealand nursing curriculum was introduced by Council in 1992 as a way of addressing some of the issues raised above (NCNZ, 1996). Council recognises that Maori as tangata whenua hold a unique place in New Zealand. The Treaty is acknowledged as New Zealand's founding document. Council accepts that the securing of the Treaty's place within the health sector is fundamental to the improvement of Maori health. There are now Maori members on the Nursing Council (NCNZ).

In terms of nursing research, Bishop (1994) believes that non-Maori people should be involved in Maori research for two reasons. Firstly, he recognises that there is a cohort of highly skilled, professionally trained non-Maori who are becoming bicultural and are willing to work in contexts that are Maori controlled. Secondly, he feels that for Pakeha researchers to leave it all to Maori is to abdicate their responsibilities as Treaty partners. This issue is still being debated amongst Maori academics (Cram, 1997).

In the New Zealand of the $21^{\text {st }}$ Century we have a deeply divided society split by growing economic inequality and poverty. This society is "founded on the suppression of Maori economic, political, cultural and spiritual self- 
determination" (Kelsey \& O’Brien, 1995, p. 63). The refusal of the New Zealand government to recognise health as a taonga, with recognition of its proper place under Article Two of the Treaty continues to be an obstacle to Maori seeking tino rangatiratanga and equity in health for their people (Durie, 1998b).

\section{Conclusion to chapter two}

This chapter has described the research context and focus. The first section concerns my journey towards and through the research process. The concept of cultural safety is defined, as is the consultative process that was necessary before the work could commence. In the second section, the background to the project is explored. The state of Maori health in New Zealand before colonisation is presented as a comparative backdrop to health problems faced by Maori in the present day. Factors that impact on Maori health have been identified, and three Maori health models have been briefly explored. Section three introduced the Treaty of Waitangi and elucidated its relevance to Maori health in New Zealand, both historically and currently.

The next chapter examines the literature relevant to this project. International literature concerning the definitions and interpretations of primary health care around the world is included for purposes of comparison. New Zealand literature provides both the relevant government and Maori perspectives. 


\section{Chapter Three Literature Review}

\section{Introduction to chapter three}

There is a wealth of literature available, such as that cited previously, which deals with many aspects of Maori health. However, I was unable to find any literature that explores issues of primary health services for Taranaki based Te Atiawa children as perceived by their female caregivers.

I am aware that a wide audience may read this thesis. I have therefore included this literature review to lend congruence to the project. That is, I believe it is important that the reader understands the definitions I have used here for the various concepts that inform this research. In particular, I have considered various definitions of primary health care and the barriers thereto. This is to illustrate how the concept of primary health care can change, depending on the political environment in which it is applied.

Definitions are given of barriers to health care. International issues of access, socio-economic contexts, the New Zealand experience, the indigenous experience and the Maori experience are explored, and commonalities have been sought within the literature.

This literature review examines both international and New Zealand literature in terms of barriers to primary health care, specifically those that affect children. International literature has been included here because the concept of primary health care was originally defined based on a Western model of health. Different countries have interpreted the concept of primary health care differently, though there are commonalities between first nation peoples in terms of difficulties accessing primary health care. The literature concerned with primary health care access typically focuses on the family, and not specifically on children. The reasons for this are further explored in this chapter. New Zealand literature has been used to contextualise this project, and to enable comparisons to be made between the international community and New Zealand. 
Health issues that affect children also affect the whole of society (King, King \& Martodipoero, 1980); for this reason children's issues in terms of access and child health have not been separately covered in this literature review.

\section{Primary health care}

For the purposes of this thesis, primary health care is defined as "essential health care based on practical, scientifically sound and socially acceptable methods and technology, made universally accessible to individuals and families in the community through their full participation and at a cost that the community and country can afford to maintain" (World Health Organisation, cited in Johnstone \& McConnan 1995, p. 891). This definition - the Alma Alta Declaration - was originally constructed by the World Health Organisation in 1978. A wide range of developing countries have successfully developed a model of primary health care based on this statement, for example, countries in Africa, Asia, Indonesia and Central America (King, King \& Martodipoero, 1980; Werner, 1980).

Interestingly, this model of primary health care differs fundamentally from the primary health care systems currently being used in the United Kingdom (Johnstone \& McConnan, 1995) and the United States of America [USA]. Here, the Institute of Medicine in 1998 defined primary care as "the provision of integrated, accessible health care services by clinicians who are accountable for addressing a large majority of personal health care needs, developing a sustained partnership with patients, and practicing in the context of family and community" (Visser, Thurmond \& Stinson, 1998, p. 5-10). Another definition from the USA defines primary health care as a central, affordable and cost-effective component of maintaining health, both at individual and public health levels (Newacheck, Hughes \& Stoddard, 1996).

These different definitions have been included to illustrate that, at a fundamental philosophical level, health providers may understand quite 
divergent concepts of primary health care, as may their clients, and the expectations of the different groups may conflict.

Barriers to primary health services are the main focus explored in this thesis, so a section defining barriers to health services has been included here. Again, both international and New Zealand literature are incorporated.

\section{Barriers to primary health care}

Barriers to primary health care have been identified in health systems all over the world, from those considered wealthy to those that are desperately poor. Barriers that affect families have a direct impact on children, who depend on adults to ensure their health needs are adequately met.

Sword, in her work on prenatal care in Canada (1999) claims that the concept of barriers is useful in explaining utilisation behaviour. She believes that barriers tend to be defined by health care providers, policy makers and researchers and so do not necessarily reflect barriers to health care as perceived by the consumers. Sword proposes instead a socio-ecological model that offers a more comprehensive position to understanding multiple factors that determine health care provision and utilisation behaviour. I feel that Sword's views have merit in the New Zealand health environment.

Examples of contextual barriers for women of low income are: problems with transportation, childcare, fear of disclosure of drug and/or alcohol abuse, lack of knowledge of services, lack of perceived need for care, negative attitudes towards health professionals, excessive stress, depression, physical problems, job demands, needing time and energy to deal with personal and family problems, and cultural values and beliefs (Sword, 1999).

Research conducted in Canada investigating barriers to prenatal care for low income women, who are at risk for poor pregnancy outcomes, found that the appropriate design and delivery of services is critical to enhancing utilisation (Sword, 1999). The author felt it useful to extend the notion of prenatal care beyond the boundaries of the traditional biomedical model into the arena of 
health promotion. The justification for what she calls a 'socio-ecological' approach to prenatal care encompasses community-based programmes, which support health lifestyles, foster links with health and social services and add to existing social support networks (Sword).

In the United States of America, Visser et al. (1998) explain barriers to primary health care service access as a lack of insurance or financial resources, lack of transportation or childcare and cultural and language differences. Other non-financial barriers have been identified as patient race, diagnosis, location, social class, culture, gender and age (Friedman, 1994). Friedman believes that these barriers will not disappear simply with the provision of health insurance for everyone.

"The health care system is one of the most sensitive of social barometers, and therefore what occurs in the larger society can be expected to occur with at least equal force in health care" (Friedman, 1994, p. 1537).

The Acheson Report, a social policy paper investigating the health gap between rich and poor, was released in the United Kingdom in 1998. The report includes the recommendation that all government policies that are likely to have a direct or indirect impact on health should be evaluated in terms of their impact on health inequalities and should aim to reduce them (BBC, Nov. 26, 1998).

The United Kingdom's government health strategy in 1999 was to improve the health of the worst off in society and to narrow the health gap (UK Department of Health [DOH], 1999). Their strategy recognises that, because there is such a variety of root causes of ill-health, more issues need to be tackled than only that of health.

The well-known World Health Organisation concept of health was developed at the Alma-Ata WHO / Unicef conference of 1978. It included innovative ideas about primary health care strategies, particularly in terms of the emphasis placed on intersectoral action for health, reallocation of health 
resources from tertiary care to community base health promotion and disease control and participation by the community. These concepts are now considered mainstream and are increasingly being applied in both developed and developing countries (Antezana, 1996).

\section{Access to primary health care}

Lack of access to primary health care is a major barrier for marginalised families and their children. Access has been defined as "a measure of the fit between characteristics of providers and health services, and characteristics and expectations of clients" (Gulzar, 1999, p. 15). Five dimensions of access are embodied in this definition: availability, accessibility, accommodation, affordability and acceptability. Gulzar suggests that the goal of efficient and effective access to health care is that of improved health, better health outcomes and improved quality of life.

One of the most commonly cited barriers to primary health care is the inability of people to access appropriate services in their communities. Communities that face inequities in accessing health care also face daily problems due to poverty and debt. "Poverty is a powerful determinant of poor health" (Stillwaggon cited in Omenn, 1998, p. 2131). Poverty has been found to have major consequences for both health status and access to health care (Shirley, 1995).

In the USA many believe that access to primary care is a fundamental societal right, especially for children. One recent study found that children who are members of minority groups, live in poverty or are uninsured are at much greater risk than white, non-poor, insured children of experiencing barriers in access to primary care (Newacheck, Hughes \& Stoddard, 1996).

Both the USA and Australia have attempted to address inequity of access to health for underserved populations by targeting these groups with universal health insurance. However, it has been found that in spite of these efforts, not everyone yet enjoys the same ease of access and the same cost of use for all services (Hall, 1999; Rosenbach, Irvin \& Coulam, 1999). 
Some researchers have equated access with the presence or absence of certain characteristics of the community such as income, insurance and attitudes towards health care delivery systems. However, others argue that access is better defined through outcome measures such as utilisation rates and consumer satisfaction (Gulzar, 1999).

International monetary policies directly affect health care provision in developing countries. In Nicaragua, there was a dramatic deterioration in the standard of living since the government changed in 1990. Pressure from the World Bank and International Monetary Fund forced the Nicaraguan government to slash public spending, including health and education. This has led to the poor dying of treatable diseases with malnutrition and mortality rates rising. The child mortality rate in Nicaragua is the highest rate in Cental America and is ten times higher than that of Canada. A Nicaraguan health expert, Dr. Guillermo Gonzales, believes that the lack of housing and basic services, such as lack of access to clean drinking water and sewage systems, is at the root of many health problems (Lane, 1995).

The UK has been recognised by the United Nations Development Programme as one of the most unequally developed countries in the world, in terms of child health. The British Medical Association (BMA) has recommended that four Children's Commissioners be appointed to act as advocates. Health policy makers are asked to look at ways of placing children's services much higher on their agenda, and at ways of breaking down barriers between different government agencies (BBC, June 30, 1999).

In 1999, the concept of Health Action Zones was announced by the British health secretary in a bid to "reduce health inequalities and prevent illness in places with high levels of poor health and deprivation by overcoming the barriers between local authorities and the professions" (O'Dowd, 1999, p. 17). The aim of this initiative is to improve quality of life by addressing health problems that arise from substandard housing, inadequate transport, poor school attendance and truancy. Primary health care is to be improved by 
the development of integrated health care services and by encouraging local health and local services to work more closely together (O’Dowd).

Two South African researchers describe how apartheid policies, which advocated the provision of different services to each racial group, are being blamed for the great differences in access to social services by different social groups (Bloom \& McIntyre, 1998). At present, three quarters of the money spent on public health services is spent on acute care hospitals. The government is now working urgently to improve services that are likely to reduce mortality and morbidity. Bloom and McIntyre point out that restructuring the health sector is complex, and they suggest the government base its strategies on a good understanding of the health sector. This includes understanding the socio-economic determinants of health status.

This section of the literature concerned with access issues in primary health care illustrates the importance of recognising this problem on an international level. Access issues have been defined differently around the world. However, this literature illustrates that they are all characterised by the socioeconomic contexts in which people live.

\section{Socio-economic contexts}

It is now generally accepted that the social context of people's lives has a direct bearing on and relevance to their health. No discourse on primary health care can legitimately ignore the societal impact on communities of issues such as housing and homelessness, the socio-economic environment, the link between poverty and ill health, social organisation/disorganisation, social deprivation and exclusion and the special needs of vulnerable and underserved populations such as street children (Foltin, 1995; Gulzar, 1999; Smith, 1995).

Charles Andrain, a professor of political science, has written widely on sociopolitical phenomena. In his recent research into public health policies and social inequality (1998), he found that cost containment is at the top of the political agenda for all world capitalist economies. Generous, 
comprehensive, universal and egalitarian health care benefits are becoming less and less available, and the poorest and sickest people feel most discontented with the health care system. Typically, worldwide, rural communities, the urban poor, people with little formal education, ethnic minorities, indigenous populations and immigrant workers receive the fewest benefits relative to their health needs (Andrain, 1998).

For example, research into the equity of health care services for the Aboriginal population of Australia's Northern Territory found that socioenvironmental conditions affect Aboriginal health status profoundly. So marked is this problem that to achieve equality of health outcomes between indigenous and non-indigenous populations would involve not only substantial increases in health care, but also a substantial increase in expenditures to improve housing conditions and employment opportunities (Mayston, cited in Barer, Getzen \& Stoddart, 1998).

\section{The New Zealand experience}

Three New Zealand (NZ) researchers investigating equity of health care in $\mathrm{NZ}$ found that the clearly articulated goal of the NZ public health system is "equal access to health care for people of equal health needs" (Peacock, Devlin \& McGee, 1998, p. 1).

However, funding for rural health services has been declining since 1993. In some parts of provincial NZ people are having to travel, sometimes more than two hours, to main centres for basic health treatment, and the problem of access to basic health services gets worse after hours unless local General Practitioners (GPs) are prepared to work 24 hour days (King, July 1, 1998).

Low income families in New Zealand are often unable to afford food staples, doctor's visits, medicine and adequate clothing on a regular basis and many are living in over crowded conditions, according to a survey undertaken by the Lower Hutt Family Centre Social Policy Research Unit (The Daily News, Sep. 24, 1999, p. 3). The households surveyed all contained children under 
the age of 15 years. This is a clear indication that children's health needs are not being met in some sections of New Zealand society.

Access to health services is a major problem in Northland, NZ, where the majority of people live in rural areas, according to a study into physical access to health services there (Walker, 1995). In some parts of Northland, between $61-79 \%$ of the population are Maori and between $17-19 \%$ of households do not have a car. The majority of roads in Northland are unsealed and the condition of these roads is variable (Walker). Walker's research identified that access is more than just travel. The socio-economic status of much of the Northland population was found to be at a level of social deprivation.

Walker (1995) found that the people in Northland tend to wait until they are really sick before they decide to visit a doctor. A trip to the doctor, for those without a car, often means at least one day off work, a babysitter, extra money for travel and a fee payment. Sometimes overnight accommodation is required. There may be no chemist or laboratory in the area, which necessitates another journey. Of the households surveyed, it was not uncommon for people to use cars without proper documentation.

The link between health status and socio-economic status in the North Health region was further explored in 1997 (Jackson, Kelsall, Parr \& Papa, 1998). This research report found that the highest rates for avoidable hospitalisation were found to occur amongst people in the lowest socio-economic group. The report found evidence of conclusive links between health status and socio-economic status and established that socio-economic, environmental and lifestyle factors would positively influence death rates in the area. The authors found that "There are considerable savings to be made in addressing socio-economic differences, in terms of both the dollars saved to the health system, and the numbers of avoidable deaths, as well as improving the quality of life of a considerable number of people living in the region" (Jackson et al., 1998, p. 30). 


\section{The Indigenous experience}

There are many similarities between the health experiences of indigenous people worldwide. Health has its basis in the relationships between human societies and cultures and the environment in traditional indigenous cultures (Foller, 1995).

For the Maori and Aboriginal Australians, before the arrival of the Europeans, both cultures had an holistic view of health which enabled them to prosper in healthy lifestyles (Jamieson, 1992; The Lancet, March 14, 1998). Indigenous people of the Americas and Australasia also shared a history of brutal, sometimes genocidal expulsion from their lands, followed by the curse of imported infections and disastrous health transition to the western type disease model (Jamieson; The Lancet).

This deadly process is still happening to indigenous people around the world. For example, when Foller (1995) studied a group of indigenous people in the Amazon basin, she found that the destruction of their traditional environment and the introduction of new contagious diseases threatened their health. In the urban areas, these people suffer even worse health because of urban diseases and the loss of their accustomed social networks that provide personal support and health care (Foller). According to Foller, the future health status of indigenous people will continue to be affected by the underlying causes of persistent poverty and political inequality, together with trends in population, urbanisation and the environment.

In comparison with other indigenous groups such as native Americans and Maori, Aboriginal Australians' health outcomes are "catastrophically poor...poverty [defines] aboriginal health and disease" (Blackwell \& Hayllar, 1998, p. 1363). Geographical difficulties and culturally paternalistic attitudes mean that access remains an obstacle to health services for Aboriginal Australians (The Lancet, 1998). 
Along with improved access to health services and enhanced communication, Blackwell and Hayllar (1998) believe that a concerted government approach is needed in order to substantially improve health outcomes for this group of people. Fundamental to any process of healing and reconciliation, they maintain, is the recognition of native title to native lands (Blackwell \& Hayllar).

"The most powerful tool that any population requires in bringing about fundamental change to the status quo is sovereign control over their status of health" (Zakrison, 1999, p. 539). This right is guaranteed to Maori in New Zealand by the Treaty of Waitangi, under Article two (Timutimu, 2001).

\section{The Maori experience}

The Maori definition of health encompasses all components of a person's life: spiritual, psychic, physical and family (Durie, 1998a). The emphasis in Western medicine is on an absence of illness rather than on the positive aspects of health; hospitals are seen by some Maori as Pakeha institutions with a stress on the physical condition and a complete disregard for health aspects that are particularly important to Maori (Sachdev, 1990).

The government's principal Maori health objective, formulated in 1992 and still current, is this: "The Crown will seek to improve Maori health status so in the future Maori will have the same opportunity to enjoy at least the same level of health as non-Maori" (Parata \& Durie, 1993, p. 4). However, there have been many reports published in the last decade that are concerned with various aspects of Maori health. Some of these publications come from the MOH (English, 1998; MOH, 1997; Te Kete Hauora, 1995), others from Te Puni Kokiri $(1993,1998)$ and the Maori Health Commission (1998). There is also information from the Maori Women's Welfare League (1984). Independent reports (National Health Committee, 1998; Parata \& Durie, 1993) have also been commissioned by the Department of Health (DOH). The major commonality in all this literature is the issue of the continuing disparity between Maori and non-Maori health status. 
Health statistics show that Maori health is better than it has ever been, but compared to the health of non-Maori, the figures are alarming (Pettis, 1997). This contradiction can be explained by the fact that, while Maori have achieved health gains in certain areas, when compared to the Pakeha population, they are still a long way behind. A report on Maori health in the Southern region identified the socio-economic environment, health behaviours and access to health care as the three main influences on the health status of Maori today (Pettis). Factors such as income, employment, housing and education have been shown to relate strongly to health. Over the last ten years, Maori have become worse off compared to non-Maori (Pettis). The report recommends attention to access as a major issue and suggests that supporting the continuation and growth of Maori health initiatives to provide primary health care for Maori would show a major commitment to improving the health status of Maori (Pettis, 1997). Research into the rate of utilisation and expenditure on primary medical care and related services for Maori found that inequities in access to and utilisation of primary medical care services for Maori still remain (Malcolm, 1996). Malcolm's research established that Maori are seriously underserved in primary health care despite known poor health status and therefore expected higher rates of utilisation. The barriers to access identified in this research include those of geography, client expectation and culture, though the financial barrier was most serious.

Lawrence explains that low access and utilisation of primary care services is likely to be reflected by serious over utilisation of secondary inpatient services, with the attendant higher overall health costs.

Irihapeti Ramsden (cited in Te Kete Hauora, 1995, p. 15) identifies one possible barrier to Maori seeking to access health care as that of services that may be culturally inappropriate.

The authors of the NZ National Health Committee's (NHC) report (1998) suggest that inequalities in the underlying socio-economic determinants of health have major implications in recognised ethnic and cultural inequalities 
in health. Maori health status remains relatively poor when compared to nonMaori (NHC). The reason for this is generally agreed by the committee to be mostly due to poorer socio-economic circumstances for Maori than for nonMaori. The report explains that equity of health services is important in terms of an individual's right to self-determination, as well as in terms of the practical recognition of the rights of tangata whenua under the Treaty of Waitangi. The NHC explicates the wider benefits of health equity to society in the long term, measured in the report in terms of health and social outcomes, such as alcohol abuse, mental illness, violence and social connections in communities. The NHC feel that Maori health needs to be given special consideration in terms of achieving equity. They found evidence that a lot of the socio-economic inequalities in health in NZ are avoidable, and that sound economic reasons for improving health are readily available. The saving of health resources targeted towards prevention in a wide social spectrum, rather than 'cure' in a hospital, makes economic sense.

Inter-sectoral collaboration is required as an integral part of the health and social policy development process, according to the NHC (1998). Their report suggests that existing services be enhanced, along with recommending that existing Health Funding Authority (HFA) resources be deployed in better ways. Responsibility for health outcomes rests a governmental level, where budget holders are urged to document and widely publicise evaluations of successful community development projects, both Maori and non-Maori. However, strategies for Maori health are not specifically addressed, apart from the committee's consideration that reducing inequalities in health in NZ is a very high priority.

Dr. Paparangi Reid believes that Maori, who tend to be low-income earners, are bearing the brunt of the government's economic reforms (Diamond, 1998). International research has shown income to be the single most important determinant of health and that there is a persistent correlation worldwide between low income, poor health, premature disability and death. Evidence is also mounting worldwide to suggest that social and economic circumstances have a strong effect on health. New Zealand has experienced 
the fastest increase of income inequalities in the OECD in the last 15 years with the resultant increase in relative poverty and its health consequences (Diamond).

Maori organisations providing health services have found that "differing objectives and measures for health between government institutions and Maori organisations constrain full realisation of Maori health development aspirations" (Ngaati Hine Health Trust, 1996, p. 12). Maori health initiatives typically have a strong commitment to provide easy access to health services and to facilitate access to other services, including social services (Ngaati Hine Health Trust). It is felt that using a Kaupapa Maori approach to health provision is likely to bring about improvements in Maori health status (Ngaati Hine Health Trust).

We have seen that Maori women are the main carers of their children's health. Any improvement in Maori health status in the community will thus undoubtedly benefit the health status of Maori children.

\section{Conclusion to chapter three}

This literature review has looked at barriers to primary health care both within New Zealand and internationally. Common themes have emerged from poor and wealthy countries, especially with regard to different understanding of the concept of primary health care. There is a general recognition that the concept of health must be considered contextually; that is, there are many factors that impact on health. Internationally and nationally, the recurring theme is the clear link between socio-economic environments and health status. It seems, then, that initiatives aimed at improving health status need to be based on inter-sectorial collaboration.

Until all these factors are considered together, it seems most unlikely that the poor health status amongst some sections of New Zealand society can be enhanced. Only with a common understanding of how health may then be achieved for all the population is Maori health status likely to improve. 
The next chapter examines the theoretical underpinnings and philosophical positioning of this research. The place of reflexivity in the project is addressed and the methodology and method are also discussed. 


\section{Chapter Four Theoretical and Philosophical Position}

\section{Introduction to chapter four}

In this chapter, the theoretical and philosophical position of the research project and the researcher are described and discussed. Critical social theory, an emancipatory approach, is explained with reference to its inception, development and relevance to this project. Next, the process of critical reflection as part of an emancipatory endeavour and in this thesis is examined. The process of participatory research is explicated with particular reference to this research. Finally, the relevance of participatory research in nursing research is discussed.

\section{Critical Social Theory}

Critical social theory, also known as critical social science, underpins this research project. Critical social theory is an example of the ideology of the emancipatory inquiry; such inquiries seek to achieve emancipation and social change through knowledge production (Henderson, 1995). Fay (1987) explains that a critical social theory must concurrently explain and criticise the social world, while at the same time it empowers its participants to overturn it. Members of society are empowered through the stimulation of self-knowledge; this knowledge and understanding of their society enables the members to change what they perceive to be negative influences (Fay).

Critical social theory emerged from the Frankfurt School of philosophical thought, which was the birthplace of critical theory. The Frankfurt School was set up at Frankfurt University in 1923 as an Institute for Social Research. At its inception, it saw itself as a forum for historical and sociological exploration, with Marxist theory as its starting point.

The underlying philosophical position of the Frankfurt School was its attempt to unify knowledge and purpose together with both theoretical and practical reason; the aim being transformation of society and emancipation of the population (Bottomore, 1984). The School's emphasis of inquiry gave 
greater weight to pure theoretical work than had previously been the case in other schools of philosophical inquiry. The inclusion of the elements of psychoanalysis and existentialism into the original examination of historical and sociological ideas, combined with theoretical understandings, resulted in a new form of Marxism identified as critical theory. Central tenets of critical theory considered problems of aesthetics, culture and modernism (Urmson \& Ree, 1989).

Georg Hegel's ideas were some of those reflected through the philosophy of the Frankfurt School. Urmson and Ree (1989) describe Georg Hegel as one of the most influential philosophers in history. His influence underpins modern understanding of the historical perspective of Marxism, existentialism and analytic philosophy, among others. Hegel was particularly opposed to all dogma and to authoritarianism. The history of philosophy was an idea of critical importance to Hegel, particularly in terms of a progressive revelation, over time, of truth. His view of the history of philosophy meant that it must be understood in terms of development (Urmson \& Ree).

Leading members of the School included Horkheimer, Adorno, Benjamin, Marcuse, and later, Habermas. Karl Marx was a member of the left wing group of Hegel's followers, which emerged after Hegel's death. Marx agreed with Hegel's ideas of history and development but disputed his fundamental beliefs about the human spirit and ideas. Dialectical logic and thinking were ideas that Marx took from their inception in Hegel's philosophy and then further developed. He believed that in order to attain true knowledge, dialectical thinking was necessary. For example, according to Marx, the process of history can be considered as a dialectical process through which man progresses "through the clashes of contradictory social systems" (Bullock, Stallybrass \& Trombley, 1988, p. 504).

Burns and Grove (1993) discuss the ways in which the original members of the Frankfurt School were influenced by Marx's writings. In essence, they believed that social phenomena were situated within an historical context. Further, they saw that the closed systems of thought on which most societies 
functioned lead to the emergence of dominant patterns and the restriction of personal growth of individuals within the society (Burns \& Grove).

The contemporary philosopher who best represents the school of critical theory is felt by some to be Jurgen Habermas (Urmson \& Ree, 1989). Habermas believed those critical modes of inquiry, which are aimed at understanding other people and exposing their unconscious compulsions, emerge out of communicative action. They cannot be reduced to empiricalanalytic inquiry, which emerges out of instrumental action and is directed towards prediction and control of objective processes (Urmson \& Ree).

The idea of knowledge as constructed instead of found was partially discarded by Habermas in favour of a theory involving language and communication (Bottomore, 1984). Bottomore describes this theory as one of truth and, simultaneously, a doctrine of emancipation. The communicative position of Habermas' theory is characterised by equality and reciprocity of participation. This potentially creates a forum within which to critique inequalities of social power in a way that is not solely based on personal value judgements (Urmson \& Ree, 1989). The research project described in my thesis is based on my assumption that equality and reciprocity of participation would uncover truth in an emancipatory fashion.

Habermas attempted to move critical theory beyond a simply interpretive approach in order to recognise the importance of causal phenomena on individual self-reflection and self-understanding. Individuals can thus recognise ways in which their aims and purposes may have become distorted or suppressed. They may then be able to take some action by which they can redefine their aims and purposes by ridding themselves of the sources of their frustration (Carr \& Kemmis, 1986).

\section{Basic design of the Critical Social Theory paradigm}

The terms 'critical theory' and 'critical social theory' have sometimes been used interchangeably, though they are not the same. Fay (1987) has produced important work on this topic. He explains the difference between critical 
theory and critical social theory. He considers critical theory to be a theory of society, while critical social theory is a theory of science, originated also from the Frankfurt school. Critical social theory is dynamic. It conceives knowledge ultimately as self-knowledge, so that the process of liberation is..."one in which the oppressed are educated about their situation and about their potential capacity to alter it" (Fay, 1987, p. 205). Critical social theory is particularly concerned with issues of empowerment and emancipation. A critical social theory must concurrently explain and criticise the social world, while at the same time empowering its participants to overturn it (Fay).

Critical social theory is painstakingly fashioned in order that social theories can have practical political impact. The essential features of a critical social theory (Fay, 1987, p. 109), are that it “....is clearly rooted in concrete social experience, ...it is...explicitly conceived with the principal intention of overcoming felt dissatisfaction.... A critical social theory arises out of the problems of everyday life and is constructed with an eye towards solving them." The three essential processes of critical social theory are enlightenment, empowerment and emancipation. Fay believes that the practical intent of critical social science can be achieved through these processes.

He goes on to describe ontological problems with critical social science in terms of theoretical practicality and integrity as an ideal. In particular, Fay is concerned with the ontology of people, mainly as active beings; he argues that "they are also historical, embodied, traditional, and embedded creatures whose powers of reason are inherently limited" (Fay, 1987, p. 214).

Epistemologically, critical social theory views knowledge production as a potentially emancipatory act (Henderson, 1995). This means that any research that has knowledge advancement as a goal must recognise the social, political, economic and historical content in which it takes place. Therefore, such research can never be taken to be value free, objective or neutral (Henderson). 
There have been gradual ontological and epistemological developmental changes within the paradigm in the last few years, which is to be expected when the goal of the research is to interpret or reconstruct subjective meanings (Hill Bailey, 1997). Hill Bailey suggests that reality in critical social science is actually constructed by the participants as they interact within a social environment. A further construction by the researcher occurs when this reality is interpreted.

The methodology of critical social science research may be summarised briefly by the following authors. The critical research process utilises dialectic thinking in order to critique the social situation in question. The researcher has an on-going dialogue with the data as it is collected, analysed and interpreted through the use of reflection and insight (Burns \& Grove, 1993; Campbell \& Bunting, 1991). Casey (2000) explains that critical social theory acknowledges the impact the researcher has on the participants. This impact is overtly informed by the knowledge and values that the researcher holds.

Reciprocity, considered a defining feature of emancipatory research, means that the researcher should be prepared to answer direct questions from the research participants. This may include personal information. Disclosure of personal information and beliefs is felt to be a necessary part of changing the social relations of research (Northway, 2000).

Lather $(1986,1990,1991)$ comments further about critical inquiry and critical social theory. She argues that critical inquiry requires a more collaborative approach amongst researchers in order to build emancipatory theory and to build up a credible database within advocacy research that is praxis oriented. In order for a research design to achieve empowerment as a goal, Lather identifies three issues that must be addressed: "the need for reciprocity, the stance of dialectical theory building versus theoretical imposition, and the question of validity in praxis oriented research" (1986, p. 263). 
Lather (1990) warns that critical social theory cannot be considered outside of ideology, though the original conceptualisation of the ideology of false consciousness has been found to be impossible. An openly ideological approach to critical inquiry is of particular interest to Lather. She recommends that the critical researcher's focus on developing interactive approaches must be combined with an awareness of the dangers of researchers imposing meanings on situations, rather than constructing meaning through a process of negotiation with research participants (Lather, 1991).

\section{Rigour, trustworthiness and limitations of Critical Social Theory}

In terms of limitations, redefining the concept of ideology in critical science has led to accusations that critical science visions are aimed only at understanding, rather than transforming ideology (Lather, 1990). Fay agrees that the strengths and weaknesses of a theory of social science can only be fully recognised and analysed when it evolves into action. Examples of how a critical social theory can be destructive in practice incorporate revolutions inspired by critical theories that have either betrayed those who believed in their doctrine, or, in promising to set people free, have ended up taking their liberty instead (Fay, 1987). There is mounting anxiety about the possibilities of "researchers with liberatory intentions imposing meanings on situations, rather than constructing meaning through negotiation with research participants" (Lather, 1991, p. 13).

Nurses have adapted a criteria for assessing qualitative work with the aim of enhancing the trustworthiness of the project, but this has been done rather uncritically, often resulting in "rule governed approaches" (Koch \& Harrington, 1998, p. 885). An example of this is the 'rule' of returning data to the research participants. Though this is a common way for nurse researchers to address issues of authenticating data and establishing rigour, Koch and Harrington describe pitfalls. They believe that there are ethical and practical problems with such a procedure, which are often not addressed. The benefits of this practice are questionable. Verbal accuracy can be assured, in 
terms of the basic data, when the interviews are tape-recorded and directly transcribed (Koch \& Harrington).

In order to expand the concept of rigour in nursing research, researchers are encouraged to "incorporate their social self into the research project" (Koch \& Harrington, 1998, p. 886). The researcher can then be more engaged in the making of the research product. Credibility of research findings should be judged on the usefulness of the product. This may be achieved through contextual writing together with a reflexive account of the research process.

Finally, artificial time limits such as those imposed by academic requirements can seriously affect the validity of critical research.

\section{Relevance to this research}

Critical social science research provides a theoretical basis for research with a focus on power and political structures. It provides opportunities within the research process for reflection, dialogue and action. Attempts are made to develop an empowerment approach in the researcher-participant relationship through research design strategies, such as encouraging reciprocity and negotiation. There is the scope to use a variety of research methods, as long as they are used in a manner consistent with the philosophy of critical social theory. Importantly, within the critical approach there is the opportunity to work on collaborative research.

Issues of power and politics in relation to the research will be discussed in the Participatory Research Process and Treaty of Waitangi sections of my thesis. A section about reflections and reflexivity is included later in this chapter, and my own reflections are included throughout the document. Chapter eight contains recommendations for action based on the research findings. An emancipatory research design utilising focus group and one-to-one interviews is described later in this chapter. The collaborative focus of critical social theory on which this project is based allowed the research process to develop in partnership. This partnership involved participation in the entire research 
project by the researcher, and participants, who are all Maori, and the community in which the research took place.

The next segment of this chapter addresses issues of critical social theory, power and empowerment.

Critical Social Theory, power relations and empowerment in the New Zealand setting

As has been established, historically Maori have been disempowered in terms of their access to appropriate health care. Also, Maori have been the subjects of research that has not brought any benefits to their lives (Bishop, 1994; Cram, 1997, Te Awekotuku 1991; Tomlins-Jahnke, 1996). Bishop points out that, since the signing of the Treaty Maori and Pakeha relations have been those of domination by Pakeha and marginalisation of Maori.

Various authors expand on the relationship between power and people here. Wilkinson (1999) explains that power is constantly present everywhere and is reproduced in all relationships, producing resistance. Power may be defined in terms of the resistance engendered, as they are different sides of the same coin. The demonstration of power may be measured in terms of unequal outcomes for the people involved (Yon, 1999).

In their work on marginalisation, Hall, Stevens and Meleis (1994, p. 27) define power as "influence exerted by those at the center of a community over the periphery and vice versa". Authority and control that flow from the center to the margins are demonstrations of hierarchical power. Horizontal power occurs when those at the margins propel innovation and resistance towards the center. Inequities in political, economic and social resources sustain those with power at the expense of those groups with least power, who dwell on the margins of the dominant social group. Those on the margins are typically indigenous people, unskilled or unemployed, lowincome single mothers, children and the homeless. Friere (1972) examines the concept of power in a context of working with underprivileged clients. 
He identifies power there as status and the possibility to control people, their actions and economic resources.

Of necessity, subordinated groups create knowledge that helps them resist oppression. Marginalisation may result in deprivation and powerlessness. However, it can also provide a locus of resistance and empowerment, with the possibility of overturning oppressive, hierarchical power dynamics (hooks, 1990). This view is particularly relevant to my thesis because the participants are all Maori - arguably a marginalised group in New Zealand society (Bishop, 1994).

Foucault, a post-modern French social philosopher, suggests that power originates from everywhere, and is involved in all human interactions. Foucault describes power as reflexive, impersonal and productive, particularly in terms of generating knowledge. Foucault is concerned with the relationship between discourses of knowledge and truth, and the concept of power. In a political system of total domination, Foucault believes people can respond to the effects of power with forms of resistance. For example, a person can be both the object and the subject of power while theoretically being able to increase their knowledge (Foucault, 1980). However, this concept can only be understood if a study of the essence of power is based on a bottom-up rather than top-down analysis (Cheater, 1999). In this way, forms of knowledge and strategies of resistance are connected. Foucault's analysis of power relations looks at power at the point of interaction between individuals and groups, as well as power based in structures and institutions (Foucault, 1980).

In the health care environment, Foucault's conceptualisation of power can be utilised to illuminate the realities of daily relationships. The manner in which power operates in these relationships to enhance or inhibit health practices in socio-cultural contexts is thus made visible (Richardson, 2000). Examples of an analysis of the power relations inherent in this research are provided in chapter six and seven of my thesis. 
Empowerment is about giving power to and enabling. It is also about addressing social inequities and injustices. Casey (2000, p. 28), in the New Zealand context, considers "that empowerment is about power and where an individual, group or community perceive the power resides".

Empowerment, in a Maori context, may be translated to mean tino rangatiratanga, the right to self-determination. The unequal power relationship between the researcher and the participants can be addressed within an emancipatory research framework and has been explored in my thesis. I have sought to present the voices of the participants without imposing my own meanings on what they are saying. The legitimation of Maori knowledge and being clear about intellectual property rights - who 'owns' the research need to be made explicit. Depowerment of the researcher as a concept acknowledges that the participants' knowledge has value and status within the Maori world (Cram, 1997).

Graham Smith (1990) offers four models that Pakeha researchers can use in order to achieve culturally appropriate research. The first model, 'Tiaki' happens where the research process is guided and mediated by authoritative Maori people. The 'Whangai' model occurs when the researcher becomes one of the whanau who happens to be doing research. In the power-sharing model, the researcher seeks community assistance so that a research project can be developed in a meaningful way. The empowering outcomes model ensures that the research supplies answers and information that Maori want to know.

I believe that the research described in this thesis borrows from the models of 'Tiaki' and empowering outcomes. I was particularly concerned with the representation of the participants involved in this project. The opportunities for miscommunication and misunderstanding are probably greatest between cross-cultural groups, especially when the researcher's group (Pakeha) holds more status and power within society than the group to which the participants belong (Cram, 1997). Representation of the participants' perspectives is more than simply objectification or presentation, and needs to consider the 
role of culture, history and societal context. Elements of collaboration, empowerment and reflexivity between the researcher and the participants need to be negotiated so that the representation is valid (Cram). This can happen by including participants' stories in the research as demonstrated in chapter six of this thesis. I recognise that the researcher must consider whose account is privileged in a final research report. The position of the researcher in such an undertaking needs to be made explicit. The issue of researcher and participant positioning is overtly addressed throughout my thesis, as proscribed by the aims of the project.

\section{Nursing and Critical Social Theory}

Nursing as a discipline of the social sciences lends itself very well to research in the critical paradigm (Carryer, 1995; Gibbs, 2001; Thompson, 1987). Modern thought and living conditions expose many more nurses to exactly the sort of social contradictions that create a pattern of reflection and challenge. Modern society is increasingly filled with social contradictions; many more upper-middle-class professionals now live a lot more closely to marginalised members of ethnic minorities. In the circumstances, Thompson points out that it is much more difficult "to miss obvious contradictions in the social definition of reality" (p. 29). Thompson suggest that nursing education could greatly benefit from the critique and challenge of critical analysis in explaining to nurses the diverse contextual backgrounds in which their clients live.

Jenkins (1997) reminds us that traditionally, health professionals have possessed a dominance over their clients. Nurses who seek to empower their clients need to be aware that marginalised, disadvantaged people may not be able to make choices about their lives. For example, they often have few options about where they live and with whom, what to eat, what to wear and what activities to pursue.

In order to help nurses deal with the issues of power relations identified through critical research, these relations must become transparent, which occurs through consciousness raising, according to Thompson (1987). She 
believes that power relations lose power when they are exposed, and then become transparent. In critical social theory, power is interpreted in terms of coercion and domination. An increase in power in one direction means a corresponding loss of power from the opposite direction (Kuokkanen \& Leino-Kilpi, 2000).

Emancipatory interventions are necessary to help nurses empower their clients, instead of merely hastening them through an uncaring and disjointed health system (Kendall, 1992). For example, Kendall believes that the long recognised effects of poverty on health status can no longer be ignored. Nurses using a critical approach can usefully tackle the contextual reality of marginalised clients.

In terms of nursing research, critical reflection is felt to be an integral part of emancipatory or critical inquiry methodologies. Inherent in such methodologies are components that emerge from the researchers' critical reflections of the information collected. This critical process reveals power relationships as well as particular interests and biases the researcher has that inform the context of the particular practical situation under scrutiny (Northway, 2000; Palmer, Burns \& Bulman, 1994).

There is an appreciation that the orientations and values that researchers bring to the research process are shaped by a range of social and historical factors. These values and the position of the researcher may be examined and their biases made explicit. Critical examination at all stages of the research process can present a clear picture of the complexities inherent within the process (Northway, 2000).

When used in nursing, critical social research endeavours to critically analyse oppressive environmental effects on health by "uncovering the relations of dominance and by demystifying the ideology that rationalises unequal power relations" (Stevens, 1989, p. 67). In nursing, critical social theory particularly values emancipation of people dominated by any constraints that inhibit health and human potential (Stevens). In a context of working with 
underprivileged clients, one definition of power has been identified as status and the possibility to control people, their actions and economic resources (Friere, 1972).

It is clear that there is much knowledge to be gained by nurses doing critical research in the emancipatory paradigm. Kendall (1992) suggests that nurses need to choose actions that empower people to escape the oppressive constraints of the socio-economic, political and health environments. Likewise, Ray (1992) believes that, potentially, knowledge gained from a critical research approach can enhance emancipation from health system constraints for both nurses and their clients.

Stevens (1989) proposes that nursing research problems be framed so that broad environmental and ideological factors are considered and structural solutions are pursued. A broad approach is necessary, in order to address oppression within social, political and economic contexts and to inform reality on a wider level. Stevens explains that the research paradigm expands from being simply a place for controlled observation to incorporate the dialogue of reciprocal interaction.

The future of nursing may depend on the ability of the discipline to reach out to diverse communities and to meet the health needs of those most vulnerable (Hall, Stevens \& Meleis, 1994). Identifying the health of vulnerable groups as a priority is not enough. Knowledge development regarding these groups is not easy. For example, they may be stigmatised, lacking access to services and mistrustful of the research process.

However, the women who participated in this research project are eager to initiate community initiatives that benefit the health of their community. For example, I have recently been asked to facilitate a training session for community members about preventing choking. As I am known as a nurse based in this community, I was the first person to be approached. The organisation of the day is being done by a group of Maori women who identified a need in their community, and set about addressing how the need 
could be met. The local Ambulance First Response Team, of which I am a member, is working in partnership with these women to provide the skills they need to achieve their aims for the day. The woman who first phoned me with this idea asked for a face-to-face meeting at which she and I drafted a plan for the day. We discussed exactly what knowledge was wanted, and how it could best be presented. I explained about the resources and skills the First Response Team would bring. She discussed how her group would advertise the training, after we had agreed a venue. We talked about the cost, and agreed that a koha would be most appropriate. This is an example of Maori and Pakeha working in partnership for the benefit of their community. The planning, topic selection, advertising, venue, timing and cost issues were all dealt with by the Maori women. This was their initiative.

As I reflect upon my position as a nurse in the local community, it seems that I was asked to participate because they know me and value the knowledge I have. Also, the acceptance of my role as a local health researcher means that these women trust that I can work alongside them in a Maori initiative that follows Maori processes. For me, being asked to facilitate this training was evidence of my place in the community. I have filled many different roles here in the last ten years. When I first came here, I was known as a nurse and one of the local doctors' daughters. I found that my father was well thought of in the community. Then I became known to more families as I spent some time working as a local practice nurse. I married a local Maori man whose family is well known in our community, forging more community links. I worked alongside Maori health workers in local child health and safety initiatives. As I walked along the street, I would stop and chat to the many people I now knew. Then I became the local child health nurse, and visited many families at home. At the same time, my children had started attending the bilingual unit at the neighbourhood school, where they made friends with the siblings of the children I visited in their homes. I became a member of the local Ambulance First Response Team and met still more community members. 
These examples illustrate that in the community in which this research took place it was impossible for me not to be known in many different roles. That is also the experience of women's lives here. For instance, many of the participants of this project play different roles in the community. I noticed that many of the older Maori women with whom I interacted wore 'many hats', as they said. They were involved in the community as grandmothers, mothers and daughters. Some were members of school boards and marae committees. Many were involved in local sports teams, as players and supporters of their children's sports. In the morning they might welcome visitors onto the marae and be found washing dishes in the afternoon. It was equally likely to find them transporting the old people to and from their homes for marae based activities. These are just a few examples, though there are many more.

As I considered the theoretical underpinnings of this project, it became clear that the Maori women with whom I liaised in the community understood an emancipatory design. They approached health projects with a view to positive, sustainable change. Further, it seemed to me that a participatory research method of data gathering would be ideal for this research project, and my Maori research partner agreed. A section about participatory research is included later in this chapter.

\section{Reflections and reflexivity}

In this section of the chapter, I explore the meaning of reflection as part of the concept of reflexivity, which is an integral part of this thesis. One of the expectations on the researcher engaged in critical inquiry is the inclusion of the researcher's reflections on every part of the research process (Burns \& Grove, 1993). I believe that reflexivity is a way of critically questioning and analysing the research reflections, thus providing a more complete interpretation of the data (Marcus \& Fischer, 1986). Some of my personal reflections are included here as part of my reflexive gaze at the entire research project, and more may be found throughout the text of the thesis. 


\section{Reflective practice in nursing}

Social anthropologists have been writing about the use of reflexivity in ethnographic research for some time (Geertz, 1988; Marcus \& Fischer, 1986). In the discipline of social anthropology, and increasingly in nursing, the research environment includes the participants and the setting. This environment is thought to be influenced by and to act as an influence on the researcher. The acknowledgment and integration of these reciprocal influences into the research report is an example of reflexive thought. That is, a process of critical thinking occurs that reflects the dynamic interaction and exchange that takes place between the researcher and the whole research context (Lamb \& Huttlinger, 1989; Marcus \& Fischer, 1986). The researcher is asking 'what is happening here?' and 'why are things the way they are?'

The interpretation of the concept of reflexivity in nursing research seems very similar to that described by social anthropologists. "Reflexivity implies a shift in our understanding of data and its collection - something that is accomplished through detachment, internal dialogue, and constant (and intensive) scrutiny of 'what I know' and 'how I know it"” (Hertz, 1997, p. vii-

viii). Reflexivity is "the critical gaze turned toward the self" (Koch \& Harrington, 1998, p. 888). These authors describe the entire research process as a reflexive exercise that examines 'what is going on' in terms of the research methods utilised. Among their concerns are the issues of representation, interpretation and legitimation in qualitative research (Koch \& Harrington). Reflexivity in research potentially promotes honesty and transparency within the research process, thus enhancing the quality of the product (Northway, 2000). A reflective approach offers in practical terms the actual integration of theory, practice and research. It takes theory and research out of the exclusively academic domain, and places them firmly back in the domain of all nurses (Fook, 1996).

Northway (2000) suggests certain strategies for promoting reflexivity. These include the use of a journal, which serves to locate the researcher in the research process. The use of dialogues, which takes different forms, may be another helpful strategy. For example, a 'critical friend' can challenge "the 
self-deceptions" of researchers (Northway, 2000, p. 395). Dialogue between the researcher and a colleague, such as a research supervisor, and between the researcher and research participants are also likely to be useful (Koch, 1998; Northway, 2000).

Waterman (1998) describes drawbacks to reflexivity. There may be a tendency to introspection that leads to immobilisation. The objectives of the project may be neglected and too great an emphasis be placed on a reflexive commentary. The unconventionality of the text may irritate readers. Researchers may have difficulty with understanding and developing selfawareness. These drawbacks can be overcome by various means, but the researcher needs to be aware that they exist (Waterman). By using a reflexive approach to inform the research process, I have endeavoured to make my values, assumptions and motivations explicit.

Much of the data I collected was imparted to me in the form of stories. Koch explores the story as research product incorporating journal data, observation and listening fused in writing. Issues in representation are dealt with by giving careful consideration to voice, audience, the researcher's and the storyteller's place in the story. Story telling can create a legitimate research product. "People live stories, and in their telling of them, reaffirm them, modify them, and create new ones. Constructions of experience are always on the move" (Koch, 1998, p. 1183). The telling of stories aims to help those who listen to gain another or a different understanding. There are a variety of ways in which listening to the voices of our clients in their stories potentially informs nursing practice. For example, stories can be used in evaluating community development, can inform social policy and can allow marginalised groups to have a voice (Koch, 1998). My thesis incorporates this use of stories as data to frame recommendations aimed at evaluating the potential for community development, informing social policy and giving voice to members of the Maori community. 


\section{Down deep and personal}

In this section, I have included some of my thoughts on reflexivity in this research project. Other reflections may be found scattered through the thesis. Points raised again here are being considered from a different focus, and I shall endeavour not to be repetitive. I have deliberately tried not to delve too deeply, as I believe there needs to be something left to explore at the finish of any research project. Also, this project is not so much about what I think, as about what the participants think, and what may come of this.

One of the main tensions for me in doing this research concerned my right, as a Pakeha, to consider being involved in this project. This issue was resolved for me in a number of ways. The idea of using a Kaupapa Maori approach was suggested by a couple of Maori academics. I felt very uncomfortable with this, as many Maori researchers feel that Maori are the best people to research Maori (Bishop, 1996; Irwin, 1994; Stokes, 1985, among others).

However, working in the emancipatory paradigm of critical social theory has resonated with my personal beliefs throughout the entire process. I have already described the unwavering support that I received from Maori representing various groups in the community. I felt it was appropriate for me to continue as long as I had this support.

The presence of Auntie $\mathrm{T}$ throughout the entire research process situated me as the researcher in such a way that I did not come across the resistance that may have been anticipated. I believe my involvement in, and commitment to, child health in the researched community enhanced my position as a Pakeha doing research with Maori.

Another tension for me was my doubt in my ability to complete the research project or this thesis. As I near the end of these journeys, I know about the theoretical and practical knowledge that I have gained. I am aware that some of my personal beliefs have altered. I see the world differently. I relate to health care consumers, as a nurse, with further knowledge of how I may work more usefully with people as they seek to meet their health needs. 
I went into this research feeling quite a bit of trepidation. The reasons for this were many. I was a neophyte researcher, and became confused by the different academic foci I encountered in terms of theoretical, methodological and epistemological aspects of nursing research. I realised that different universities have different ways of defining acceptable boundaries within which 'legitimate' nursing research will be supported.

Also, I planned to work with Maori, and this raised issues in terms of my cultural identity as Pakeha. I understand that any person wishing to research with Maori must be acceptable to the community in which they wish to research, whether they be Maori or non-Maori (HRC, 1998; Te Kete Hauora, 1995; Ramsden, 1996). For this project, consultation was undertaken with interested Maori groups, as well as with the local Ethics Committee before approval was granted. I knew that no matter how much support was verbally given for the project, the true test of its acceptability to the community would come when the interviews began. I hoped to get at least ten participants, but ended up with nineteen who started and eighteen who completed their participation in the project. This was a clear indication to me that this research project was timely and relevant to the women in this community and that they felt culturally safe about taking part.

Sometimes the journey has been really difficult. Family and work demands have needed to be appeased. The research participants and readers of this thesis will surely decide on the value of this work. For myself, there is no question.

The next part of this chapter describes the meaning, development and process of participatory research in this project. Issues of validity and reliability of qualitative data collected by participatory research methods are addressed. The final section of the chapter examines participatory research and health. 


\section{The Participatory Research process}

In this section, the emergence and method of participatory research in an emancipatory research design are discussed. Participatory research is an example of emancipatory research, which collectively investigates reality, and uses knowledge gained to increase "awareness of the contradictions distorted or hidden by everyday understanding" (Lather, 1991, p. 52). Thus is reality transformed, rather than simply being recorded as observable facts. In this way, the traditional separation between knowledge and action is removed, and the creation of knowledge about social reality is linked with concrete action. Maquire refers to participatory research as a systematic approach to personal and social transformation. The aim of participatory research is "to develop critical consciousness, to improve the lives of those involved in the research process, and to transform fundamental societal structures and relationships" (Maquire, 1987, p. 3).

I believe that the principle of partnership, described in the Treaty of Waitangi, is maximised in this research through the use of a participatory research process. The process used in this project, based on this principle of partnership, enhanced the participants' engagement in the research. It is hoped that this project was emancipatory in some way for the participants.

\section{The emergence of Participatory Research}

The appearance of participatory research is linked with the radical and reformist reconceptualisations of international economic development assistance. Also involved is the reframing of adult education as an empowering alternative to traditional approaches, and the ongoing debate within the social sciences that challenges the dominant positivist social science paradigm (Maquire, 1987). Either / or positions of 'value-neutral' positivist authority are being replaced by both / and logic, which assumes that power permeates all aspects of the search for knowledge (Lather, 1991).

de Koning and Martin (1996) describe six recognised historical trends in the evolution of the theory and practice of participatory research since the 1970s. 
The first was a debate about the sociology of knowledge and its implications for forms of knowing throughout human history, a philosophy of science. A central question in this debate asks whether knowledge of human social evolution is conditioned by historical context; that is, by human history (Habermas in de Koning \& Martin, 1996, p. 20).

The second trend originated from adult educators working in third world countries who began facilitating a horizontal dialogue between teacher and learner, instead of the traditional approach that considered the teacher as the powerful person with most relevant knowledge. These adult educators, who were also trained researchers, found an unworkable contradiction occurring as they tried to carry out research in a way that had little or no impact on the participant. The reformulation of research that resulted went on to inform and change the assumptions on which the practice of adult education was entrenched. The phrase 'participatory research' came from this group of adult educators and was then disseminated throughout their educational networks throughout the world (Tandon in de Koning \& Martin, 1996, p. 21).

Thirdly came the acknowledgment of Paulo Friere's contribution to an alternative educational pedagogy, and Ivan Illich's critique of schooling in modern societies. It became evident that the processes of knowing and education were interlinked, and that humans were fundamentally capable of knowing, learning and reflecting (Freire in de Koning \& Martin, 1996, p. 21).

Another trend was the contribution of action research, which disputed the myth of research as static. Instead, action was emphasised as an authentic mode of knowing, and thus took the realm of knowledge into practice (FalsBorda in de Koning \& Martin, 1996, p. 21).

A further trend developed from the work of phenomenologists whose work legitimated experience and the meaning of the experience or phenomena as a basis of knowing (Solomon in de Koning \& Martin, 1996, p. 21). Their contribution to the debate legitimated human emotions and feelings as 
genuine ways of knowing, along with action and cognition (Kolb in de Koning \& Martin, 1996, p. 21).

Finally, the question of participation was raised. As it became clear that topdown, expert-designed development projects were failing, it was agreed that the knowledge and skills of those who are critical participants in the development process must be used in the research process (Chambers; Oakley in de Koning \& Martin, 1996, p. 22).

These six historical trends, each with their own unique contributions, illustrate the rapid, dynamic and complex development of the theory and practice of participatory research over the last three decades (de Koning \& Martin, 1996).

\section{The method of Participatory Research}

Henderson (1995) describes participatory research in terms of its differences from traditional research methodologies. This approach integrates scientific research with education and political action. Benefit to those involved is a primary goal of participatory research, and this may occur through social change. Henderson recognises that this change begins, and may well end, with the participants. That is, raising the consciousness and changing the behaviour of individual participants may manifest potential social and political changes generated by the research.

Participatory research recognises many forms of knowledge and maintains an alternative position regarding the purpose of knowledge creation. The purpose of participatory research is to radically change social reality working with, rather than for, dispossessed people. Human self-determination, emancipation and personal and social transformation are the central goals of participatory social science research (Maquire, 1987).

Participatory research is based on an ideology that recognises people's life experience as the basis for the development of strategies and programs, rather than theories and assumptions (Barnsley \& Ellis, 1992). The members of the 
community who experience the problem have ownership of the research process. This context helps to define the role of the participants, which is manifested in the way they involve other members of the community in the research process, ask questions of people in that community and use their perspective in analysing the data uncovered (Barnsley \& Ellis). In participatory research, the community participants define the research questions and control the research process. They make decisions concerning the research, and are involved in planning the research process and making changes along the way if this is necessary. These same participants help to collect and analyse the data gathered (Barnsley \& Ellis).

When utilising a participatory research approach, the members of the group under investigation take part in the whole research process (Stevens, 1989). Together with the researcher, the members work on concept identification and development, design, data collection and analysis and broach solutions to problems, which includes critiquing identified sources of domination. Along with seeking to produce information, participatory research aims to generate open discussion and debate, raise a community's awareness of broad environmental constraints on, for instance, its health, and to encourage strategic action for change (Stevens). Such an approach seems to me to fit

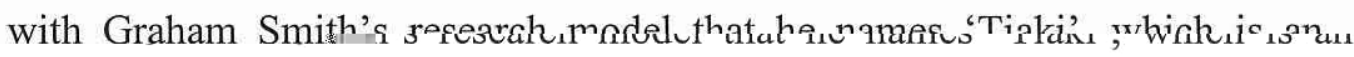
example of a model that Pakeha researchers can use to achieve culturally appropriate research (G. Smith, 1990).

Different interpretations are given to participatory research, based on the degree of participation of the research participants in the entire research process. Participation should be empowering, and not just task sharing with the participants for the researcher's convenience (de Koning \& Martin, 1996). The quality of participation in PR can be measured in terms of the community involvement at each stage of the research process. It is important that the reasons why involvement has not occurred at any stage are documented and discussed, so that gaps are identified and local community needs are met by the research. Participatory research methodologies uniquely serve the shared interests of both researchers and the researched (de Koning \& Martin). 
Co-operation, working openly together and reciprocity are key issues in partnership research. Cram (1997) examines how research partnerships between Maori and Pakeha might operate. She suggests that issues of representation, collaboration, empowerment and reciprocity must be addressed so that a common understanding between parties can be reached. The purpose of knowledge, for Maori, is to serve the community. Thus Cram's model of partnership research is for research that primarily benefits the Maori community, and for which the researcher is chiefly accountable to the community. The community must trust the researcher. Maori 'rituals of first encounter' may help to achieve the trust and cooperation of the community. Using Maori processes to bring the researcher and the participants together shifts the balance of power in the research relationship. The power to define the context of the research and the conduct of the researchers is placed within the hands of the community. A collaborative model of research involves the researcher and participants in the research process with information that flows both ways. A partnership approach to research makes the power of the researcher participant relationship dynamic, and other issues of the research process thus become explicit. For example, the researcher needs to reflect on the values, biases and assumptions they bring to the research project (Cram).

For me, this meant looking at my assumptions about the health of the Maori children in my community. I needed to consider my privileged position in terms of the power I had both as a well-educated Pakeha health professional, and as a researcher. One incident that I recall clearly illustrated for me how great the imbalance of power can be in our society. This realisation came to me as I played the 'biscuit game'. This game was part of the training I undertook as a Women's Refuge volunteer. It involved a group of women trainees, a packet of biscuits, an empty plate each, and our trainer. The brief was simple. A list of items was written on the board. For each of these that we had, we got a biscuit. At the end of the game, we looked around at each other's collection of biscuits, and the one with the most shared hers all around. The items on the board were things like: attended high school, white, married, has a telephone, can read and write, has a bank account, has a 
qualification, has a job, has a car. I got heaps of biscuits, and one woman there got one. I remember looking at that list and at the varying number of biscuits on plates around the room. It brought home to me that many of the things I took for granted were things that other people just did not have. I could see how disadvantaged they could be in a Pakeha majority society, where what you have counts for a lot. I have never forgotten the biscuit game.

I brought assumptions to this research project, based on government health statistics. I brought myself along as a neophyte researcher full of good intentions. I carried a feeling of responsibility for the way things were because of my culture and race, and because of my knowledge of how my ancestors had been part of a terribly destructive colonisation process amongst the people I was now working with. Unrealistic expectations that I held included assumptions I had about academic expectations. I mistakenly thought that research went along in the same smooth way as it is described in texts. Interviews would happen as I had planned them, I thought. Participant selection would not be difficult.

Once I got into the project my understanding of the reality of 'dwelling in the research' expanded hugely. My assumptions and expectations disappeared, in some cases with loud resonant bangs. I learned so much from working with the community kuia. A major learning for me was the appreciation that my way was not the best way here, and that I needed to attend to the way the kuia organised things. Everything worked out much better than I had hoped, but initially I was so scared that it would not, that I did not look to see how it was happening. When I opened my eyes, I saw that the project was flowing smoothly. I can see many possibilities for ways in which the knowledge gained here may help the researched community. I understand that working in partnership with Maori need not be as scary as I had thought; in fact, it can be great fun. I am no longer a 'new' researcher. I have survived this rite of passage and emerged without my original assumptions and expectations. 
There is a generally recognised process used in participatory research. The next section of this thesis examines this process and uses examples taken from the process that I used.

\section{The process of Participatory Research in this project}

Researchers engaged in participatory research are not detached 'others'.

"The principle of shared power is central to participatory research" (Maquire, 1987, p. 38). Participatory research is designed to address the traditional unequal power relationship between the researcher and the research participants. The power and control of decision making and decision taking shift increasingly into the hands of the participants. As the participants become partners in the research process, and take part in the design of the project and analysis of the data, the potential benefits of the research become more equitable (Maquire).

The balance of power within the research process is typically shared more equitably between the researcher and participants in a participative inquiry. The point of working in an emancipatory research paradigm is to allow the process and outcomes of the research to directly benefit dispossessed people on their terms. The voice of the participants articulates their perception of their problems and relevant solutions. This way, the inquiry can lead to action in terms of becoming a tool for self-determined social transformation for the participants, instead of the customary positivist research tradition of maintaining inequitable social relations (Maquire, 1987).

Researchers who espouse participatory inquiries assume that knowledge has become the most important basis of power and control, (Tandon, as cited in Maguire, 1987, p. 35) and that there is a political aspect to all we do. This means that there can be no value free social science, so the researcher must be clear about where they choose to stand in relation to the daily struggles of dispossessed people (Horton, as cited in Maguire, 1987, p. 35).

The democratic foundation of participatory research assumes that returning the power of knowledge production and use to oppressed people will help to 
create a more accurate and critical reflection of social reality. As well, it will contribute to the liberation of human creative potential and to the mobilisation of human resources to solve social problems (Hall, as cited in Maguire, 1987).

Maquire (1987) describes a dialectical relationship between inquiry and action (or theory and practice) as being explicit. The use of critical inquiry is structured to help people to see themselves and social situations in new ways. This change of perception informs "further action for self-determined emancipation from oppressive social systems and relationships" (Maquire, p. 14). Action taken then informs reflection, as people are able to see their social conditions and relationships more clearly.

Acknowledging the political aspects of the research context and process are important components of emancipatory research, and need to be clearly explained by the researcher. Recognition of the presence of power relationships within the research relationship is also important. Emancipatory researchers realise that knowledge production can never be impartial. Knowledge production creates power, and the researcher is either in collusion with those who have power or those who don't, whether they are aware of this or not (Maquire, 1987). Reason and Rowan (1981, p. 489) state: "Research can never be neutral. It is always supporting or questioning social forces, both by its content and by its method. It has effects and side-effects, and these benefit or harm people."

Maquire identifies a dilemma for the participatory researcher in terms of finding a balance between the understanding of oppression that the researcher has, and the understanding that oppressed people have about their own oppression. Participatory research offers a partnership, with both parties recognising that each of them knows some things, but neither knows everything. Working together is necessary in order for both to learn more, and to be open to personal transformation and social awareness. The assumptions are made that both parties come to the research process with 
knowledge and experience to contribute, and that, given the tools and opportunities, ordinary people are capable of critical analysis and reflection.

Participatory research emphasises the process of knowledge production, and goes beyond merely documenting local people's needs and perspectives. It helps marginalised people gain self-confidence in providing a useful contribution to community life. It builds respect among professional groups for the knowledge and insights local people have and the problems they face. Listening to the local people helps avoid making mistakes and to take into account the specific conditions and context that will influence the outcomes of programs (Chambers, as cited in de Koning \& Martin, 1996, p. 4).

It is recommended that participatory researchers seek alliances with groups already in place and evaluate carefully the opportunity for groups begun by the research to continue. They can then examine how the outcomes of the research can be integrated into existing services and look at how community action and lobbying can be supported (de Koning \& Martin, 1996).

Some questions that a participatory researcher should consider are those such as: Who identifies the oppressed? Do leaders who act as advocates for different sections of the community have their own political agenda for wanting to be involved in the research? Does this mean that the research participants may miss out on true power sharing in the project? Maquire (1987) believes that many of the difficulties and limitations facing participatory researchers have to do with the issue of people's organisations.

Suggested guidelines for participatory action research are as follows: the research has a design, the questions to be covered are agreed on before the data collection begins, assumptions are declared, the research respects the group's rules about confidentiality, the analysis of the research information takes into account the experience of everyone who was interviewed, and the research findings must be a transparent account of what the people said (Barnsley \& Ellis, 1992). 
The method chosen to gather data is an important feature of a participatory research process. Barnsley and Ellis (1992) explain that issues such as literacy levels, the participant's understanding of the proposed methods and any special needs of participants must be taken into account.

There are numerous models within the literature in regard to conducting participatory research. There is no one research approach for participatory research; indeed, a valid participatory research project must evolve out of, and in response to, the unique conditions and context of the specific situation. In spite of the fact that there are many possible approaches to participatory research, various authors have identified five phases common to actual participatory projects, and guidelines for conducting participatory research (Vio Grossi, Martinic, Tapia \& Pascal; Hall, as cited in Maquire, 1987, p. 40).

The first phase is concerned with organisation of the project and knowledge of the area to be researched. It is at this stage that existing information about the research area and the main problems facing the people there are gathered. During this phase, relationships are established with key groups and people in the community, and potential community research partnerships begin to be established (Maquire, 1987).

For this thesis, it was at this stage that I talked with Auntie $\mathrm{T}$ and also with the chief executive officer of a regional Maori health provider. They work together, and both agreed to support the project. I was able to provide letters of support from them for the Taranaki Ethics Committee as proof of consultation and of community support for the project, which was invaluable. A local Maori academic expressed an interest in this project. M became my 'critical friend' and has been involved in this project from its inception to the completion of the thesis.

In phase two, described as generating problematics, the participants' identification, understandings and perceptions of their most significant problems are explored with the researchers. The dialogue begun between participants and researchers during this stage of the research continues over 
time, taking "the researchers and participants to a deeper and more critical understanding of reality as perceived and experienced by both participants and the researcher" (Maquire, 1987, p. 41).

This phase for me involved working with Auntie $\mathrm{T}$ identifying potential participants for this study. Auntie T knows who everyone in the community is in terms of their tribal / iwi affiliations, and knew to whom they were related. She knew who met the inclusion criteria for the study, and was able to access them. Auntie $\mathrm{T}$ found more participants than could be included. This was because some heard by word of mouth, and either did not fit the inclusion criteria, or came forward after the data collection phase had been completed. The trial of the interview questions and the interviews happened in this phase of the process. It was during this phase of the research that I became aware that the problems I had anticipated participants discussing did not necessarily surface. I drew the conclusion that, though there were many women who had the same problems, there were others for whom problems were different. I laid aside more of my preconceptions about the barriers the women would identify and listened, recorded, transcribed and continually reflected on what they had to say.

Phase three concentrates on attempting to link participants' individual interpretation of problems to the broader context. The researcher(s) and participants work through the process of compiling the questions and themes to be investigated. Maquire (1987) comments that as each phase concludes, the participants have become increasingly more involved in deciding how the project will be controlled. As the process of the research progresses, the participants' awareness of their own resources and abilities for action strengthens.

Auntie $\mathrm{T}$ and $\mathrm{M}$ helped me to identify the themes evolving from the data during this phase of the research. $\mathrm{M}$ and $\mathrm{I}$ had informal discussions and she also critiqued some of the work, which was not identifiable (with the participants' signed consent). At this stage, I had to decide how best to explain the data in terms of analysis. M helped me develop a framework on 
which to hang the data that made sense of what the women had said. M pointed out that there was a strand of the data that was clearly Maori, and that there was also one that was not Maori. The framework designed to support the data would need to reflect these two perspectives. I had intended to let the interview questions act as an outline for the analysis, but after discussions with $M$, it became obvious that this approach was not congruent with the research. The approach I eventually used is described in Chapter six.

Once the main problems have been defined, in phase four, the researchers and participants design a process together to investigate specific concerns. Participants can decide how involved in gathering and analysing collected information they want to be. The solutions that the participants develop here should be applied to creative strategies and action for social transformation, to ensure that the new knowledge increases people's power (Maquire, 1987).

Auntie T, M and I worked together on this phase. I expected that there would be issues surfaced in the data that I would not understand, because the participants were talking about their experiences as Maori women, and I am not Maori. It was very important that the voices of the women came through clearly. One crucial point raised by $\mathrm{M}$ concerned the use of the English language in the research. For example, different audiences are likely to put their own interpretations onto words such as nutrition, shelter, love and health among others. These interpretations may not be those that the participants intended to impart. For this reason, the findings chapter, chapter six, contains many quotes and simple language. I am not sure of how else to address this issue, but I believe it to be a matter worthy of more consideration and reflection.

Phase five involves defining action projects. The researcher and participants decide what action should be taken to address the dilemmas that they have defined and investigated together. This means that the process and the findings of the research can be of direct and immediate benefit to those involved. The participants become the beneficiaries of the research, instead 
of dispossessed subjects, and the researcher becomes an active member of the enterprise, instead of a detached 'observer' (Maquire, 1987).

During this phase, disseminating the research and dealing with issues that arose from this kept Auntie T and myself occupied. Defining action projects was not included as part of this thesis. Indirectly however, the thesis, as a credible research source, may be used to support projects instigated by the local community to meet their health needs. I imagine these initiatives will follow a Maori kaupapa and may utilise Pakeha health professional such as myself to support such initiatives in practical ways.

In this research project, some of the participants took part in most of the process. Some of the kuia helped to define the problem in the researched community. Many of them also assisted by suggesting questions to be asked at interview. They helped identify and solicit participants who fit the inclusion criteria to take part in the interviews. These kuia were part of the trial of the trial questions and gave feedback on which questions and techniques worked in their opinions, and which did not. Others only took part in the interviews and shared their knowledge and ideas. The interviews were semi-structured, so there was enough flexibility to allow participants to follow an idea that had especial interest for them.

\section{Validity, reliability and limitations of qualitative data collected by Participatory Research methods}

This section follows on more specifically from a similar part in the critical social theory section of this chapter. Examples are included here from the research project that this thesis describes.

To assess participatory research projects, it is important that appropriate methods are used to obtain data. The researcher needs to check with the research participants that the information collected from them accurately reflects the meanings that the respondents sought to convey. Confirmation of the findings as accurate greatly enhances the credibility of the research (de Koning \& Martin, 1996). I did this by giving a copy of the interview 
transcripts to each participant. I asked them to read these and check them for accuracy. I explained that we could change anything they were not happy with and asked them to return the transcripts to me with any alterations. One kuia declined to do this, as she said that she trusted I would stick to the truth of what she had said. Other participants asked if we could go through the process together face to face, and this we did. I spoke to others on the phone. Hardly any alterations to the transcripts were requested, and I found the meaning of the women's comments unchanged by any changes.

Words such as 'trustworthiness' and 'credibility' are sometimes used instead of 'validity' and 'reliability' when assessing qualitative research projects, which are critiqued in terms of data collection or the interpretation of data. This is because the threats to validity and the ways that validity is ensured differ when using qualitative and quantitative research methods, and changing the terminology may cause less confusion (de Koning \& Martin, 1996). The authentication of critical research findings in qualitative research is considered crucial. It is determined by the adequate visibility of the process of the research, which is thus auditable (Hill Bailey, 1997). The audit trail of this research project can be found at the end of chapter five.

There are some well-recognised difficulties and limitations of participatory research. For example, such research potentially makes great demands on the researcher as the researcher's role expands to include educator and activist. The transfer of project control from the researcher to the participants may be difficult if the community group of participants have not been involved in the whole research process. Building necessary relationships within the community-based groups that represent the marginalised and powerless before the research commences is also an area that has been fraught with difficulties (Maquire, 1987).

If people require both the will and the resources to participate and act collectively (Elden, as cited in Maquire, 1987, p. 45), then those without a material base may find that increased knowledge is not sufficient for increased power and action (Vio Grossi, as cited in Maquire, 1987, p. 45). 
Put another way, there is no guarantee that the practice of participatory research will result in an increase of power among marginalised people. It may be that change occurs slowly, and in the context of the marginalised research participants, the researcher may not be aware that this is happening.

One of the most underrated limitations on participatory research is time. Establishing the necessary community contacts and networking may take up a great deal of the researcher's time. Possible emancipatory outcomes and the transfer of project control from researcher to participants may be adversely affected by time constraints, and may result in the minimising of the empowering outcomes of participatory research (Maquire, 1987).

\section{Participatory Research and health care}

There are a variety of reasons for the growing popularity of participatory methodologies in health. One explanation is an increasing recognition of the gap between the understandings and interpretations of researchers and health workers, and the reality, concepts and perspectives of different groups in the community. Many factors, such as cultural, historical, socio-economic and political, are difficult to measure using a biomedical interpretation of disease. Even so, they clearly impact on the outcomes of interventions and efforts to improve people's health (de Koning \& Martin, 1996; Te Puni Kokiri, 2000).

The primary implication of participatory research in health care concerns the definition of health and situating of responsibility in maintaining and improving health. The biomedical model of illness and disease is no longer adequate as a basis for researchers working in health care. "Human health is not something independent of human life and human lifestyle" (de Koning \& Martin, 1996, p. 24). Health is as important as education, knowledge and learning as part of life and lifestyle.

The second implication challenges the researcher to discover the value of indigenous health practices and knowledge systems. Many traditional health practices were eroded and destroyed as colonisation occurred. However in the 
last few decades, there has been resurgence in the relevance and practice of indigenous approaches in health care.

The third implication is the need to de-mystify modern knowledge, technology and medicine. Otherwise people are compelled to become dependent patients as opposed to active agents who are responsible for their own health care (de Koning \& Martin, 1996).

These implications when applied to health care mean that people have the right to know about things such as health status and the causes of ill health. They are entitled to information about the nature and type of treatment and resources available to enable them to improve their health. People need to know how to most easily gain access to services they believe are appropriate for their needs (de Koning \& Martin, 1996). Participatory research has a part to play in helping people to acquire new skills and knowledge in a society where health issues have become increasingly more complex. The use of participatory research in health care means that both issues of control over health and the political economy of research in health science can be addressed in theory and in practice. Thus health can be an endeavour that belongs to the people, and is not limited to experts and scientists (de Koning \& Martin).

\section{Conclusion to chapter four}

This chapter has explicated the theoretical and philosophical position of this thesis. Critical social theory is explained, as is its relevance to this research project and to nursing more generally. A discussion about power and empowerment in critical social theory and this project was followed by a section about reflections and reflexivity. Finally, the emergence, method and process of participatory research are described as it relates to this process and to health care. 
The next chapter looks at the research design of the project, along with participant selection, methods of data collection and analysis and ethical considerations. 


\section{Chapter Five Research Design and Process}

\section{Introduction to chapter five}

In this chapter, the aims of this project are revisited, and the concept of rolling consent explained. Participant selection, the focus group method of data gathering and the use of one-to-one interview technique are explored with particular reference to this project. The interview process, including the formation and trial of the interview questions is described along with my reflections on what occurred. Then there is a section on data analysis, followed by a discussion of the ethical issues for this project. The research process utilised in this project is then summarised as part of an audit trail of the process.

\section{Aims of the research:}

This is a participatory exploratory study, which aims, through collaborative and explicitly interactive discussion and selective conversations, to:

1. Provide insights into Maori child health through the voices of female caregivers.

2. Allow the voices of local women to define what is important to them in terms of Maori child health.

3. Contribute new knowledge to the discussion on Maori child health.

\section{Consent}

A 'rolling' consent was used for this project. This enabled both the researcher and the participants to revisit the consent form and add to it, or amend it as the project progressed, if there were other issues that needed consent. Indeed, at the time of the analysis, the participants were contacted again to request consent that someone other than the researcher would be examining the raw data, though any identifying details had already been removed. Some of the participants were happy to give verbal consent, and this was expected with Maori participants who are typically comfortable with verbal exchanges rather than more formal, written communication (Kura Taylor, personal communication, August 1, 2000). 


\section{Participant selection}

In the last two decades, the number of Maori children in two-parent households has continued to decline, with a corresponding increase in the number of one-parent households. In 1991 the estimation was made that $44 \%$ of Maori children lived in one-parent families and the rate is expected to rise; moreover it is predicted that most solo-parents will be mothers (M. Durie, cited in Te Whaiti, McCarthy, A. Durie, 1997).

In light of these findings, and because this is a small project, only female caregivers of Te Atiawa children were included in this study. The inclusion criteria for this project were that the women involved had one or more children with Te Atiawa iwi links. This meant that, as long as the children could whakapapa to Te Atiawa through their maternal or paternal lineage, their mothers, or female caregivers, could still be included in the research, even if their tribal affiliations were not those of Te Atiawa. The women needed to have had at least one child that they had cared for, and preferably two, to enhance the richness of the data.

The issue of lineage, or whakapapa, is an important one in Maori society, as much now as it has been in the past. Knowledge of one's lineage is the way one knows who one's relations are, and of knowing one's history. Knowing whom a person is means knowing who their parents are and where they, their parents, and their parents' parents came from and where their family's tribal lands are located. For Maori, history and lineage are about iwi, hapu and whanau, and not about an individual (Makereti, 1986). For these reasons, the whakapapa links devolved to the children of the women involved in this research.

The kuia in the researched community knew exactly who fitted the criteria for the research because they knew who all the likely participants were. Moreover, these kuia were themselves involved in the research, as participants, support people, resource sources and holders of knowledge in terms of kawa and tikanga. These women used their Maori networks, which 
work through whanau links, to suggest and help select participants for this project. Through their involvement in different groups in the community, they were able to guide me through the correct protocol (kawa) in terms of gaining access to participants. This meant that they established my credibility as a researcher in the community through their community and family links. They also guided me through the necessary Maori consultation process that needed to happen before this project could gain credibility in the community, with the elders, amongst potential participants, and for regional and academic ethical approval.

Women were chosen as participants because they are typically the ones who care for the children of the family (Durie, 98a). This is especially true of the community that was researched, where the percentage of Maori women who are solo parents is at least $43 \%$.

The women who agreed to take part in this project are mothers, grandmothers, aunts and sisters. Their children are all related through $\mathrm{Te}$ Atiawa bloodlines, though the mothers were not necessarily related in this way. However, in terms of social relationships, these women were all related through kohanga reo, kura their children attended, or that they themselves had attended. They shared sports teams, blood relations, workplace environments, and membership of the same runanga such as the Maori Women's Welfare League. The importance of their identity in terms of who they are and where they fit in the whanau of their community are issues that cannot be underestimated. There has been a great deal written and spoken about how Maori identify themselves in their communities and in society generally, and about how the break down in traditional social structure has led to a loss of identify and self esteem for Maori (Durie, 1998b; Makereti, 1938, among others).

The participants in this research encouraged their relations and friends to also talk to me. Indeed, I had to refuse participants who came forward after I had completed the interviews. This was difficult to do, but I have come to discover that there are many more people in the community who have valid 
and interesting points of view about issues of primary health in terms of their children's health, and I simply could not have included them all.

Two participants literally walked in off the street, and when some others who had been anticipated did not show up, one of the kuia who actively supported this project suggested I include these two women. They both agreed and gave consent, largely I believe because of the regard in which they held this kui. She is the grandmother of one of the women.

I knew some of the participants personally, and I asked them if they would consider being involved. I did not speak to the participants about who else was involved, but they talked among themselves about this, and would sometimes come along to an interview with someone else in tow who was also keen to be present.

Some women were nervous or unsure about speaking with a tape recording the conversation. Most of them had not been involved in any taped research before. Before each interview started, I offered a karakia to be included, either by myself or by the participant(s), as preferred. Then we spoke about how the interview would happen, that is, that I had some questions I'd like to ask them.

I hoped that women of all ages would participate, as I felt that the presence of both younger and older women might highlight different points of view between the generations. Unfortunately, I was unable to access as many older women as I would have liked. In the group who agreed to trial the questionnaire for me were four Te Atiawa women who were grandmothers. The information they shared was so exciting, I asked for their consent to include what they had said in the research project. They have all agreed, so by way of Maori processes, I was able to gather information from a wide range of participants. Much of what they said has common themes, though their life experiences are different. 
Some of the participants found that they had Te Atiawa blood links in common with my husband. This knowledge led to some interesting discussions about the family members we both knew and that helped create the informal environment that I had hoped for in the interviews. Other women found that they knew my father, who had held a prominent role in the community for a time, and again, this helped to break down the inevitable barriers of the research interview situation.

I was lucky to be invited into the homes of some women, and always brought with me some kai to share, usually over a hot drink. I also gave a koha to each participant at the end of the interview. Auntie $\mathrm{T}$ had suggested that a petrol voucher would be appropriate, so I gave out $\$ 20.00$ vouchers. At the finish of the taped portion of the interviews, once the tape recorder was switched off, it was not uncommon for a further reminiscence to surface. Sometimes I was able to include these additions on the tape, but other topics were very personal, so I simply recorded field notes about anything we had discussed that was not on the tape.

I trialed the questionnaire before beginning the interviews with the participants, and though some of the questions were rewritten, the focus of the asking remained the same. The questions were changed in an attempt to elicit more information from the participants by making the questions simpler and easier to understand.

Confidentiality was a major issue for me in terms of my credibility as a member of the community and as a researcher. I was aware that the participants would probably discuss the project with others. This they did, as I found while out doing my shopping locally; someone would stop me and ask how the project was going. One of the participants phoned me one weekend with a concern she had with a child in her care. Others would stop to chat in the street or at our children's school. To me, these conversations were affirming messages for me as researcher. 
It was suggested to me that the Maori male point of view could have been included in this research project. I agree that men's points of view in this matter would certainly be interesting, especially in terms of family violence, drug and alcohol abuse, but this was beyond the scope of this project.

\section{The Focus Group Method in qualitative research}

This research project is an exploratory qualitative study. Qualitative inquiry emphasises exploration and discovery, and enables people to speak for themselves (Beanland, Schneider, LoBiondo-Wood \& Haber, 1999). It is critical for the validity and reliability of the data collected that the data collection techniques employed are suited to use with the Maori participants involved in this project. Many Maori researchers participate in local hui in order to share information and collect research data is a way that is most culturally acceptable to the Maori community being researched. Thus hui participants are able to control the whole research process (Broughton \& Koopu, 1996; Broughton \& Lawrence, 1993; Ratima, Ratima, Durie \& Potaka, 1994).

For these reasons, focus group and one-to-one interviews were selected as the appropriate methods to gather data from participants in this research project (Bishop, 1996; Tomlins-Jahnke, 1996; Taylor, 1994). These methods have been demonstrated to work in qualitative research (Holloway \& Wheeler, 1996; Krueger, 1994), and are also well suited to a semi-structured interview format, which is what I used.

Krueger (1994), who has done a lot of work on the focus group method, defines a focus group as being a carefully planned discussion that is designed to acquire perceptions on a defined area of interest in a tolerant, nonthreatening environment. Historically, focus groups have been very popular in private sector research (Krueger). Yelland and Gifford (1995) suggest that this method is especially well suited to explaining the wider social context of behaviours relating to health. Health policy advisers on a national level in New Zealand are familiar with the valuable data such discussions can provide (Ross Smith, personal communication, Oct. 15, 1998). 
The focus group method is becoming more popular with nurse researchers. It uniquely combines qualitative research methods with useful elements of group process theory by providing insight into beliefs and attitudes that underlie behaviour (Dilorio, Hackenberry-Eaton, Maiback \& Rivero, 1994). Focus groups are capable of generating rich data by facilitating detailed narrative information amongst people of similar backgrounds who are discussing issues that affect them all. Dilorio et al. (1994) found that, for the purposes of nursing research, a group composed primarily of friends was more interactive than a group composed of strangers. I felt that the Maori participants in the focus groups I organised might prefer to know others in the group. This proved to be the case, and certainly generated a great deal of conversation. We did not need to hold a series of interviews, as sufficient data came out of one session. The participants also did not feel they needed more time; they all finished what they had to say in the initial interview.

A focus group session typically lasts from one to three hours and includes four to twelve research participants as well as the researcher, who moderates the discussion (Ashbury, 1995; Kingry et al., 1990; Krueger, 1994; White \& Thomson, 1995). Sessions are audiotaped, and sometimes the researcher utilises facilitators to take notes of dynamics that cannot be recorded by a tape recorder (Ashbury, 1995; Krueger, 1994).

Question development is a critical part of focus group research. Sequential open-ended questions are recommended, and there is a generally accepted format for the question development used in focus groups (Kingry, et al., 1990; Krueger, 1994; Nyamathi \& Shuler, 1990). A general introductory question, which is specific enough to trigger short answers, begins the discussion by allowing all present to participate. Progress follows from general to more specific questions and from neutral to sensitive questions. Asbury (1995) recommends that as the researcher develops questions to help focus the discussion, probe questions should be included to further explore any unclear comments, and to help refocus the discussion if necessary. The concluding questions are designed to summarise ideas and bring the group to a conclusion. Kingry et al. and Krueger recommend that the researcher 
record key insights or summary comments as soon as practicable after the session completes.

I found these suggestions useful, and created a list of semi-structured questions, with help from Auntie T and M. Auntie T and I trialed this list of questions at the first focus group, which was not intended to be included in the research project.

I always made notes of each interview as soon as I could after the conclusion of the session. These field notes helped me to remember things that were not spoken while the tape was on, or other things, such as facial expressions that could not be recorded by the tape. I included in my field notes how I felt after each interview, and any thoughts that I thought I should note down immediately.

\section{Advantages and limitations of the Focus Group}

Krueger (1994) identifies several advantages of focus group interviews. Firstly, this method is socially oriented, encourages dynamic group interactions. Secondly, the focus group allows the researcher to probe, and is flexible enough to explore unanticipated issues.

Some limitations of focus group interviews include the following. Focus groups may be difficult for the researcher to control without a facilitator, data may be difficult to analyse, researchers require special moderation skills, groups may be quite different and difficult to assemble, and a suitable environment may be hard to organise (Krueger, 1994). Findings from a focus group cannot be extrapolated to the wider population (Dilorio et al., 1994; Kingry et al., 1990). The limitation I experienced with relevance to this project was the difficulty assembling groups at times.

\section{The interviews}

Ten interviews took place and included nineteen participants in all. One participant moved away and was dropped from the research project, as she 
had moved away and could not be contacted. The first was a trial of the focus group guiding questions, and because of the rich data generated from a group of grandmothers, consent was sought to include this interview in the data collection. The questions in subsequent interviews were similar to those used in the trial interview, and all the participants involved granted consent.

In five interviews, only one participant took part. In three interviews, two participants took part. In one interview, three participants took part, and in one interview, five participants took part, though one was dropped, as she had moved away and could not be contacted.

The total of participants in the project is eighteen, which is more than was projected. There were women keen to offer feedback about the local community health centre after I had finished the data collection phase of the project. However, because of the high number of participants, and to try to keep somewhat to a timetable, reluctantly they were not included.

The venue for five of the interviews was a local Maori health suite run by Te Atiawa women. All of the remainder of the interviews except for one took place in the participants' homes, with one interview taking place at a participant's work place. Participants chose these venues.

At the beginning of eight of the interviews, karakia opened the interviews. Two participants chose not to have karakia. Auntie T gave the karakia in two instances, by the participant in one instance, and by me in the remaining five instances where karakia were used. The karakia given by the Maori women were in Te Reo, while the karakia offered by the researcher were in a mix of Te Reo and English language.

Of the women who participated, twelve were mothers and eight were grandmothers. While all the grandmothers were also mothers, there were two women who were classed as both mothers and grandmothers in terms of their stance in this project. For one woman, her youngest child had only recently left home, she had a baby grandchild, and she was markedly younger than the 
other grandmothers who took part in the project. The other woman had a young child and a young grandchild.

In terms of data analysis, the views of these two women have been included as those of 'mothers' because of the younger ages of these women relative to those of the other 'grandmothers'. Initially, I had thought to simply look at the various responses to the questions asked. However, it seemed to me that there were marked differences in the way the two generations of women approached the whole research process, and that these differences were worthy of comment.

All of the mothers requested to be interviewed in their homes, apart from one who asked me to come to her place of work. The only exception to this was one interview when two of the participants had literally walked in off the street to the interview venue. They were encouraged by a kuia whom they knew to participate in an interview already arranged to take place in the Maori health suite. These two mothers agreed to take part.

The kuia preferred to discuss issues at greater length in a group. None of the kuia requested a one-to-one interview. In the two interviews where there were either two kuia or one kuia and one mother, all participants had expected more women to turn up for the discussion.

Many of the kuia had known each other for years, and also had blood ties. This was evident in the way they spoke together, and in the way the interviews became conversations between the kuia, with only the occasional prompt required from me. Talking with the mothers was quite different, as they tended to require more prompts. They were younger, and thus had not established the same length and depth of links in the community as had the kuia. They talked about their children, while the kuia mainly discussed their grandchildren.

At every interview where there was more than one participant, it became evident that all the participants had social links, and often had blood ties as 
well. I knew of some of the links the women had, but not of some family links. It was interesting to see how much more relaxed the women were around their relatives, however unexpected their presence was at the interview.

The dynamics of the interviews, and the way that those with kuia present tended to flow and unfold despite my presence was something I had been told could happen with Maori kuia who trusted the process. It was clear to me that a more prescriptive approach would have stifled the flow of information that was elicited in our relatively informal chat sessions.

Some participants raised specific health issues during the interviews, and I was able to explore with them relevant issues for them and their children / grandchildren. Some participants wanted to discuss certain issues in more depth than did other women, and there was room for this within the interview framework created for this project.

\section{One-to-one interviews}

Some participants did not want to be part of a focus group, and chose to speak to me individually. Tomlins-Jahnke (1996) describes the technique of semistructured interview as including a participatory, interactive and inclusive nature of approach that is achieved between the researcher and the participant within the data gathering process. This technique has the potential to remedy the "historical legacy of ignoring the voices and ideas of Maori or having non-Maori speak for Maori” (p. 42). Ellison-Loschmann (1997) chose to use individual interviews as well as focus groups in her research into Maori women's experiences of breast-feeding for the following reasons. She felt that focus groups would be very dependent on the interaction of the group participants, and that individual interviews would allow a more in-depth discussion to take place within a less structured time frame. I found her thoughts had relevance to my research project. The women in the focus groups who knew each other generated relaxed and easy conversation, while interviews in which the participants did not know each other tended to result 
in stilted conversation and much shorter answers to the questions proffered. Much more time was needed to draw participants out in groups in which they did not know the other participants.

Women who chose one-to-one interviews chose these for a variety of reasons. One women who worked full time wanted to utilise her lunchtime for the interview. Another felt shy to speak amongst other women, even though she would have known other participants. Conversely, other women were so keen to speak about their concerns that they did not care who was part of their focus group.

I felt it was important that participants could choose whether to be part of a focus group or speak in a one-to-one situation. Some of the planned focus groups became conversations between myself as the researcher and a couple of participants, because no one else had turned up. The different dynamics that arose out of the varying number of participants at each interview was quite fascinating, and worthy of further study. For example, in the interview with the group of kuia, the women spoke to each other as much as to me. The conversation flowed as they compared stories about their children and grandchildren. I did not need to use prompt questions to keep the talk flowing. I also noticed a major difference in how the older women / grandmothers conversed compared to the younger women / mothers. There tended to be only one, two or three mothers in the interviews with the younger women. I generally needed to use prompt questions to elicit information, or to encourage the talking to continue. Even when the women in the interview knew each other, I noticed that the younger women were more reticent than the older women. I believe this may be of major importance when planning dissemination of information to Maori communities.

\section{Trialing the focus group / interview guiding questions}

The interview questions to be used in the focus groups and for the one-to-one interviews were formulated by Auntie T, M and myself. These questions, 
found in Appendix three, were trialed with a group of local Maori women. The information that came out of this focus group was so rich that I sought permission to include this interview as part of the data. All the women involved granted permission.

The trial of the questions was done in a local Maori health suite and was facilitated by Aunty T. I felt quite nervous at the beginning of the session. Having the tape recorder made it all seem serious. As a member of the local community based child health group, I was accustomed to sitting around this same table with some of the same kuia who were present for the interview. In the event, I need not have worried. I found that I was privileged to be part of a research session that, despite occasional reference to the guiding questions that had been assembled, the participants controlled themselves. I considered the dynamics of power between the researcher and the participants, and my role as researcher. It seemed to me that my role evolved as more of an observer who referred the group to the next relevant guiding question when the dialogue wound down, or when the discussion seemed to be going off the track I had hoped to pursue. The women ran the session themselves. They laughed and joked as they compared the experiences they had had with their children and grandchildren.

Five participants were assembled, Auntie $\mathrm{T}$ offered a karakia, and I introduced the session. I had written up each guiding question on paper, which I attached to a frame at one end of the table. One of the kuia present had previously suggested to me that this might be a helpful way to keep us all focused. A lively discussion ensued, and all the participants spoke in turn and occasionally, at the same time. At the end of the session, Auntie T listed the themes that she felt had emerged. I also asked about mental health and dental health after the tape was switched off because these topics had not been mentioned. No more information was added to the taped data from this interview.

At the conclusion of the session, we closed with a karakia from Auntie T. The women all went about their business as I sat thinking about what had 
happened. I found that this focus group interview with the kuia was quite different to my expectations. These expectations had been assumed from the academic constructs of research that I had studied and discussed with other nurses enrolled in university Masters programmes.

After the trial of the interview questions, Aunty T, M and I decided that most of the questions were fine as they were. Some we amalgamated together, as that was the way the participants in the trial group had answered them. I had tacked on a couple of 'why' questions, which we felt did not need to be asked, as the participants had included this information when answering the initial question. I retained these 'whys' as prompts for further interviews. It was clear that there needed to be a question about how the participants felt about the access that they had to health services for their children or grandchildren, so this was added. The order of two questions was swapped, and the resulting question list was used throughout the rest of the interviews, but only as guiding questions.

Each participant was interviewed once. The participants chose the venue for the interviews. Auntie T was able to offer some space that was private but local, known to the participants and easy to access. The interviews were held in the daytime, as that suited the participants best. Ethical approval had been obtained from the Taranaki Ethics Committee and from the Victoria University of Wellington Human Ethics Committee prior to commencement of the research. Consent forms were offered to each participant and I requested that they sign them before the interview commenced. One participant did not want to sign, but gave her verbal consent. She stated that she trusted that I would safeguard any information she shared with me.

I made sure that the participants understood that I planned to audiotape the interviews, and that I would then transcribe the tapes myself, and give a copy of the transcripts back to the participants. I asked that the participants alert me to any errors in the transcripts, or for any changes that they wanted, which I then actioned. I transcribed the tapes myself for two reasons. Primarily, I felt that I wanted to be immersed in the interviews while I typed out the 
spoken words. Doing this took me back to each interview, and jogged my memory about details that I had perhaps not noted at the time, and was then able to record with my field notes. It is important to note that these notes did not form part of the transcriptions, rather they helped me be aware of underlying nuances as the women spoke. I found transcribing the tapes an incredibly rewarding experience, though time consuming. The other reason I did my own transcribing was for reasons of confidentiality. I felt privileged to hear what the women said, and understood that some of them might not have been comfortable with a stranger being privy to their thoughts.

Once the interviews were finished, the task of transcribing the data began. I had chosen to do this myself for several reasons. I hoped to absorb some of the richness from the conversations. I anticipated remembering the atmosphere and the environment in each interview, thus bringing a greater awareness to the analysis of the conversations I had had with the women. As I listened, I laughed again, and cried again and ached through some of the stories that I was privileged enough to share. I found I really enjoyed transcribing the tapes, once I had found a transcribing machine. The fact that I couldn't afford to have anyone else transcribe for me was not an issue, because I had planned to do it myself all along, and I enjoyed it so much.

Next came the analysis of the data. Auntie T, M and I examined the raw data and discussed what the women had talked about. We looked at the commonalities and differences between the conversations, which had been based on the guiding questions. For this, we needed to gain additional consent, as $\mathrm{M}$ was now going to see the raw, though unidentifiable data. This is an example of a rolling consent.

\section{Data analysis}

This research is an exploratory study into what female caregivers of $\mathrm{Te}$ Atiawa children identify as issues around primary health care services. I recognise that my worldview is culturally different from those views of the 
research participants. This means that great care must be taken with analysis to ensure the voices of the participants, rather than the researcher, are heard.

There is a wealth of literature that discusses the traditional unequal power relationships between the researcher, who typically controlled the research process, and the community in which the research was being undertaken (Smith, 1992; Stokes, 1985; Teariki \& Spoonley, 1992; Te Awekotuku, 1991). It has been suggested that, because of this, Maori are now often reluctant to participate in any research (Smith, 1992; Stokes, 1985). In order to ensure the veracity of the data collected and the overall integrity of the research project, and to meet the aims of the project, I believe that the voices of the participants need to be heard as clearly as possible.

Originally, I planned to include the full transcripts in the thesis, but after transcribing them I found that many of the participants said much the same things in response to the interview questions. Therefore, it seems that a simple analysis along with a plentiful mix of participants' quotes will enable the participants' voice to be heard equally as well as if the entire transcripts had been included.

The data analysis that has been employed is one of thematic analysis. Common themes that emerged in response to questions asked at interviews have been identified, compared and discussed in relation to the aims of this research project. A synthesis and summary of all of the data presented is included in chapters six and seven, and is interpreted in relation to the literature.

\section{Ethical issues}

I have examined ethical issues from overlapping perspectives. Firstly, there are valid ethical concerns generic to all research participants. Secondly, I am a Pakeha engaged in research with Maori participants. Research with Maori holds special ethical concerns for the participants and the local Maori community (Health Research Council [HRC], 1998). Lastly, there are some 
ethical concerns specific to focus group methodology that also deserve consideration.

Ethical responsibilities towards participants taking part in this research are based on the New Zealand Health Research Council's Guidelines for Researchers on Health Research Involving Maori (1998) and the Code of Health and Disability Services Consumers' Rights (1996). The Taranaki Ethics Committee and the Victoria University of Wellington Human Ethics Committee both approved this project.

A researcher has a responsibility to safeguard certain rights of research participants with regard to "the rights of all persons to life, esteem, selfdetermination, privacy and protection for all forms of injury and manipulation" (New Zealand Nurses Organisation [NZNO], 1996, p. 2). The New Zealand Nurses Organisation (NZNO) emphasises the importance of the adequate competency of the researcher, which in the case of this research is supported by the presence of academic research supervisors, one of whom is Maori.

The NZNO (1996) have this to say about informed consent, a major issue in any research; valid consent depends on a full understanding of the purpose of the research, including the nature and extent of involvement expected of the participants. Informed consent must also be free of coercion and deception, and actual and potential risks and benefits of the research must be explained to participants, as must be their right to refuse or withdraw participation at any time without prejudice to their care or welfare. Every participant has the right and must have the opportunity to contact the researcher for further discussion and clarification of any aspect of the research; participants also have rights with regard to any published material arising from the research. Written and oral consent were sought from all the research participants; oral consent being consistent with the expectations for Maori participants (Smith, 1999). 
Confidentiality, privacy and anonymity of participants and data are other concerns of both researchers and the ethical review bodies (HRC, 1996; NZNO, 1996). The information sheet given to all the participants contained statements assuring confidentiality and privacy of any information shared within the focus groups and one to one interviews. It was made clear that issues that arose during the course of the research would have to be agreed by both the participant and myself as the researcher. A statement was made clearly explaining that anyone could withdraw from the project at any time, without needing to explain why and without penalty.

The Maori Health Committee (MHC) of the HRC of New Zealand has produced guidelines (HRC, 1998) for researchers undertaking research involving Maori participants or on issues relevant to Maori health. These were formulated in order to support "greater Maori participation at all levels... and the development of culturally appropriate practices and procedures as integral requirements in the...provision of health research" ( $p$. 3). Researchers can glean from these guidelines when consultation is necessary and the processes involved in consulting with Maori. The guidelines explicate the HRC's responsibility, via government directives, to improving Maori health status and this intention is reinforced by a stated recognition of the Treaty of Waitangi, endorsing the status of tangata whenua. The HRC is encouraging long term research partnerships between non-Maori researchers and Maori groups and communities because the perceived need for this research is urgent, and because of the belief that there is a shortage of a Maori health research workforce (HRC, 1998). The HRC guidelines make certain assumptions, of which the researcher should be aware before commencing any research. The researcher must be clear about the purpose of the proposed research, and have a clear commitment to the Treaty of Waitangi and the concept of cultural safety. The researcher should have a background from which high quality research can be anticipated, and they must know the correct process of obtaining all the necessary consents. The collaborative nature of any research between the Maori community and the researcher must be clearly understood and undertaken (HRC). The same guidelines go on to explain in detail what the authors mean by 'consultation', 
why researchers must consult, when consultation should take place and who should be consulted.

The process of researching issues concerning Maori in New Zealand is different from research involving other cultures, due to Maori tangata whenua status under the principle of partnership described in the Treaty of Waitangi. The issue of whom may undertake research with Maori has been debated for some years. Some feel that it is best for only Maori to research their own people (Bishop, 1996; Irwin, 1994; Stokes, 1985). Others recognise that the dearth of information in priority areas, such as Maori child health, cannot wait until there are sufficient Maori researchers available to seek the knowledge so urgently required (Te Kete Hauora, 1995).

Because of this debate amongst some Maori, the risks and benefits of any proposed research must be presented openly and honestly to potential participants, who may then make an informed decision to take part or not, or to withdraw at any time.

I am aware that any information gained from research with tangata whenua belongs to the participants and the local iwi. These intellectual property rights will be respected and negotiation will take place before any publication of the findings commences.

A major ethical issue specific to group research methods is that of overdisclosure by the participants (Smith, 1995). This may lead to privacy concerns as the researcher cannot promise or ensure absolute confidentiality. To address this issue, Smith suggests that participants be asked not to share what others in the group say with people outside the group. I discussed this with the participants at all the interviews at which more than one person was present. I felt that, as long as the women were aware of my concerns regarding confidentiality, what they did was then up to them. 


\section{Summary of the research process utilised in this project}

The questionnaire was trialed and then discussed with my Maori research partner, Auntie T and the Maori academic support person M. We agreed on changes needed and these changes were made. Next, the participant selection took place and the participants chose a preferred method, venue, time for the interview. The interviews commenced by either focus group or one-to-one method. Karakia opened and closed each encounter if desired by the participants. Koha was distributed at the end of each interview. The interviews were conducted over four weeks. I made field notes and journal entries as soon as possible after each interview took place. I then typed up transcripts of the interviews and returned a copy to each participant requesting them to confirm veracity. Data analysis commenced after this.

\section{Conclusion to chapter five}

In this chapter, each step of the research design and process have been defined and explicated. A summary of the entire process has also been included.

The next chapter identifies and discusses the key ideas in the findings from the research interviews. 


\section{Chapter Six Findings}

\section{Introduction to chapter six}

This chapter relates to the data collected using an interactive interview model. As is usual in Maori interaction, participants' affirming body language such as nodding, smiling and other physical movement were indications of a similar point of view to that being stated (K. Taylor, personal communication, February 7, 2002).

To enable the women's voices to be part of the discussion, direct quotes from the transcripts are included. The transcript material has been loosely edited. For convenience fillers such as 'um' and 'yeah', repeated phrases, pauses and false starts have been omitted in the thesis text. Grammatical errors have been left in because I felt that they helped retain the qualities of the women's spoken language. Quotes are intended to communicate the unique voice and character of each participant. The participants' voices in the text are numbered for reasons of confidentiality and anonymity.

The data collection questions are listed. Responses to the questions are organised and then grouped according to key ideas that emerged from the data. Each group of responses is then analysed and two major themes are identified and explored in chapter seven.

Key ideas, from which two main themes were eventually identified, appeared from the research data in response to the following questions.

1. What is important to you in terms of your mokopuna / children's health?

2. What do you do when your children are sick?

3. Who is most helpful when your children are sick?

4. How do you feel about the access that you have to health services?

5. What else would be helpful when your mokopuna / children are sick, and what else would you like to have here in (the local community)? 


\section{Question One}

"What is important to you in terms of your mokopuna /children's health?"

Several of the participants asked me to tell them what I meant by 'health', but I explained that I really wanted to know what THEY thought. Some of the women spoke exclusively of physical health problems or of sickness when defining what health means to them:

P\#1: "Well, mine are in good health, thank goodness, they don't have any major problems healthwise, apart from the usual scrapes and falls and so on." P\#16: "I haven't got any special needs children. So, healthy to me is them just being normal; and when they get a runny nose and start coughing, they're sick.... For my whanau, health is if they're eating all right, then they're all right."

P\#18: "I think the main thing is being able... is how fast I'm able to get to medical help if need by, especially now moving back to (the researched community), and after a certain time there's nothing here in...."

Others spoke about health in terms of environment, lifestyle, prevention and spirituality. For instance:

P\#2: "I guess out of my fifteen mokopuna the major thing that we have...is that one...has had treatment for talipes of both feet.... Apart from that, they've all had measles, all had mumps, haven't had whooping cough, haven't had scarlet fever, all those things that are covered by immunisations. The benefit that they had was that they were isolated. They lived in the country and they were fed from things off the land, as it were. Fresh vegetables, they had fresh milk and that."

P \#3: “....all of them had their immunisations. They've had measles and just the normal things. Also one of the mokos had a cleft palate, which they have operated on and his speech is a lot better. He had to go to the speech therapist, but he's coming out very good. And my great grand daughter, well she" very good, she" quite energetic. No problems."'”

P \#4: "They can move out of the house quite easily; the TV is not the centre of attraction, it's getting outside to make sure their chickens have got their kai.... and they eat well, considering they're city kids. Absolutely chocked 
with pollution...car fumes, burial grounds all around them.... The parents talk to each other about how to cope with school lunches, kindergarten lunches, dad's lunch, their kai at night, they're talking nutritional food. Greens, not much meat, meat is very expensive. If it's fish, it's fish heads, that's the cheapest they can get. And if it's going to be meat, it's mostly mince.... We encourage a lot of good healthy lifestyle living as well. Come to visit us, we go for walks, we take them to the river, teach them to fish, and all the planting...we have flowers galore and it's picking the flowers to go to the urupa so that they know that they take this pretty flower to share with someone else....I think they are fortunate that the health service is there for them in the city. If anything that's a problem, it's the cost. They have to balance the cost of it. Dad's one for walking, so no trouble to go for walks with grandad and I think those are the things that really help the children. It's sharing that understanding of the environment, because they love it I think." P \#11: "Health...being spiritually aware of health within your own body, because your body's a temple.... a lot of our people are frightened of that system; of the Pakeha system.... It's like, for example, my Mum. She knew that if she was going to go to hospital, that she wouldn't be leaving...."

P \#5: “...income, cos you've got to have money to take them to the doctors, and I feel that being unemployed as I am, me and my husband, we don't get those benefits...like the higher paid people are getting... Education...he knows karakia, he knows take his shoes off and respect and love.... I can't speak the Reo myself, which is really sad, but I've given it to my children....Both my children ended up at bilingual [units at school], and I find their education is really, really strong now cos of what my choice in putting them in bilingual."

P\#5: " $\mathrm{X}$ is asthmatic and we put him in swimming three years ago and that's helped him, and this year we put him in league, and he hasn't had any asthma since he's been exercising." 
P\#5: "Their lunches; my husband refuses to put rubbish in their lunches....I feel that they need their parents home after school, and my husband's always home for them after school....if I had more money I'd rather give my children more...education."

P \#8: “...my oldest son, he was very sick when he was a baby.... He was diagnosed with epilepsy.... not just him being sick too, it affected his education, his schooling, being judged by the teachers, and they had no idea. It wasn't until they actually seen him have a seizure that it brought them down to earth. He was always in trouble; they thought that he was daydreaming and stuff like that; he was actually having fits.... and me not being there to cope... and them not knowing put a bit of a stigma on us there for awhile...."

P \#10: “...if your child's...not into some sport, well, there's something wrong with them. Now we've taken him to karate,...league, football, soccer, everything; he's not interested."

P \#12: "Well, I think the most important, is to make sure that they're healthy and getting the right nutritions and that; clean, dressed properly. Yeah. Make sure they're going to school everyday and doing their learning;... make sure they get a better education for themselves as they grow.... So when they leave school they've got a job that can secure them once they leave school, and make sure it's there for doing for themselves....they've got to really focus on what they really want and need for their future."

P \#13: “...immunisation, ears.... I still think they should go back to the grass roots and bring back in a district nurse, because I can remember when I had my first baby, and it was nurse X.....She came and I was bawling my eyes out, cos we lived in a place with a wooden coal stove. My washing machine had broken down and she stayed all day with me. X was my baby, it must have been just this one day he was playing up and I had all these nappies to wash, and my washing machine had broken and the fire wouldn't start. Look, she just stayed there all day, lit the fire.... She chucked all the nappies in the bathtub, she said 'This is how they used to wash.' Took her stockings and her shoes, hitched her skirt up, jumped in the bathtub and used her feet. And I thought that was wonderful. She stayed there; she cooked me a lovely meal,... and then $\mathrm{X}$ went to sleep and she said to me, 'Now, you go and have 
a sleep.' She said, 'It's all right, I'll be sitting here reading a book when you wake up.' And when I woke up she was still there, had the fire going, you know. I think the young mums, if they had that sort of awhiness now, I think they'll be fine; I reckon they'll get on the right track...."

P \#17: “...to me, it's their education; I think that's the most important thing....I also think it's important that the parents get involved....I think about the drug and alcohol; that's a big one for me, because my kids have been brought up in a dysfunctional life, and I think that it's really, really important that,...I think it's important that the kids should be educated in school....because a lot of our kids are coming from dysfunctional families. Even though there may not be any drug or alcohol problems, there's still behaviour problems, which is not healthy for the kids."

P \#17: “...the other thing that I think is really important too is obesity....the only reason that we can't eat...properly...it's because of the price of things, and so we buy the cheapest, but it's unhealthy. But then we've got no choice, because we've got a big family. Extended whanau for that matter.... and we all put money in, but it's because of all our kids...."

P \#18: “...especially mentally, with such a big family it's really important, you know, for me, for my children that I'm all right, so I can be all right for them; that's one of my big concerns."

A few women included tikanga when they talked about health. As in:

P \#11: "For myself, I'd like to go back to the old ways. Missing out all the Pakeha system, and relying on our own sources....In the old days, you had people, Maori women that were trained in the tikanga of health.... using all Maori remedies, like plants growing in your back yard, and all that. It was just plentiful in those days; no injections, no diseases, none of that crap.... and a karakia goes a mile."

From question one, key ideas emerged related to a concept of health, childhood illnesses, descriptions of environment, physical health conditions and everyday practical considerations. Participants' concept of health was stated within areas of mental, spiritual, physical, nutritional and a safe environment. Most spoke broadly about health as "everything, just being 
normal, good health". Some mentioned mental health and commented upon love, the effects of parental / caregiver stress upon mokopuna or children. Most commented on a spiritual awareness of health. A few spoke of making space for Maori things in a Pakeha environment, and recognised that Maori are frightened of the Pakeha health system.

Concerning physical health, most stated physical health, physical outdoor activity, being clean, dressed properly for warmth, hearing, immunisation and dental health as important aspects. Many commented about nutrition, and a few mentioned breast-feeding. Childhood illnesses of concern were: asthma, chest infections, convulsions, ear problems, eczema, psoriasis, rheumatic fever, whooping cough, rotten teeth and snoring.

Most comments about the effects of the environment included a good health[y] living lifestyle, and the importance of Maori language (Te Reo) and bilingual schooling. There were some comments about shelter and a few spoke of a smoke free environment. About safety, most spoke of parents being there after school and parental income. A few commented on voluntary work they were involved in.

\section{Question Two}

"What do you do when your children are sick?"

The data suggests that all participants placed importance upon being alert to the signs of mokopuna / children's health deterioration, using their common sense, applying both Maori and Pakeha remedies, and visiting the doctor early rather than later. For example:

P\#1: "Cos basically, they're totally different to what they're usually like, aren't they, if they're sick."

P\#1: "Try and assess it yourself, just what you think it is.... Or you ask Mum, cos that's happening to me now. Before they'll make the next step, if there is to be one, they will ask somebody else, because they want to know that they are doing the right thing....Yeah, cos if you're a new mum...it's real hard to be able to assess those things straight off, and you're sort of wanting 
guidance...before you take them to the doctor....they're not as easily accessible as they used to be."

P\#2: “...it's just coping with it."

P\#3: “Just observing, if they've got a temperature; it's just really plain common sense, really....I find some doctors don't check young children out properly, and that's very upsetting to the mothers; a lot of them are the young mothers."

P\#1: “... and I think it's hard too when they're a lot younger, cos a lot of them can't exactly tell you how they're feeling and you've got to try and figure it out yourself."

P\#3: “...and usually, when they ARE sick, they usually want their mums. You can usually tell by their eyes if they're not well."

P\#4: “...because I was away from home, I didn’t have my family, or Mum and Dad around, cos none of my husband's family's nearby. My biggest problem was I took it on too long. By the time I got to the doctors, I was getting yelled at, so I learnt that I had to go as soon as the baby felt unwell....But the boys, ...I thought, oh, they'll get over it, you know, just another day in bed, come right, and that's when I was getting growled at by the doctor. And so, having the mokos with me, it's quite the opposite now. They got a temperature, take em to the doctor!" 
P\#5: "Keep them warm for a few days. Mainly keep them warm, and heaps of fluid, lemon drinks and a bit of honey I add with it. Puha juice, some puha juice, and I was making up my beetroot juice too for them to bring his phlegm up [for an asthmatic child]....the kumarahau I got from my own marae, and that's helped him a great deal....I've got him a waterbed, because around in the room it's quite damp, and no woollen blankets or carpet in his room."

P\#7: "When I take him to the doctor I ask him to check him right through, you know, his ears, his chest and everything. Cos usually he just looks and says 'oh yeah, runny nose' and asks if he's coughing, then he just puts it down to something. But I sit there and make him do everything, just in case he hasn't caught up with something, you know; he might haves something more than just a little cough and that. I did a couple of weeks ago, made him do his chest and that, his breathing and that, and we found out that he had a bad chest infection that could have led to asthma as well."

P\#9: “...depends what they’ve got; whether it's just a snotty nose, or whether it's an accident, but I always like to start off with lemonade. If they've got a headache or something, half a disprin, in those days it was half a disprin and just keep them warm. But if it's serious, take them to the doctor....I do the same for my mokos too."

P\#10: "Well, you have to have common sense, eh."

P\#11: “...they know themselves if they're really sick and they need to go[to the doctor]; they can sense it within them. Basically, it's just bed for the day, and they know no TV, no nothing. If you're sick, you're sick.

P\#12: "I take them to the doctors; I have to make an appointment, though I do tend to take them to the doctors."

P\#14: “Usually I ring up my Mum, 'This kid's sick, what do I do here?' But if she's not there I usually take him to the doctor....If not Mum or my grandmother,...it's straight to the doctor."

P\#13: "Well, my husband, the rest of my kids, they like to know when the mokopuna is sick, and also my Mum, but we sort of keep Mum for the last resort....[she] is very much up front, but not physically, eh, that's what I mean." 
From question two, three key ideas surfaced: accessing medical help, treating herself and involving whanau.

Almost all of the participants sought medical help. Most got the child straight to a doctor, while one took the child to the emergency department in her car. Some took children to hospital if they had an accident. A few commented that they needed to be able to access a health professional other than a doctor. One remarked that some doctors don't check children properly.

When treating the child herself, most participants talked about how they knew when a child was sick, and about what they did without any other intervention. For example, the use of natural substances and traditional Maori remedies was favoured by many. They used beetroot juice, garlic, heated oil, kawakawa, kumarahau, lemon and honey drinks, puha and Vicks. Many spoke of using common sense in coping with childhood illness, putting children to bed, the importance of having sick children's mothers close, and the need for reassurance for the caregivers. A few commented about the different picture of how families care for children now, and how it was harder with younger children.

All the women identified the importance of whanau involvement when their children were sick. Most of them contacted their mothers or grandmothers. One commented about the difficulty she had when her children were ill as she lacked family support.

\section{Question Three}

"Who is most helpful when your children are sick?"

Reliance upon Maori kinship ties of whanau or extended family support is particularly important to the participants. A few health professionals were also identified as useful. To illustrate:

P\#4: "If you ask my children who [is most helpful when the children are sick], they would say it's a grandparent. Because that grandparent was there for me, which was our dad. He was there for the kids, and he'd go from this 
house to the next house. He'd do the circuit before he'd get home." P\#1: “... for me, it's amongst the family first. I did it, I asked my mum first; I'd go to her for help. But then, my daughter in law's the same, asking me as well. Probably because they can talk so easily to you, and you've obviously been through it with them...."

P\#2: "I think, with our dad, that was his role, to keep in touch with the family, and so he would go from house to....all the children, he would do the rounds. And if he stayed longer at one house,...my brother would be ringing and saying, 'When's Dad coming round?' ...it not only related to looking after the children, although a big part of it was. But it was just having an older person there, I think, just company or to ask.

P\#3: “... I found (my mother in law) and my mother a source of...very close as far as the children...."

P\#2: “ Well, you had the public health, you had all...there was a community service in those days, and they've been stopped....I agree, the whole change in the public health system has meant a denial of services, important services to mothers."

P\#5: "The karakia and myself, my husband. As long as we're there for one another and keep one another strong. [A local GP]'s been really good. We've been under Dr. X since my children were born and he knows their medical history."

P\#6: "I just mainly go to my Mu, get advice from my Mum or [baby's] greatgrandma."

P\#7: "I ask Mum for advice and that, what they think...I think that one of those nurses down there at [the community clinic] is better than the doctor."

P\#8: “...I've always told my Dad, but he's not here anymore, so...it was always him that was there for me and my children. My Mum is too, but my Dad was the one, because he knows what it was like when we were kids....He was the one that always gave the doctors a raak up....he would go and see them himself, and I'd feel sorry for them, cos they'd have no choice. They had to sit there, because...we're entitled to that....I don't have that anymore, but I make sure that I carry on that...because otherwise it just slips right through your fingers. It's just so easy for them; they don't even have to look 
at your kid, they can just write a prescription and make an assumption and that's it."

P\#9: "Just me."

P\#10: “...when my children were younger, I took them all along to the Plunket...to have someone you can trust. And when my children were young, I had my mother. I was lucky I had Mum."

P\#11: “The Tamariki Ora Nurse from Nga Puna Ora o Te Atiawa Trust. [This nurse has since left.] She's really helpful. But in another sense, I'm really helpful to her, cos she gives me a ring every now and then to say, 'Look, what would you do with this?' whereas massaging concerned, cos I'm right into mirimiri and using the old methods for doing it. I like them [Nga Puna Ora Service] more to Plunket because they're on the same line as, if your child's asleep, leave them asleep....they just go with the flow. X feels comfortable with them."

P\#11: “...our own doctor's really helpful. She explains things to the kids and she goes through with them and does everything. And they feel safe and aware that it's just not a five minute job....they're better by far [than the local community clinic]. You're a person to them, you're not a number or a pay ticket."

P\#12: "When I do take them to the doctors, the doctor tells me what's happened and what's needed with the kids....the public health nurse [is also helpful]."

P\#15: "...my sister would take him to the hospital or something...she's the only one I'1l trust....She won't gossip and stuff like that. The stress of having to find $\$ 5.00$ for gas and stuff. I know she's reliable there; the kids come first."

P\#15: “...I used to ring Plunket....cos I'm not fully informed like doctors, eh. That's why I ring them....Even after I've been to the doctor's, I ring Plunket.....Yeah, they're excellent; I like them....they've been very helpful and they've told me things that I've actually done that a doctor hasn't even said."

P\#15: “...wairua, that's the only thing I really believe in, eh.

P\#16: "...the nurse is nice down there" [at the local community clinic]. 
P\#16: “Oh, no, I don't ask anybody [for help]....Have you heard of Louise Hay?....Well, I believe in that."

P\#17: "My husband's really good...then I have the church people down at the XX church who are really excellent....I feel really comfortable with my own doctor and always greeted really good at [this GP surgery]."

P\#18: “... [a particular GP and her partner]; they'll sit down and you know,...they'll explain things to you. She doesn't muck around, you know. I really trust her.....I use the chemist a bit too."

P\#1: "We're all saying the same thing, aren't we? Your whanau is really the most helpful."

There were some people who were identified by the participants as being unhelpful when their children were sick. Some women gave examples of a lack of understanding by medical personnel, while others spoke of a lack of awareness of cultural issues. A few women talked about not feeling comfortable with people they didn't know. Different ways of doing and saying were interpreted by a few women as being unhelpful.

P\#4: "So the person you wouldn't want around you when your children are not well would be the one that's just come along to ask that inevitable question, 'Where are your kids? Why aren't they at school?'...They don't understand what you're going through, and yet they know...that the problem is there; there's a health epidemic going on. Children with lice in their hair." P\#4: “And, you know, we go to the creche and we've got our shoes on, we go in the building and walk all over their nice carpet, then next minute you see somebody put the baby on the floor crawling around, not worrying about what we've been walking in and walked through the building..."

P\#7: “...some looks, eh, sometimes, you know, you can read from their looks what they're thinking."

P\#10: "I've got no faith in the doctor over here (refers to the doctor at the local community clinic). I have no faith in the doctor because it costs nothing....That's why I keep going back, even for myself....I took X (one of her moko) to see him. He just look at him, 'Rah, rah, rah, rah, rah.' He was sitting down there. I said, 'Aren't you going to examine him?' 'No.' and he gave me a rotten prescription....We got to get...together and have a meeting 
and get him out. It's been going on a long time, moaning about him....No, I've got no faith in him at all."

P\#10: “But I know for my daughters, they didn't want Plunket, because the Plunket nurses they met, they didn't like."

P\#11: "Not Plunket; strip them...you know, I see no need for it. Why strip a child to nothing for no reason? Just to see if there's any bruising or any of that crap on them...."

P\#11: "Now, if you go to [the local community clinic], you're in there and out there; you've learnt nothing; you know nothing."

P \#13: “...Plunket nurses are fine, but I feel that they haven't got that aroha that our district nurse had;... and you could call on the district nurse for any age kids...."

P \#13: "I'll tell you one thing that gets my goat now, because when I was having children, the doctors would say that the best thing in the world for them is Mum's milk. Nothing better than breast milk. Now I've got a daughter and I've got a daughter in law and the doctor has told both of them to stop breastfeeding their babies... one was because of X's teeth; the breast milk ruins his teeth.... and two, because XX is so wheezy in the chest, it's because of breast milk.....and I said, 'I don't believe it! I was never told that!' I said, 'I was told, cow's milk, anything with dairy products, we weren't to give them when they were wheezy, because that could set them off.' ...Look, I fed all my kids... until they were six.... So I went to see the doctor concerned, it was (at the local community clinic) and he said, 'Oh no, breast milk, no, it's only good for certain time, when the baby little. After that', he said, 'no, no.' I said, 'No, sorry, I'll have to disagree with you there doctor.' I said, 'I'm sorry, I don't believe that.' And so I said to my daughter, 'No, you keep feeding baby.' Cos she was going to put him off. I said, 'No, you leave him on the breast. He's really enjoying it there."”

P\#15: "Well, I don't like that doctor down here at (the local community clinic). Oh, he's terrible!"

P\#16: "No, he's [the GP] not helpful.... I'm disgusted with that (emergency clinic in New Plymouth). You got to have money before you go in there.....When my X and XX were little, they were always sick, and I always used to take them to the doctors in (another NZ town), and it was terrible. I'd 
have; they're 11 months apart, so I'd have 2 babies and go in and the doctor, every doctor I went to; I went through heaps of doctors; they would just make us sit and wait, and wait, and wait. It used to make me angry, man, the kids are crying and sick...."

P\#17: “...I really, really hate taking my kids to A and E....not for the fact that they're sick, but I think those doctors up there are utterly rude. I'm not racist or anything, but it's the Indian doctors that put me right off."

P\#18: “...I used to go to (the local community clinic), but the doctor they've got here....you can hardly understand him, and you're lucky to get a couple of minutes with him....We need quality doctors. I feel that, maybe because...it's a Maori centre, they're giving us...I don't want to be mean to the doctor, but.... and the time you're given in there, it needs to be quality time."

From question three, the key ideas identified were family / whanau, health professionals and spiritual support.

Most of the women found family members to be most helpful. Many accessed health advice through general practitioners or other health professionals in the community, including telephone advice services. A few mentioned spiritual aspects of health, for example, wairua, karakia and church contacts. The women are quite clear about who they found to be not helpful. They were unlikely to access health professionals they perceived to be unhelpful when their children were ill.

\section{Question Four}

"How do you feel about the access that you have to health services?"

Some of the quotes include reference to more than one access issue, and they have been left that way, as this is the way the women spoke of them. I have used subheadings in this section to clarify each access issue brought up by the participants. Some of the participants stated that the reason they were involved in the research was because they recognised the opportunity to state the case of what is needed in the community where the research took place. 
The quotes have been divided into subheadings under the following topics: cost, lack of availability of preferred choice, lack of reliable transport and issues of cultural safety.

\section{Cost}

P\#4: “...the chemists are expensive."

P\#1: "Yeah, that the annoying thing; we don't have someone here....[the higher cost is] another reason that would stop you from going to a doctor in the weekend."

P\#8: "I find...I know that you don't pay for your child when you go to the doctors, but, oh, there's lots of things, lots of things that interfere with...money, prescriptions. I, at the moment, have a $\$ 600.00$ medical bill..."

P\#11: “It's there if you use it. Right, you've got to be aware that it's there if you use it, and I very seldomly use it. One, it's costly; it can be costly. Two, why take them if I know what's their problem?..."

P\#16: "Yeah, I wish the government would subsidise (natural remedies)."

P\#18: “...I know a lot of cases where the mother'll go to the doctor, but they won't fill the prescription. Cos, I mean, if it's a choice of a prescription or food, the prescription will always miss out. Cos she knows what's wrong with her... and she can go home and do something. Just takes that worry that it's not something major, I suppose.... I know that's been happening a lot. They'll put the prescription in, but they won't go and pick it up, cos they haven't got the money. Or they need that antibiotics there and then, but they'll have to wait til payday to go and get it."

\section{Lack of availability of preferred choice}

P\#14: "Once at my local doctors, and the lady in the office said something, and I said, 'Look here, I'm not paying to see you, I want to see a doctor. I don't want the dogsbody telling me what's wrong.' Cheeky..."

P\#13: "Yes, when Dr. X was still...well, he had one person over there who would try and diagnose what's wrong with you, and you sort of sit there thinking, 'Shall I stay here or shall I go home, or what shall I do?' and I 
thought, 'No, I'll stay here and see what the doctor has to say.' One time she said something totally different to what this person was telling me."

P\#14: “Cos doctors don't make house calls anymore."

\section{Lack of reliable transport}

P\#6: “Just money and transport really. Cos I don't drive and we don't have a car; just trying to find the money to get someone else to take us in or get on buses, or even the bus that goes into the hospital, but that's like early in the morning, and last one goes....the times are no good, and it's way too long for the kids to be around a strange place and that."

P\#7: "Usually Mum helps put in if we've got no money and that....Going to the doctors during the day, I just have to depend on the weather. If it's a nice sunny day I have to get him down to the doctor, but if it's raining, I just have to try and depend on Mum, you know."

P\#12: “In the weekend...it's difficult; I've got no vehicle...have to walk round to my cousin's place to use the phone....the only problem is getting there [doctors], especially like rainy days. Haven't got no phone. It's hard for me to get them there if they're really sick; things like that. Advice is really important, especially for your kids and I think I would want that too....yes, I always find it really hard to come up with money to pay for my kids' medicine..."

P\#17: "Well, sometimes I find it difficult, because when the kids are sick, then we're broke....it is hard to get the kids into town.....and more than likely, my kids get sick after everything's closed, so I've got to go to (an emergency clinic in New Plymouth). That's been a big problem for me, and I've left here on the van with nothing in the van and prayed all the way to town. I don't care if we run out on the way back, as long as my kids get in there. And it's stressful too; my husband and I are arguing because we don't know whether we're going to get into town."

\section{Issues of cultural safety}

P\#11: "With the hospital system, especially the outpatients...it's when they're available, not when it's suitable to us. Like, we've got to reshuffle, 
save money for petrol, all that sort of stuff. So, yeah...get pissed off with that....with the...specialist appointments you've got to wait for the doctor to be available, and then your waiting list is forever and a day. So it can be frustrating. Tikanga wise, they're not sensitive to our needs. To them, you're a number, basically. And they shuffle you as fast as they can get you out the door...[about the local situation]: Now, you've got to ring for a doctor and they say, 'Look, come in to the (emergency clinic which is $20+$ kilometres away).' 'Go to the hospital.'...why pay for all these services if they're not there after hours?....You know, like travelling from here to New Plymouth; it's cost, once again. And you can't really budget for emergencies, things like that...."

P\#18: "Well, with specialists I'm not (always comfortable) because you've got to wait so long...the waiting list, yeah, that's the main thing....I used to (feel embarrassed or judged by the health provider) with head lice; having to go and get the stuff for head lice. Because it was cheaper to go to the doctor for a prescription than go through and buy it from the chemist...."

All the women expressed negative experiences when discussing question four. The key ideas most commonly identified here were: cost, availability, transport, childcare, waiting times, cultural issues and communication. These ideas often overlapped in terms of the women's experiences, making access very difficult indeed for many of the women.

Most of the women identified cost as a major access issue. Many spoke of their lack of money, the cost of GP visits, the cost of petrol to get to the doctor at night, the cost of prescriptions and the cost incurred when calling an ambulance.

The lack of local availability of health services, especially after hours, was also a concern for most. This lack of local availability had repercussions in terms of cost and time. For example, participants spoke of the cost of petrol to get to a doctor at night, which is compounded by the time it takes some to get to a doctor after hours. Some women noted that there was no local chemist available for most after hours time. 
Transport was problematic for many women who did not have access to reliable transport. Some of the women spoke of the stress they felt when they tried to organise care of their other children when taking a sick child to the doctor. This problem was compounded by lengthy waits at GP and specialist doctor clinics, and made worse if the other children were also present.

Some women felt that the health system was not sensitive to Maori needs. Communication issues, including confidentiality, were troublesome for some of the women. For example, a few felt embarrassed asking for help; some found the doctors in the emergency department rude while some did not understand what they were told. A few women felt that their confidentiality had been breached at the doctor's surgery or at the chemist counter.

\section{Question Five}

"What else would be helpful when your children are sick, and what else would you like to have here in [the researched community]?"

Many of them spoke of rectifying the gaps they had identified as barriers to accessing health care. Again, I have used subheadings to help clarify about which issues the participants were talking. The topics discussed here are: community based / environment, cultural issues, someone to phone, support, after hours / house calls, parenting course, quality of doctors, budget and nutrition advice, well child checks, information, continuity, addiction issues and confidentiality. These topics have been sorted into access issue categories of lack of availability of preferred choice and issues of cultural safety. These overlap somewhat, as has been discussed in interview question four. The access issues of cost and lack of reliable transport are negated by the women's suggestions that arose in response to this interview question.

\section{Issues of Cultural Safety}

P\#2: "Retention of Maori health concepts: tapa whaa, whanaungatanga; each person has talked about this. Each of us has a role of looking after the rest of 
the family plus the moko. A lot of knowledge about infection and sickness amongst the group."

P\#11: “. ...it would be awesome to ring someone within the Maori industry, if not industry, Maori tikanga that knows the tikanga of Te Reo Maori and doing it the old ways. For me, I'd rather go back to that day...."

P\#18: “.....and the ways that a lot of our kaumatua need to be treated, with respect from all of these doctors, you know. They get shoved through like, you know, they're just a number, and it takes a lot for a lot of them to go to the doctor. And then when they get there, they're treated, you know, like...in and out, see you later kind of thing....Public health nurses need to be given more funding, too, so they're more around the community. When that was taken, I think a lot of our health issues became more predominant...."

\section{Preferred Choice}

\section{Community Based / Environment}

P\#1: "One based in our community for sure. A pharmacy that's...not just a Saturday morning, because not many people get sick before Saturday 1200."

P\#4: "Well, the degree of unhealthy environment must surely cause all these things to be upgraded. If it means bringing in extra doctors and nurses, then so be it."

P\#6: "I don't think it really matters..."

P\#7: “...whether it's Maori or Pakeha [service].”

P\#18: "I think one thing is that our health issues in [the local community] is not a Maori thing; it's a community thing. It affects us all the same... In a lot of issues, and in health issues, I don't believe it should be treated as a Maori issue, it should be treated as a community, with all of us the same....I think Maori providers, because there's a place, you know, like a lot of Maori women, pregnant; they might feel better with a Maori midwife and things like that. Talking to Maori people might be easier for them. I think for smears and things like that, it' $d$ be good to have Maori women doing it, where Maori women can go.... I think the choice needs to be there, you know. The choice needs to be there." 


\section{Someone to phone}

P\#6:..."Yes, I think so. Then you'd know, to take them into the doctors, and whether you'd get in straight away, instead of having to wait...."

P\#11: "After hours, being able to ring a doctor...for advice...."

P\#18: "Even a service where they do...like a lot of these young mothers and that don't have cars, families, and when their babies have got the flu, they've got to push them down in the pushchair, so maybe a home service. And it'd maybe just need to be a nurse, and if that nurse thinks that they need to go to the doctor then they go.... Cos sometimes you can talk to someone on the phone, and if you're really depressed, how your babies can get you, but it's a bit different if you can have that one on one, and someone's there with you. Because the mother's more, or, if she's upset, the baby's going to be upset. There's no qualms about that, that's even happened to me, but I think, because I'm an older mother, I don't panic so much now, and things don't get me down so much."

\section{Support}

P\#8: “Just a bit more...I don't know how to explain...a bit more support from the nurses, or from some of them behind the counter....Cos some of them make you feel like you're stupid, like you're dumb. They ask you all what's the matter with your child, but we're not doctors.... and they can be rude. I actually thought that all the consultations were... when you go, there's some private things. There's some things that you cannot say, you'd prefer not to say over the counter, and they can speak so loud that everyone in the waiting room can hear, and sometimes it could be private. When my daughter X was sick, she was very sick... She had a bug, she had a virus and I wrapped her up in a blanket; I actually hid her because her eyes were just about dropping out of her sockets, and she was, what do they call it...just over a period of 24 hours...dehydrated, yeah, cos she couldn't keep nothing down, so as much as what I did was right, and I hid her in the blanket. I didn't take the blanket off of her until I was on the other side of that door.... And they said, 'Oh, what's the matter with her?' and I said, 'I'll show you on the other side of the door.'...I was frightened in case I had done something wrong... and I hadn't done anything wrong...." 
P\#6: "Just try and be more sensitive about how we're feeling."

\section{After Hours / House Calls}

P\#8: "...someone who is always available just to help you through it, just to help you through that half an hour, or whatever it is, that time that you're at the doctors, where you're really worried, you just need someone to talk to....That would be really good, having an after hours service."

P\#10: "Need more. If you've got no vehicle, how the hell are you supposed to go to A \& E or (one of the emergency clinics in New Plymouth)?”

P\#13: "Have a doctor on call. Or even if there was a doctor living [here], you could ring up and say, 'My child's sick, can I come to you?' and then you just have to go down the road, instead of.... Even weekends, it's a problem. Yes, so that's what I would really like, to be able to access back into a doctor."

P\#15: "Weekends, until 10 o'clock at night, like they do in town....more informed....yeah, a GP... home [visits]; yeah, that'll do, specially if you got no car.... But they charge the earth, don't they? There's always a catch, eh."

P\#17: [If a trained health professional was available after hours] "that would be excellent, especially if they could come to us; that would be good....Well, I know our doctor can't work 7 days a week, but it would be lovely!...”

P\#8: “...or even if they're able to come and see you, to reassure you about things, that would be awesome."

P\#14: "Yeah, housecalls."

\section{Parenting Course}

P\#8: [Would a parenting course be useful?] "Definitely. I think it's very important, cos just through the grapevine I've heard little bits of things, like health things, and why baby get sick, it's because the baby's doing da da da da da, and if you avoid this sort of thing, and this, it'll maybe stop them getting sick. Yeah.”

P\#7: [The parenting course] “...it's meant to help you with driver's license and that,...budgeting's a really good one, I really need help with that, lots of things probably, yeah." 
Quality of doctors

P\#10: "Oh, a decent doctor for one...."

\section{Budget and Nutrition Advice}

P\#9: “...I'd like to teach them how to budget their money; how to grow a garden; doesn't have to be a big garden, as long as baby's got their fresh fruit and veges most of all, for most days. Yeah, cos I find that a lot seem to spend their money elsewhere....just to teach them how to grow a garden and just keep their cupboards going, that'd be all with the budget....also, to me, we're getting away from that immediate whanau. We've got the love there, so why not have the immediate family?"

P\#18: "So many kids...they're feeding their kids...lollies, it's quick foods and things like that. This is at breakfast, cos they haven't...I don't know if it's they haven't got budgeting properly where they can buy proper food that'll last them the whole week. Maybe the first three or four days, they're feeding all right, and after that, it's whatever they can afford."

\section{Well Child Checks}

P\#13: "... you know how we go and get our children's teeth checked every six months? I always thought, 'Why can't we take the kids and get a body check every six months, like their teeth?' That would be wonderful, instead of just going to the doctor when they're sick..."

\section{Information}

P\#16: "Yeah, inform you more... when your kid's sick, you don't take them to the doctor and ask questions, cos they're sick, and you're stressed. The should tell you, eh."

\section{Continuity}

P\#17: ...'I think too that if my doctor wasn't available, the fill-in doctor that she has is a fill-in doctor that she always has. Instead of getting these different doctors, because I don't think you get the same as you would if you got to know your doctor a bit better.... just think that there should be, she 
should have one or two other partners, so that we as clients feel comfortable...That's asking a bit much, eh, but that's how I see it."

\section{Addiction}

P\#17: “...there needs to be something for our children...just about all my kids are in the addiction, and I have a son who wants help, but because there' not enough resources, there's nothing to help from here. And I believe that four our young tamariki, there should be a live in program for them, here in Taranaki. My son really wants help, and he's screaming out for it, and he's asked me to take him to there places, but because, again, you've got to travel to get there, and because I work, sometimes I'm not available, but if it was in (the local community) it would be so much easier."

\section{Confidentiality}

P\#18: [at the chemist] "I think the counter could be a bit more discreet when it comes to giving out mediation and where you have to go.... Cos sometimes they need to talk to you about something, and you're there with a whole lot of people behind you."

This final quote seems to sum up the feelings of frustration that surfaced in the interviews:

P\#8: "A bit more than what we have. I go to the doctors on XX Street. Now, you can't always get in there and when you do, you're double booked, or it's late in the afternoon. Especially when she was really sick, and you really want to do something about it as soon as possible. I don't know; some people who can just support you, and make you feel a bit better. I mean, I've only got...there's only me, and I try to do the best I can."

From question five, the key ideas surfaced are very similar to those of question four. The most common of these were identified as availability, cultural issues, and cost. Again, these notions overlapped and it was sometimes difficult to delineate clearly between them. For this reason, I have included comments about choice with availability, as they seem to be closely related. 
All the women mentioned availability as being important. Specifically, most were interested in a community based twenty-four hour service through which they could access a health person, not necessarily a doctor. Many wanted to be able to phone someone for advice. Some expressed a desire to have the option of home visits by health professionals. Several women commented that an upgraded public health service was required. A few felt that it would be useful to have a pharmacist on-call after hours, and a local pharmacy open at the same time. Many women expressed the need for a greater choice in the health care available to them. Some took this point further, suggesting a service that felt 'comfortable' with support present and no judgements.

Several women spoke about the need for more cultural sensitivity in the health service offered. They felt that there was a need for health professionals who knew Maori tikanga to be available. A few women spoke about the importance of knowing the person whom they would phone for health advice.

Only a few women mentioned cost as a concern. They suggested that free medical care for children under six years was helpful for them. Free and cheap prescriptions were important. One woman suggested that free medical and dental checks be done on children at six monthly intervals.

\section{Conclusion to chapter six}

This chapter describes the participants' responses to the interview questions. Their voices are included in the form of quotes in the answers for each question. Each participant's points are compared to those of the other women to enable common concepts to be recognised and grouped together. Similar notions that are raised by more than just one or two women are included. Subheadings are used for a couple of question in which the participants had a lot to say. These related notions are then assembled more broadly into categories that I called key ideas. 
The next chapter identifies and discusses the two major themes that emerge from the cluster of key ideas. These themes are then considered in relation to the literature. 


\section{Chapter Seven Discussion of the Findings}

\section{Introduction to chapter seven}

This chapter sets out to discuss the findings from the interview data in more depth. The data analysis that has been employed is one of thematic analysis. The key ideas that emerged from the findings, as discussed in chapter six, were identified in terms of their commonalities and relevance to the questions asked of participants. These key ideas were then clustered under the headings of the two main themes. I consulted with my Maori critical friend $\mathrm{M}$ before naming the two themes. We agreed that there were two critical concepts that arose from the data.

The first theme is concerned with what the concept of 'health' means to the Maori women who took part in this study. Secondly, the theme of access issues arises strongly from the research findings. These themes are discussed in relation to the aims of this project and the literature. A synthesis and summary of all the data presented is included here, reflected upon and is interpreted in relation to recommendations for further research and action.

\section{First theme: The concept of health is not the same for Maori as} it is for Pakeha.

One of the major findings to emerge from the interviews is that a concept of health is not the same for Maori as it is for Pakeha. It seemed to me of critical importance to understand what the participants mean when they talk about health. This meant that I was not assuming that their understanding of the concept of health is the same as mine. This is especially relevant, as this is an exploratory study measuring the effects of a dominant health culture on an indigenous culture.

When I asked the participants what was important to them in terms of their children's / mokopuna's health, several of them asked me to tell them what I meant when I asked them about 'health'. I explained that I really wanted to know what they thought. At this stage, I had to reflect on the assumptions I 
held about the concept of health. I purposefully did not prompt the women about what they considered to be about health. This led to some initial pauses in the interviews, but revealed interesting ideas that illustrated the participants' views of health. All the participants are Maori, and this has relevance when comparing traditional Maori and Pakeha ideas about meanings of health.

The concept of Maori health encompasses the whole family, though female whanau members typically give care (Durie, 1998a; Metge, 1995; MOH, 1998a; Pihama, 1993). The traditional Maori view of health is holistic, encompassing spirituality, Te Reo Maori, thoughts and feelings, physical health, land and environmental issues, and extended family, including the ancestors (M. Durie, 1995; Pere, 1997).

The participants in this project incorporated a wide range of aspects into their concept of health, as illustrated by their comments earlier in this chapter. They told stories that illustrated ways in which health was important in their lives. Their stories and comments from the interview conversations plainly support the literature that describes an holistic Maori view of health. The participants spoke of many different aspects of health that, when woven together, incorporate people, their extended family and their communities as well as the past, present and the future (Pomare, 1995; Te Puni Kokiri, 2000). The key ideas utilised when assembling the first theme came mainly from the responses participants gave to the first interview question. For example, some of the women talked about health problems exclusively. Others spoke about health in terms of lifestyle as well as specific health problems or health deficits. Some women included tikanga when they talked about health. The ability to speak Maori was considered important by some women.

The key ideas arising from interview questions two and three also informed the conception of the first theme. Question two is: what do you do when your children are sick? Question three is: who is most helpful when your children are sick? The actions the women take when their children are sick, and the people they find helpful and unhelpful are based on their concepts of health. 
The data suggests that all participants placed importance upon being alert to the signs of mokopuna's / children's health deterioration, using their common sense, applying both Maori and Pakeha remedies, and visiting the doctor early rather than later. Reliance upon Maori kinship ties of whanau or extended family support is particularly important to the participants. A few health professionals were also identified as useful. There were some people who were identified by the participants as being unhelpful when their children were sick. Some women gave examples of a lack of understanding by medical personnel, while others spoke of a lack of awareness of cultural issues. A few women talked about not feeling comfortable with people they didn't know. Different ways of doing and saying were interpreted by a few women as being unhelpful.

When the women spoke about what they would do when their children / grandchildren were sick, many of them spoke about knowledge that was held in their families already. Sometimes they had this knowledge, or it was shared between others in the family across different generations. Isolation from knowledge and expertise was identified as being problematic.

All the women found family members were most helpful in giving advice and support when children / grandchildren were ill. The doctor's input was generally sought if interventions by family members were unsuccessful, or if the child was felt to be seriously ill or in need of a prescription. Health professionals were sometimes helpful, as were karakia. However, health professionals are not always easy to access, as has been established.

Many of the women spoke heatedly about their dissatisfaction with the local community clinic, which was initially set up to cater for perceived unmet local Maori health needs. Other health professionals were perceived as being unhelpful. Judgements made by 'outsiders' were felt to be unhelpful, as were cultural practices that were identified as unhealthy. 
The major theme of a concept of health for Maori being different from the traditional Pakeha concept of health arose as a comparative mechanism, based on how the participants defined the concept of health. The health services in New Zealand are philosophically and culturally based on the beliefs and assumptions of the dominant Pakeha culture.

Health status or deficits are measured in terms of specifically defined outcomes and statistics (Ministry of Health, 1998b, 2001b; Te Puni Kokiri, 2000; The Public Health Commission, 1995).

Some of the research participants spoke of health in terms of only physical health, which is an approach usually associated with the biomedical Western model of health of the New Zealand Pakeha culture (M. Durie, 1998b; PHC, 1995; Shipley, 1995).

The New Zealand government is at last acknowledging a link between socioeconomic, cultural factors and health (MOH, 1998b; NHC, 1998; Stephens, Frater \& Waldegrave, 2000). Traditionally, health for Maori has always included these factors among many others in an holistic understanding of the concept of health. Measuring health as statistical deficits in the physical aspects of health obviously is far too narrow a focus in which to examine Maori child health issues.

It is clear by the remarks made by participants that there is a continual tension for them in accessing health services based on a Pakeha model. They constantly seek what they believe is best for their children's health based on their knowledge and on what is available to them in terms of health resources.

I have considered what the women conversed about when they spoke of what 'health' is to them. The way these women defined and described 'health' fits into the description of Durie's Whare Tapa Whaa Model (1998a). This model is based on the four walls of a house. One wall is spiritual, one is thoughts and feelings, one is the physical side, and one is family. Clearly, any model of health used in the researched community must include all the aspects of 
health mentioned by the participants, if it is to have relevance to them. To base health strategies solely on a Pakeha / Western model is to ignore what the concept of health means to these women. It may be that other Maori communities consider health in a more encompassing way than that of the traditional New Zealand Western model of health. Thus there may be potential for further research in this area.

In summing up this first part of the discussion chapter, the following ideas were clearly expressed. When the women spoke about what they would do when their mokopuna and / or children were sick, many of them spoke about knowledge that was held in their families already. Sometimes they had this knowledge, or it was shared between others in the family across different generations. Isolation from knowledge and expertise was identified as being problematic, as there was a lack of family support in such situations.

All the women found family members are most helpful in giving advice and support when mokopuna and / or children are ill, and their input is considered critical. The doctor's input is generally sought if interventions by family members are unsuccessful, or if the child is felt to be seriously ill or in need of a prescription. Health professionals are sometimes helpful, as are karakia. However, health professionals are not always easy to access, as has been established.

Many of the women spoke heatedly about their dissatisfaction with the local community clinic, which was initially set up to cater for perceived unmet local Maori health needs. Some women found health professionals, other than those already mentioned, to be unhelpful when their mokopuna and / or children are sick. Judgements made by 'outsiders' were felt to be unhelpful by some women, as were Pakeha cultural practices that were identified as unhealthy. 


\section{Second Theme: Issues of access.}

The second theme about issues of access came in response to asking how the participants felt about the access they had to health services. Some of the participants stated that the reason they were involved in the research was because they recognised the opportunity to say what is needed in the community in which the research took place.

The perennial issue of access to primary health services has been theoretically recognised as problematic in achieving improved health outcomes for Maori for decades in New Zealand (English, 1998; Malcolm, 1996; MOH, 1997; Pomare, 1995; Te Puni Kokiri, 2000, to cite some examples). Sadly, it appears that years of New Zealand government commissioned publications have made little or no difference to the health of Maori children, at least based on the Pakeha statistical methods of analysing health status.

Much more alarming is the indication by the research participants in this project that for them access issues are still the major barrier as they seek available health resources for their children. Cultural barriers identified by participants were included under the theme of access. In spite of any government health reforms, various issues of cost, lack of availability of choice, and lack of cultural safety were felt by the participants to still be problematic for them. The situation was more likely to have worsened for these women, and without change, further deterioration seems inevitable.

The theme of access was discussed from both negative and positive aspects. The negative aspects arose from the question: "How do you feel about the access that you have to health services?" All the participants had had access problems of one kind or another. Many women consistently had multiple access difficulties. I encouraged the women to identify what access meant to

them. Some women did not understand what I meant by the use of the word access in relation to health, so I prompted them by asking if they ever had any trouble getting the help they needed when their children were sick. When they then identified a problematic issue such as cost, I explained this as an 
example of an access issue. The participants identified access issues as: cost (especially for prescriptions), lack of availability of preferred choice, lack of reliable transport, and issues of cultural safety. The women identified feelings of inadequacy as access barriers to health services. It seemed to me that feelings of inadequacy could at least partly stem from the legacy of the effects of colonisation on Maori women in New Zealand. I consulted with my Maori critical friend $\mathrm{M}$ on how to include this finding under the umbrella of a wider theme. Based on our discussion, I have referred to this as lack of cultural safety, in the discussion.

I was unsure if there were health services in the local community of which the participants were unaware. This assumption was unfounded, as is clearly illustrated by the interview data. Ngaati Hine Health Trust (1996) and Ramsden (cited in Te Kete Hauora, 1995) both agree that there are cultural constraints evident in a Maori choice not to access certain health care services provided by a Pakeha health system.

Physical barriers found to be problematic are those of cost, lack of availability of choice and lack of reliable transport. Ironically, these issues of physical access are the very same issues that various New Zealand governments consider to have been addressed over the last few decades $(\mathrm{MOH}, 1994$; 2001b; Te Puni Kokiri, 2000). In fact, the centralisation of health services has meant that access issues have become more, not less, problematic for the participants in the researched community. To illustrate, after hours medical access that was once available has been discontinued. There are no local GPs on call in the weekends, as there once were. The local Plunket clinic hours have decreased. The position of well child health nurse for Nga Puna Ora Trust had been vacant for eight months when this thesis was written.

Participants identified positive aspects concerned with the issue of access when I asked them for any recommendations they wished to make about what they would like to see in their local community. Many of them spoke of rectifying the gaps they had identified as barriers to accessing health care. They commented on the following points: community based / environment, 
cultural issues, support, sensitivity, continuity, after hours service, someone to phone, parenting course, house calls, six monthly well child health checks, addiction support, budget and nutrition advice, confidentiality, quality of doctors, and information. These topics have been arranged into two of the same categories as those of the negative aspects of access: lack of availability for preferred choice and issues of cultural safety. Interestingly, the issues of cost and lack of reliable transport were negated when the other issues were addressed.

\section{Issues specific to this research project, concerning non-Maori doing research with Maori}

The findings from the research are now described in terms of the theoretical premise of this project, which is critical social theory. In order to link the findings to the theory on which this project is based, I have used as a framework questions suggested by Maori academic Linda Smith (1999, p. 173) for consideration by researchers engaged in research with Maori. In this section, I will revisit the title of the project, and then link the findings through consideration of Smith's suggested questions: "An exploration of issues of primary health services for Taranaki Te Atiawa children based on the expectations and perceptions of their female caregivers".

These questions are listed here:

-Who defined the research problem?

-For whom is this study worthy and relevant? Who says so?

-What knowledge will the community gain from this study?

-What knowledge will the researcher gain from this study?

-What are some likely positive outcomes from this study?

-What are some possible negative outcomes?

-How can the negative outcomes be eliminated?

-To whom is the researcher accountable?

-What processes are in place to support the research, the researched and the researcher? 
Who defined the research problem?

Auntie $\mathrm{T}$ and myself defined the research problem as discussed in chapter two. Much has been written about primary health services and Maori child health (see also chapter three). However, no one has researched what female caregivers of Te Atiawa children in a community in Taranaki think about the services available to them. Thus an exploration of this issue was planned.

The presence of more women than could be included as participants, eager to speak of their concerns, led me to believe that the research problem had been identified appropriately for the researched community.

Question one ("What is important to you in terms of your mokopuna / children's health?") was devised in order to find out what is important to the participants in terms of their children's health. The findings from this question illustrate clearly that the Maori women involved defined the concept of health much more broadly than is typical in a Western framework. Many of them spoke of an holistic concept of health that is similar to the Tapa Wha Maori health model of the four sided house (Durie, 1998a). A few women identified issues of racism inherent in the Western system of health predominantly used in New Zealand, and the importance of Maori language in defining Maori health.

\section{For whom is the study worthy and relevant? Who says so?}

I have considered these questions in terms of how the women felt about the access that they have to health services (Interview Question four). All the women had something to say about access issues, and they all expressed negative experiences when discussing this question. Some women spoke about how they were keen to be part of this project in order to have their voices heard. It appears that the women who chose to be part of this project felt that the study would be worthy and relevant to them. Their presence at the interviews reinforces this. I believe that this study may be worthy in both a short term and longer-term way. That is, in the short term, an exploratory study has been carried out and the aims of this study achieved. In the longer 
term, the potential for positive action arising from the findings is a possibility, though it is not part of this thesis.

\section{What knowledge will the community gain from this study?}

It is likely that the community has gained some knowledge from this study. For example, they may have learned something about research processes. It is hoped that knowledge gained will inform the community, in terms of commonalities of issues that the participants identified. For example, many of the participants identified the same issues as being problematic. Addressing primary health care access issues could potentially empower the researched community. The community may be able to transform the reality of the current situation with locally based health initiatives, perhaps based on the recommendations described in chapter eight.

\section{What knowledge will the researcher gain from this study?}

I have gained a huge amount of knowledge about the processes inherent in exploring an issue as a Pakeha researcher with Maori participants. In terms of exploring issues of primary health services for Te Atiawa children in the researched community, my assumptions were generally upheld. Referring again to interview question four ("How do you feel about the access that you have to health services?"), clearly the access is unacceptably poor for the participants. This is in spite of the rhetoric about the perceived problem of Maori child health and the limitations of rural access (see also Chapter three). For more than ten years the New Zealand government has expressed a commitment to improving the status of Maori child health. It seems that, in the researched community, they have failed. In fact, for some families things are worse with more centralised health services. There used to be after hours medical and pharmaceutical services in the researched community. Now, with no after hours services, the distance some women have to travel into the regional hospital can take up to forty-five minutes.

What are some likely positive outcomes from this study?

This study is an exploration of primary health service issues based on expectations and perceptions of Te Atiawa children's female caregivers. It 
may be that having their voices heard and their messages taken seriously constitute a positive outcome. However, I feel that more tangible positive outcomes are possible. The participants identify quite clearly what they think is needed in their community. Interview question five asks "What else would be helpful when your children are sick, and what else would you like to have here in [the researched community]?" The answers to this question are concerned with rectifying the deficits to access defined by the answers to interview question four. For example, all the women mentioned the availability of health services as being important. Further, they described how they felt better access could be achieved in their community. Some illustrated ways in which cultural issues could be addressed. Surprisingly for me, strategies for reducing cost were not seen as important by most of the women, once access and cultural issues were satisfactorily achieved.

\section{What are some possible negative outcomes?}

The worst possible negative outcomes could be achieved in at least two ways. The first would be by ignoring the content and importance of what the women had to say. The second would be by trying to rectify the problems identified by the participants without using a Kaupapa Maori model. At the very least, participation, partnership and protection between Maori and Pakeha must frame and be part of any plan and action undertaken. Simply mouthing these words as principles would potentially be incredibly disappointing for the women who were part of this project. Findings that describe racism and classism in terms of social deprivation need to be addressed to the satisfaction of the people who described these issues. For example, in discussing issues of lack of access raised by interview question four, most participants identified the lack of money, cost of GP visits, the cost of petrol to get to the doctor at night, the cost of prescriptions and the cost of calling an ambulance as problematic for them. Lack of available transport when their children are sick was identified as a major problem for many women.

\section{How can the negative outcomes be eliminated?}

It is up to Maori in this community to decide what they need, and what would work best for them. The participants in this study have already stated quite 
clearly what they need. For example, most wanted a community based twenty-four hour service through which they could access a health professional. Many wanted more choice in the health services available to them and their children. Some women considered more cultural sensitivity in any offered health service very important. The Ministry of Health could work in conjunction with people in the researched community to fund what the people who live here want. I believe that Maori must drive any initiative that is designed to promote Maori health of any kind.

\section{To whom is the researcher accountable?}

I am accountable chiefly to the research participants and the Maori people of the researched community. I am also accountable to the Maori groups that supported this project. They are the local branch of the Maori Women's Welfare League, Te Atiawa Health Forum and Te Whare Punanga Korero. I am also accountable to Victoria University of Wellington. I am, just as importantly, accountable to my personal ethic of social justice, and to my children, who are Te Atiawa of Taranaki.

What processes are in place to support the research, the researched and the researcher?

Members of the community have supported the project throughout. The groups to whom I am accountable are very interested in the ultimate findings of this research. A research process that was a partnership between Maori and Pakeha in this community supported the participants. This research design is described in Chapter five. Auntie M., K. and many members of my community have supported me. I have also been continually encouraged by my belief that the Treaty of Waitangi must be honoured in New Zealand society.

\section{Summary of the discussion}

At this stage, I will return to the beginning of the research project, reiterate the aims of the project and discuss whether they have been met. The starting point in deciding on this research topic was considering how the New 
Zealand government's aims to improve Maori child health translated at a practical level in a local community. That is, are the government aims being achieved in a rural Taranaki community amongst local Maori children there?

I wondered when and why the female caregivers of Maori children decided to access the available local health services. If they chose not to access them, I wanted to hear their reasons for such a choice.

When this project started, I assumed that barriers to health access would be probably due to poverty, possibly to ignorance of available services, and probably because of cultural relationships. There is a high level of unemployment in the researched community, and many families there have daily concerns about money. The literature supports my assumption that poverty might be a barrier to health access in the researched population (National Health Committee, 1998; Shirley, 1995; Sword, 1999; Visser et al., 1998; Walker, 1995).

This project was an exploratory study, which had three aims. It was hoped to achieve these through interactive discussion and selective conversations with the participants. The aims are listed here.

1. To provide insights into Maori child health through the voices of female caregivers.

2. To allow the voices of local women to define what is important to them in terms of Maori child health.

3. To contribute new knowledge to the discussion on Maori child health.

It seems to me that these aims have been comprehensively met. The first two aims were achieved more or less simultaneously, as the defining of important issues by the participants provided insights into Maori child health. A great deal of rich data was generated from eighteen participants. They were quite clear about what is important to them to meet their children's health needs. It seems that they use the system as well as they can to get what they need for the children in their care. However, as they graphically describe, the New Zealand health system often does not meet their needs. In terms of 
contributing new knowledge to the discussion on Maori child health, the two major themes that I have identified from the data are not new. Since before the time of The Treaty of Waitangi Maori and non-Maori have had different ways of defining the concept of health (Buck, 1910; Makereti, 1938). As time goes on, these concepts have evolved, though there are clearly still major differences between the present day Maori and Pakeha concepts of health.

I believe that it is of great concern that access issues are a major problem to the women who took part in this project, particularly in light of the New Zealand government's often repeated aim of improving Maori health. "The Crown will seek to improve Maori health status so in the future Maori will have the same opportunity to enjoy at least the same level of health as nonMaori" (Parata \& Durie, 1993, p.4). In the rural community where the research took place, things have not improved since the health reforms of the 1990s. In some ways they have gotten worse as community health initiatives lost funding in the drive to centralise health services.

\section{Conclusion to chapter seven}

Two major themes emerged from this research project. They relate to providing a culturally safe service for Maori children, and accessing health services for Maori children. These themes have been critically analysed in order to provide points for discussion and in order to provide a platform for the recommendations made in the next chapter.

A thorough literature search revealed that most Maori communities in New Zealand have not been involved in similar research. I recognise that some literature is not available outside specific Maori communities. It seems that women in rural communities have not had the opportunity to say what they believe their primary health service access needs are. Interestingly, the women involved in this project had many positive ideas for ways in which access issues for them and their children could be satisfactorily addressed. Their suggestions are community based, and mean that many of the problems of cost and transport can also be nullified. 
This is the end of the research discussion chapter. However, the problems for the Maori women and children in this community have not gone away. It seems that the problems identified by the participants may yet be resolved. I believe that there are enough local resources within the Maori and wider community to be able to achieve the positive outcomes suggested by these participants.

There is more discussion about this in the conclusion and recommendations chapter that follows. This chapter also includes a reflective section on how I believe this research project has been beneficial to the participants and to me. 


\section{Chapter Eight Conclusions and Recommendations}

\section{Introduction to chapter eight}

In this concluding chapter, there is a discussion about the conclusions drawn from the research. Recommendations are made based on these conclusions and my personal reflections of the research process and on the relevance of this topic to the discipline of nursing. I discuss how this research may have benefited the participants, and how it has benefited myself. Limitations and areas of possible further investigation are outlined. I identify the way in which the research report will be disseminated to the various interested parties, including the research participants themselves.

To begin, I revisit the title of this thesis:

"An exploration of issues of primary health services for Taranaki Te Atiawa children, based on the expectations and perceptions of their female caregivers."

It has been established in the discussion chapter that the aims of this project have been met. Two major themes that arose from the research interviews have been identified, discussed and reflected upon.

Insights into Maori child health, specifically those of Te Atiawa, have been provided through the voices of female caregivers, who are local women. These women have defined what is important to them in terms of health for the children they look after. New knowledge has been contributed to the discussion on Maori child health. In particular, it has been possible to measure the success of the New Zealand Ministry of Health's principal Maori health objective in the community in which the research took place. "The Crown will seek to improve Maori health status so in the future Maori will have the same opportunity to enjoy at least the same level of health as nonMaori" (MOH, 1998b). Also considered was whether or not the social and economic gaps in the research community, measured by the experiences of Maori women and their children, had closed. 
The experiences of the participants illustrate quite clearly that for them, the gaps have not closed. It seems that, for this community at least, the New Zealand government's primary health strategies are not helping Maori women access the care they need for their children. The following recommendations to this dilemma suggest themselves. Some recommendations are specific to the unique researched community, while others are aimed at New Zealand nationally.

\section{Recommendations}

\section{Recommendation One}

That health initiatives only be undertaken in partnership with the community for which they are intended. This may seem self-evident, but as I explored the literature available for this research, it became obvious that research based on community consultation is rarely published in New Zealand. As can be seen from the Discussion chapter, the research participants had plenty of ideas that they felt would work in their community.

\section{Recommendation Two}

That the philosophy of health care provision in New Zealand be expanded to embrace holistic models suggested by Maori as working best for them. For example, Durie's (1998a) Nga Tapa Whaa model is widely quoted in the literature. It seems that the pathway between the national health funder, currently the Ministry of Health, and the rural consumer featured in this research, is fraught with pitfalls and potholes. The large number of government generated reports cited in the literature review chapter, chapter three, have not yet managed to address access issues for some groups of consumers.

\section{Recommendation Three}

That the Treaty of Waitangi be used as a framework for health care delivery for New Zealand. The principles of participation, partnership and protection need to be incorporated into every level of health provision. For example, legislation needs to reflect these principles. As can be inferred from the 
findings of this research, racism is still flourishing in parts of New Zealand society. Once this fact is recognised, it can be addressed, but that is outside the scope of this project.

Richard Hill (2000, p. 3) in his paper "The Treaty of Waitangi Today" states that "the Treaty cuts straight to the cental issue of power relations in our society - who wields power and on whose behalf and by what right?" Article Two of the Treaty seems mainly concerned with the settlement of historical grievances and recognising the importance to Maori of tino rangatiratanga. Hill suggests that Crown movement towards conceding rangatiratanga could be based on both articles two and three. An example of Article Three's emphasis on strategies is given as supporting the Maori desire for social and economic bases in the community on which to build, that would also assist in closing the gaps.

\section{Recommendation Four}

That the nursing role for independent practitioners in the community be further developed. For example, in the researched community, a telephone advisory service could be set up. Perhaps a nurse could be employed after hours as a primary reference to help parents decide how sick their child is and if, or how urgently, they need to see a doctor. Health promotion and education could also be part of this nursing role, as could further nursing research on various issues of interest to members of the community. This nursing role would be based on a Maori health model, utilising available community resources, both Maori and non-Maori as chosen by the community. The role would be defined in terms of partnership, participation and protection, and would be flexible and dynamic.

\section{Recommendation Five}

That the New Zealand government financially support community research initiatives similar to this project. These could perhaps be followed by action research initiatives dealing with access issues raised in the communities involved. Nurse researchers need to be actively sought and supported financially to work in the areas of, for example: primary health, access issues, 
and expanding the nursing role in community health over both short and long term timeframes.

\section{Recommendation Six}

That the New Zealand government's health documentation reflects the views of nurses as well as those of doctors and midwives. It is still unusual to find included more than one or two names of nurses in the list of those with whom the government consulted in a particular publication. This shows an ignorance of the role and experience nurses have in the health system in New Zealand. Involving nurses' voices much more at a national level has the potential to aid in the planning, development, actioning and auditing of any government health initiatives. As nurses expand their roles in all places in health care, they must be involved in health policy and planning. Not to include nurses is to waste a valuable resource that the community of health consumers regards highly (Hill Cone, 2002).

\section{Recommendation Seven}

The New Zealand government needs to follow action suggested on paper concerned with improving Maori child health with initiatives at a community level. It would be useful if the government re-examined the audit process in place for community based health providers, and carried out on-going audits and evaluation processes appropriate to the community of consumers. There needs to be a re-evaluation of structures and health providers already in place and funded by the government for cultural appropriateness and relevant evaluation by consumers.

\section{Recommendation Eight}

That local district health boards work with local councils to provide a community based resource book including all available community resources/groups/helpful people for various situations. For example, information could be compiled in the areas of health, healing, mental health, socio-political-economic resources, cultural support and rescue issues. Links could then be established between each and all of these areas as an on-going community resource tool. 
There may be other useful initiatives that arise over time, but those listed here should provide a helpful starting point for further action in supporting the community to improve primary health services for their children and themselves.

\section{Benefits of the research process to myself and the participants}

I have been a part of this research since its inception, and I complete this thesis knowing that there is much more to explore than can be covered here. I have learned a huge amount about qualitative research methods, in particular those involving a Pakeha researcher working with Maori participants in the current New Zealand socio-political climate. Being involved in this project has opened my eyes to the vast number of research opportunities that there are for nurses, in many different fields and using both qualitative and quantitative research designs.

In terms of my increased academic nursing knowledge, I now know how to access information that I need both nationally and internationally. My computer skills have increased alongside my growing understanding of the necessary rigours of nursing research. My expanding knowledge of critical social theory, empowerment and oppression have led me to consider the way that the Treaty may be used to delineate a partnership model for a New Zealand health framework.

I have learned something from all the literature that I have read, particularly around the topics of primary health care, research with Maori, child health and emancipatory research designs. My journey through this process has been paralleled by my own personal journey. My thinking about health and marginalised people has expanded positively. My belief in the benefits for nursing in supporting and working within a partnership model of health is now profound. My clinical practice in paediatric emergency care reflects my learning by enabling me to work much more in partnership with children and their families than I was able to before. I have certainly gained an appreciation of the meaning of 'jargon' as used in academic literature. I am 
able to assist my nursing colleagues in accessing information and in constructing written reports. I can chat together with other nurses undertaking academic study, and understand what we are all talking about. My belief in the potential future growth of the nursing role has saved me from becoming demoralised by the limits sometimes placed on nursing practice within institutional settings.

My place as a useful health resource in the researched community has been established with some of the kuia there. They also know me as an ambulance officer and a nurse with an interest in child health. Members of the community have phoned me on occasion with worries they have, and I have been able to help in offering support and advice if needed.

Similarly to Casey (2000), I cannot speak for my participants as to whether they found being involved in this research to be beneficial. However, many of them commented during the interviews that they really appreciated the chance to air their views about community health issues that affected themselves and their families.

\section{Limitations of the research project}

The main research limitations for this project were concerned with the time frame allowed for data collection and the limit required in accepting participants. I wish I could have included all of the women's stories. I am aware that my analysis of what they said comes inevitably from my Pakeha perspective. The limitations on the scope of the project encourage me to hope that further research in this area will be initiated. I have not considered any traditional quantitative research limitations, as I consider them to be irrelevant to this research. I have addressed areas for further research in the recommendations made.

\section{Dissemination of the findings and feedback to the participants}

Copies of the final research report will be sent to the Maori research units specified by the Taranaki Ethics Committee. This was a condition of ethical 
approval for the project. The participants will be given a copy of the final research report and a hui will be organised by Auntie $\mathrm{M}$ and myself at which time we will orally disseminate the findings of this research. The findings of this research will be available to the Victoria University of Wellington Graduate School of Nursing and Midwifery, the Victoria University of Wellington Library, and to Tui Ora Ltd. in Taranaki.

\section{Conclusion to chapter eight}

In this chapter, there is a discussion based on the conclusions drawn from the research. Eight recommendations for areas of further investigation and future action are made, at both local and national level, based on the research findings. Benefits and limitations of the research are noted, and an explanation is given of the dissemination process for the research report.

\section{Concluding statement of the thesis}

I found it difficult to conclude this project, because I believe that this research has the potential to continue through other phases. For example, if the recommendations are followed up, and the progress of initiatives monitored, knowledge and information can be added to that gathered here.

I close with a well-known Maori saying: "He aha te mea nui? He tangata, he tangata, he tangata" (Mina Timutimu, personal communication, October, 2001). In English, this may be translated to mean: "The most important thing is the people, the people, the people." Kia ora koutou. 


\section{Appendix One}

\section{The Treaty of Waitangi}

\section{A. Maori version}

Ko Wikitoria te Kuini o Ingarani I tana mahara atawai ki nga Rangatira me nga Hapu o Nu Tirani i tana hiahia hoki kia tohungia ki a ratou o ratou rangatiratanga me to ratou wenua, a kia mau tonu hoki te Rongo ki a ratou me te Atanoho hoki kua wakaaro ia he mea tika kia tukua mai tetahi Rangatira hei kai wakarite ki nga Tangata maori o $\mathrm{Nu}$ Tirani - kia wakaaetia e nga Rangatira maori te Kawanatanga o te Kuini ki nga wahikatoa o te wenua nei me nga motu - na te mea hoki he tokomaha ke nga tangata o tona Iwi Kua moho ki tenei wenua, a e haere mai nei.

$\mathrm{Na}$ ko te Kuini e hiahia ana kia wakaritea te Kawanatanga kia kaua ai nga kino e puta mai ki te tangata maori ki te Pakeha e noho ture kore ana.

Na kua pai te Kuini kia tukua a hau a Wiremu Hopihona he Kapitana i te Roiara Nawi hei Kawana mo nga wahi katoa o Nu Tirani e tukua aianei amua atu ki te Kuini, e mea atu ana ia ki nga Rangatira o te wakaminenga o nga hapu o $\mathrm{Nu}$ Tirani me era Rangatira atu enei ture ka korerotia nei.

\section{Ko te tuatahi}

Ko nga Rangatira o te wakaminenga me nga Rangatira katoa hoki ki hai I uru ki taua wakaminenga ka tuku rawa atu ki te Kuini o Ingarani ake tonu ate - te Kawanatanga katoa o o ratou wenua.

\section{Ko te tuarua}

Ko te Kuini o Ingarani ka wakarite ka wakaae ki nga Rangatira ki nga hapu - ki nga tangata katoa o $\mathrm{Nu}$ Tirani te tino rangatiratanga o o ratou wenua o ratou kainga me o ratou taonga katoa. Otiia ko nga Rangatira o te wakaminenga me nga Rangatira katoa atu ka tuku ki te Kuini te hokonga o era wahi wenua e pai ai te tangata nona te wenua - ki te ritenga o te utu e wakaritea ai e ratou ko te kai hoko e meatia nei e te Kuini hei kai hoko mona.

\section{Ko te tuatoru}

Kei wakaritenga mai hoki tenei mo te wakaaetanga ki te Kawanatanga o te Kuini - Ka tiakina e te Kuini o Ingarani nga tangata maori katoa o Nu Tirani 
ka tukua ki a ratou nga tikanga katoa rite tahi ki ana mea ki nga tangata o Ingarani.

[signed] W. Hobson Consul \& Lieutenant Governor

$\mathrm{Na}$ ko matou ko nga Rangatira o te Wakaminenga o nga hapu o Nu Tirani ka huihui nei ki Waitangi ko matou hoki ko nga Rangatira o Nu Tirani ka kite nei i te ritenga o enei kupu. Ka tangohia ka wakaaetia katoatia e matou, koia ka tohungia ai o matou ingoa o matou tohu.

Ka meatia tenei ki Waitangi i te ono o nga ra o Pepueri i te tau kotahi mano, e waru rau e wa te kau o to tatou Ariki.

(Note: This treaty text was signed at Waitangi, 6 February 1840, and thereafter in the north and at Auckland. It is reproduced as it was written, except for the heading above the chiefs' names: ko nga Rangatira o te Wakaminenga. 


\section{B. English Translation of the Maori Version}

Victoria, the Queen of England, in her gracious remembrance of the Chiefs and Tribes of New Zealand, and through her desire to preserve to them their chieftainship and their land, and to preserve peace and quietness to them, has thought it right to send them a gentleman to be her representative to the natives of New Zealand. Let the native Chiefs in all parts of the land and in the islands consent to the Queen's Government. Now, because there are numbers of the people living in this land, and more will be coming, the Queen wishes to appoint a Government, that there may be no cause for strife between the Natives and the Pakeha, who are now without law: It has therefore pleased the Queen to appoint me, WILLIAM HOBSON, a Captain in the royal Navy, Governor of all parts of New Zealand which shall be ceded now and at a future period to the Queen. She offers to the Chiefs of the Assembly of the Tribes of New Zealand and to the other Chiefs, the following laws: -

I. The Chiefs of (i.e. constituting) the Assembly, and all the Chiefs who are absent from the Assembly, shall cede to the Queen of England forever the government of all their lands.

II. The Queen of England acknowledges and guarantees to the Chiefs, the Tribes, and all the people of New Zealand, the entire supremacy of their lands, of their settlements, and of all their personal property. But the Chiefs of the Assembly, and all other Chiefs, make over to the Queen the purchasing of such lands, which the man who possesses the land is willing to sell, according to prices agreed upon by him, and the purchaser appointed by the Queen to purchase for her.

III. In return for their acknowledging the Government of the Queen, the Queen of England will protect all the natives of new Zealand, and will allow them the same rights as the people of England.

(Signed) WILLIAM HOBSON

Consul, and Lieutenant-Governor 
We, the Chiefs of this Assembly of the tribes of New Zealand, now assembled at Waitangi, perceiving the meaning of these words, take and consent to them all. Therefore we sign our names and our marks.

This is done at Waitangi, on the sixth day of February, in the one thousand eight hundred and forthieth year of our Lord.

(Note: Text from J. Noble Coleman, A Memoir of the Rev. Richard Davis, London, 1865, pp. 455-56. 


\section{C. 'Official' Version / English Text}

Her Majesty Victoria Queen of the United Kingdom of Great Britain and Ireland regarding with Her Royal Favor the Native Chiefs and Tribes of New Zealand and anxious to protect their just Rights and property and to secure to them the enjoyment of Peace and Good Order has deemed it necessary in consequence of the great number of Her Majesty's subjects who have already settled in New Zealand and the rapid extension of Emigration both from Europe and Australia which is still in progress to constitute and appoint a functionary properly authorized to treat with the Aborigines of New Zealand for the recognition of Her Majesty's sovereign authority over the whole or any part of those islands - Her Majesty therefore being desirous to establish a settled form of Civil Government with a view to avert the evil consequences which must result from the absence of the necessary Laws and Institutions alike to the native population and to Her subjects has been graciously pleased to empower and to authorize me William Hobson a Captain in Her Majesty's Royal Navy Consul and Lieutenant Governor of such parts of New Zealand as may be or hereafter shall be ceded to Her Majesty to invite the confederated and independent Chiefs of new Zealand to concur in the following Articles and Conditions.

\section{Article the first}

The Chiefs of the Confederation of the United Tribes of New Zealand and the separate and independent Chiefs who have not become members of the Confederation cede to Her Majesty the Queen of England absolutely and without reservation all the rights and powers of Sovereignty which the said Confederation or Individual Chiefs respectively exercise or possess, or may be supposed to exercise or to possess over their respective Territories as the sole sovereigns thereof.

\section{Article the second}

Her Majesty the Queen of England confirms and guarantees to the Chiefs and Tribes of New Zealand and to the respective families and individuals therof the full exclusive and undisturbed possession of their Lands and Estates Forests Fisheries and other properties which they may collectively or 
individually possess so long as it is their wish and desire to retain the same in their possession: but the Chiefs of the United Tribes and the individual Chiefs yield to Her Majesty the exclusive right of Preemption over such lands as the proprietors thereof may be disposed to alienate at such prices as may be agreed upon between the respective Proprietors and persons appointed by Her Majesty to treat with them in that behalf.

\section{Article the third}

In consideration thereof Her Majesty the Queen of England extends to the Natives of new Zealand Her royal protection and imparts to them all the Rights and Privileges of British Subjects.

[signed] W. Hobson Lieutenant Governor

Now therefore We the Chiefs of the Confederation of the United Tribes of New Zealand being assembled in Congress at Victoria in Waitangi and We the Separate and Independent Chiefs of new Zealand claiming authority over the Tribes and Territories which are specified after our respective names, having been made fully to understand the Provisions of the foregoing Treaty, accept and enter into the same in the full spirit and meaning thereof in witness of which we have attached our signatures or marks at the places and the dates respectively specified.

Done at Waitangi this Sixth day of February in the year of Our Lord one thousand eight hundred and forty.

(Note: This English text was signed at Waikato Heads in March or April 1840 and at Manukau on 26 April by thirty-nine chiefs only. The text became the 'official' version.

Reference: Orange, C. (1987). The Treaty of Waitangi. Wellington: Allen \& Unwin NZ Ltd., pp. 257-262. 
1. Full project title

An exploration of issues of primary health services for Taranaki Te Atiawa children, based on the intersecting expectations and perceptions of their female caregivers, within a framework of Kaupapa Maori.

2. Short project title (lay title) Issues of primary health services for Taranaki Te Atiawa children.

3. Lead Principal Investigator's name and position Patricia H. Adams-Smith. MA candidate in Nursing (by research) at Victoria University, Wellington, NZ.

4. Address of lead Investigator

\begin{tabular}{|c|c|c|}
\hline 24 Hutchins Street, Waitara, Taranaki. & \multirow{4}{*}{$\begin{array}{l}\text { Work ph } \\
\text { Home ph } \\
\text { Fax } \\
\text { E-mail }\end{array}$} & N/A \\
\hline & & 067544219. \\
\hline & & C/ 067546637. \\
\hline & & Tricia.AdamsSmith@tipnet.co.nz \\
\hline
\end{tabular}

5. Lead investigator's qualifications and experience in past 5 years (relevant to proposed research)

Tena koutou katoa, e kui ma, me nga mema of tena ruunanga.

Ko Tricia Adams-Smith toku ingoa.

Ko Bill raua ko Diana oku maatua.

Ko Shane Warren toku tane.

Ngati Tama me Maniapoto onu iwi.

Tokomaru me Tainui onu waka.

Ko Te Riu raua ko Ropata maua tama tane.

Taranaki te maunga; Waitara te awa.

No reira, tena koutou, tena koutou, tena koutou katoa.

Qualifications: NZ Registered General and Obstetric Nurse. UK Registered Sick Children's Nurse, NZ Advanced Diploma of Nursing (Child Health), BA Social Science - double major in nursing and social anthropology, post-graduate Diploma in Nursing.

Relevant experience: Invited participant in a focus group interview concerning maternal health, held at Owae Marae, Waitara in 1999, facilitated by Te Puni Kokiri.

Whanau member, Te Kohanga o Waitara, from 1999 on going.

Whanau member, Ngaa Reo e Rua, Waitara East School, from 1999 on going.

Invited guest at child safety forum meetings at Te Maunga Hauora, Waitara, from 1999 on going.

Member of the Waitara First Response Ambulance Team, from 1999 on going.

Whanau member, Nga Pekanga Kohanga Reo, Waitara, from 1996-1999.

Health professional representative on the Taranaki Ethics Committee, from 1993-1999.

Member of The Children's Health Liaison Group Inc. NZ, from 1997 on going.

Participant in an MA Thesis nursing research project, 1999.

Research paper (unpublished): Paediatric Day Surgery: National and International Perspectives, 1997. 


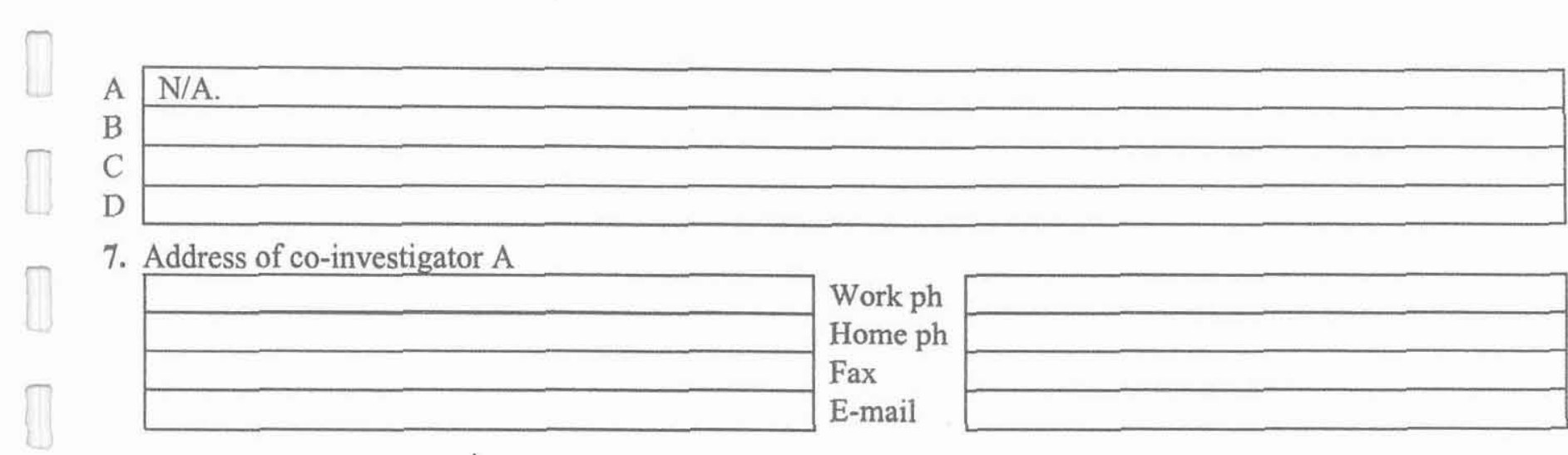


8. Address of co-investigator $B$

\begin{tabular}{|l|}
\hline N/A. \\
\hline \\
\hline \\
\hline
\end{tabular}

Work ph
Home ph
Fax
E-mail

9. Address of co-investigator $\mathrm{C}$

\begin{tabular}{|l|}
\hline N/A. \\
\hline \\
\hline
\end{tabular}

Work ph Home ph

Fax

E-mail

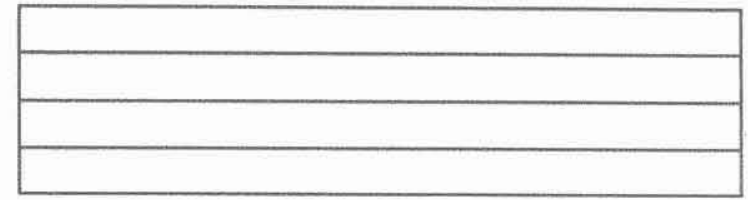

10. Address of co-investigator $D$

\begin{tabular}{|l|}
\hline N/A. \\
\hline \\
\hline
\end{tabular}

Work ph

Home ph

Fax

E-mail

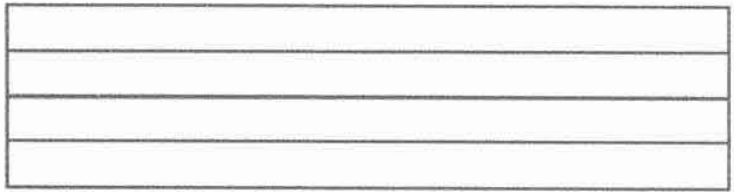

11. Where this is supervised work
11.1 Supervisor's name
Position
Day time phone number
11.2 Signature of supervisor (where relevant)
Declaration: I take responsibility for all ethical aspects of the project

Margaret Southwick

Senior Lecturer, Department of Nursing and Midwifery, Victoria University, Wellington, NZ.

044635233 extn 8491 .

12. List any other New Zealand Ethics

Committees to which this project has been submitted and attach their letters of approval where available
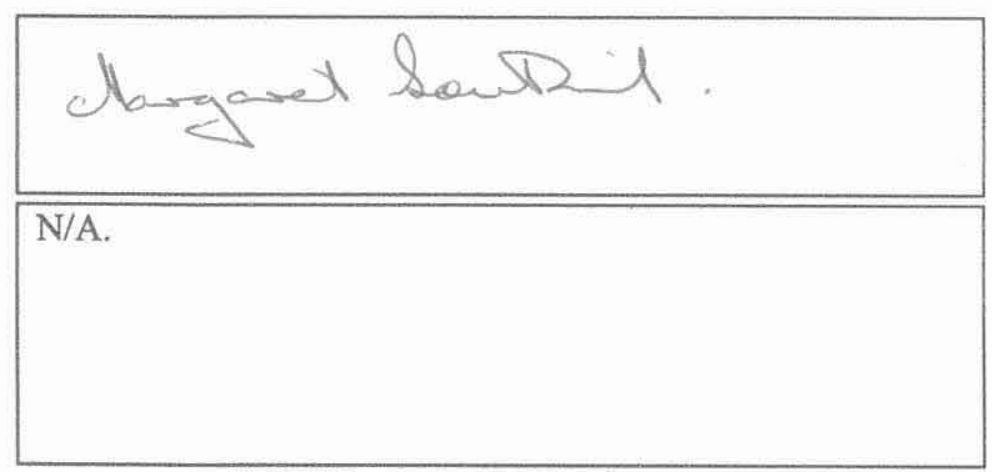

13. I wish the protocol to be heard in a closed meeting (If yes the reason should be given in a covering letter)

14. I request a fast track procedure

15. Proposed starting date $(\mathrm{dd} / \mathrm{mm} / \mathrm{yy})$

16. Proposed finishing date $(\mathrm{dd} / \mathrm{mm} / \mathrm{yy})$

17. Duration of project ( $\mathrm{mm} / \mathrm{yy})$

18. Proposed final report date $(\mathrm{mm} / \mathrm{yy})$

\begin{tabular}{|l|}
\multicolumn{1}{c|}{ Yes } \\
\hline April 2000. \\
\hline March 2001. \\
\hline Eleven months. \\
\hline June 2001. \\
\hline
\end{tabular}




\section{PART II : PROJECT SUMMARY}

\section{Multicentre proposals}

(Important: read the guidelines, Appendix 1)

1.1 Is this a multicentre study? (if no, go to question 2)

1.2 Is this committee the primary ethics committee?

If no, name the primary ethics committee

1.3 Has the protocol been submitted to any other ethics committees in New Zealand? (If yes, attach copies of relevant correspondence)

1.4 Who is the lead investigator or institution in New Zealand?

1.5 List the other New Zealand centres involved, and the Principal Investigator for each centre

1.6 If the study is based overseas, what other countries are involved?

\section{Scientific Assessment}

Has this project been scientifically assessed by independent review?

If yes, by whom? (name and position) A copy of the report should also be attached

If no, is it intended to have the project scientifically assessed, and by whom?

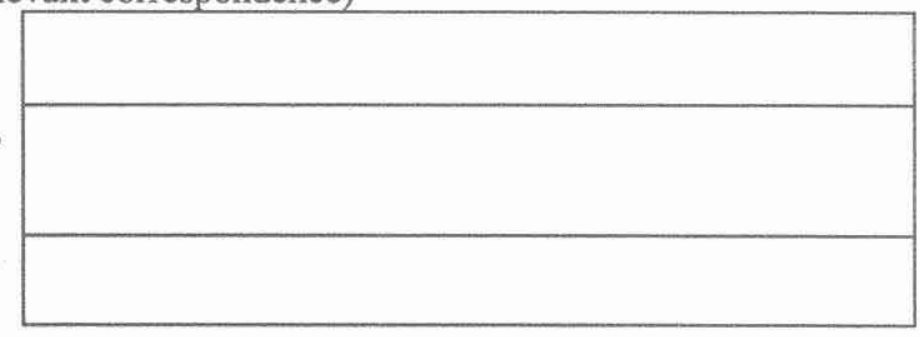

3. Data and Safety Monitoring Board (DSMB)

3.1 Is the trial being reviewed by a data and safety monitoring board? If yes, who is the funder of the DSMB?

\section{Summary}

Give a brief summary of the study (not more than 200 words, in lay language)

There have been many research documents published in the last decade concerned with various aspects of Maori health, that clearly identify an on going disparity between Maori and non-Maori health status in terms of a wide variety of health indicators, with Maori children still needing a greater amount of treatment in hospitals and being under-represented at a primary health level (Durie, 1994; 1996; MOH, 1998, Pomare, 1995; Ratima et al., 1996).

This proposed exploratory study aims to allow the voices of Taranaki Te Atiawa women to define what is important to them in terms of Maori child health and to make visible expectations and perceptions of Maori child health that have so far been invisible or unheard. No such study has been done before with Taranaki Te Atiawa. Therefore this study will give insights into Taranaki Te Atiawa child health, perceptions of caregivers of Taranaki Te Atiawa children and will contribute new knowledge to the discussion on Maori child health.

References: All works cited in this application are listed in the appendix. 


\section{PART III : PROJECT DETAILS}

\section{SCIENTIFIC BASIS}

\section{Aims of Project}

1.1 What is the hypothesis/research question(s)? (state briefly)

What are the expectations and perceptions of female caregivers about primary health services for Taranaki Te Atiawa children?

This study proposes to explore issues of the primary health services for Taranaki Te Atiawa children based on the intersecting expectations and perceptions of their female caregivers within a framework of Kaupapa Maori.

\subsection{What are the specific aims of the project?}

1. To allow the voices of Taranaki Te Atiawa women define what is important to them in terms of Maori child health.

2. To contribute new knowledge to the discussion on Maori child health.

3. To give insights into Te Atiawa child health in Taranaki through the voices of female caregivers.

4. To make visible expectations and perceptions of Maori child health that have so far been invisible and unheard.

\section{Scientific Background of the Research}

Describe the scientific basis of the project (300 words maximum) Where this space is inadequate, continue on a separate sheet of paper. Do not delete page breaks or renumber pages.

This is a qualitative research project. Qualitative inquiry emphasises exploration and discovery, whereas quantitative inquiry tests or measures pre-determined hypotheses or research questions. Mariano (in Talbot, 1995) explains that qualitative research enables people to speak for themselves, and its aim is understanding people's thoughts and feelings. This view is pertinent to this research project.

The theoretical framework to be used is Kaupapa Maori. Kaupapa Maori research has been defined as "research over which Maori maintain conceptual, design, methodological and interpretative control" (L. Smith cited in Tomlins-Jahnke, 1996, p. 29). By nature indigenous, such research validates, legitimates and centralises Maori knowledge, its oral traditions, beliefs, values, pedagogy, collectiveness, family structures and aspirations (L. Smith cited in Taylor, 1994).

Maori children still need a greater amount of treatment in hospitals and are under-represented at a primary health level (Durie, 1994; MOH, 1998; Pomare, 1995). Maori elders and a variety of health professionals consistently highlight the health of children as an important health problem currently affecting Maori (Durie, 1983). For Maori, the whanau is where health status is determined; one of the main roles of the whanau is to nurture and protect the young (Smith, Durie \& Metge in Ratima et al., 1996), which is why the participants in this study will be caregivers of Maori children; specifically, Te Atiawa children who live in Taranaki.

There is a growing recognition of the importance of the link between health and culture. It has been shown conclusively that, for Maori, health cannot be separated from other social and economic considerations. Socio-economic factors such as income, employment, housing and education have been found to be strongly related to health (Pomare et al., 1995).

The Treaty of Waitangi has been identified by many Maori health workers as a suitable framework within which to consider health (Pomare et al., 1995). The right to sovereignty over health services for Maori children and their families, and to have whanau, hapu and iwi involved in decisions about them is guaranteed by the Treaty (Ratima et al., 1996). Maori aspirations for increased autonomy and the demand for culturally safe health services have been illustrated by Maori efforts to provide and manage health services by and for Maori (Pomare et al.). Durie (1997) suggests that in order for Maori to retain a secure identity and advance in today's world, a Maori centred approach to Maori research is needed, in which Maori are located at the centre of the research. 


\section{Participants}

3.1 How many participants is it intended to recruit?

3.2 How will potential participants be identified?

3.3 How will participants be recruited? (e.g. advertisements, notices)

3.3.1 Where will potential participants be approached? (e.g. outpatient clinic) If appropriate, describe by type (e.g. students)

3.3.2 Who will make the initial approach to potential participants?

3.3.3 Is there any special relationship between the participants and the researchers? e.g. doctor/patient, student/teacher
Between 10-15 consenting female caregivers of Te Atiawa children who live in Taranaki.

They will live in Taranaki and be female caregivers of 2 or more Te Atiawa children. They will self-select, using a Maori protocol through Te Maunga Hauora Trust.

Word of mouth, networking and hui held in Waitara. Hui will be organised by the researcher in conjunction with Te Maunga Hauora Trust.

In the local community via word of mouth, networking and hui as described above.

The researcher, through Te Maunga Hauora Trust.

Participants may know each other and/or may know the researcher.

Participants may be related by whanau links to each other and/or the researcher.

3.4 Briefly describe the inclusion/ exclusion criteria and include the relevant page number(s) of the protocol or investigator's brochure

Due to the small size of the research project, it has been decided to ask only women to participate, as per the inclusion criteria stated here. Caring for children has traditionally been a family responsibility for Maori (Durie, 1994), though Maori women are generally responsible for enhancing and maintaining family health (MOH, 1998). It is estimated that single Maori women head at least $43 \%$ of Maori families with dependent children in NZ; and in the researcher's local community, there are at least 186 single Maori mothers (Statistics NZ, 1996).

It was decided to include caregivers of more than one child, as their experiences with child health are likely to be richer. It is anticipated that the female caregivers involved in this exploratory study may be Te Atiawa.

3.5 If randomisation is used, explain how this will be done

N/A. 


\section{Study Design}

4.1 Describe the study design. Where this space is inadequate, continue on a separate sheet of paper. Do not delete page breaks or renumber pages.

The theoretical framework and methodology to be used are Kaupapa Maori. A good deal of material has been written about Kaupapa Maori research (R. Bishop, 1996; L. Pihama, 1993; G. Smith, 1995; L. Smith, 1999).

Russell Bishop (1996) explains that the promotion of self-determination of the research participants is a primary goal of Kaupapa Maori research; it is a research strategy that enables the relation of theory to practice in an indigenous based context and in a manner that aims to promote symmetrical dialogue.

Graham Smith (1995) describes Kaupapa Maori as a theory of change in terms of a coherent philosophy of social practice and change, and as a theory of social transformation in which the notion of whanau is crucial, and plays a central role in providing both a structural and pragmatic framework for Kaupapa Maori as a theory of change. He believes that Kaupapa Maori theory provides a critical matrix by which the success of any strategies that impact on Maori should be measured.

Linda Smith (1999) defines Kaupapa Maori research as being for, by and about Maori. This means that the researcher who is non-Maori (myself) must thoroughly understand a Kaupapa Maori research framework and work within the principles of partnership and participation explicated in the Treaty of Waitangi, to ensure that the research remains culturally appropriate throughout the entire process. Local Te Atiawa have helped to define the research problem, and will gain new knowledge from the research; and I, as the researcher, am accountable to the Maori community in which the research will take place. I will work alongside the Maori community throughout the whole research process with my local Te Atiawa advisers. Selecting participants, questions used in the interviews and dissemination of results will all be done in partnership with them. It is possible that the community may take over the practical process.

The sampling strategies to be used in this study are those of purposive sampling, where the researcher selects participants according to the needs of the research (Morse, 1989) and snowballing, as it is my understanding that the local Te Atiawa community shares a huge amount of information by word of mouth.

4.2 How many visits/admissions of participants will this project involve? Give also an estimate of total time involved for participants.

Two or three focus group meetings with different participants will be required, depending on how many participants choose this interview method instead of one-to-one interview. Each focus group meeting may take approximately two hours. At this stage, only one focus group interview is planned for each group, though another may be added if participants have more to discuss. This will mean a total time of between two to fours hours, approximately, for each participant.

It is expected that the one-to-one interviews will take between one to two hours each. Participants may request more than one of these.

4.3 Describe any methods for obtaining information. Attach questionnaires and interview guidelines.

The focus group interviews will be semi-structured, in order to generate rich date (Krueger, 1994). Guiding questions will be used to commence the discussion and to get it back on track, if needed. The researcher and a local Te Atiawa kuia from Te Maunga Hauora Trust will be present at both focus group interviews and, with permission, at the one-to-one interviews.

Please find a copy of suggested interview questions in the appendix.

4.4 Who will carry out the research procedures?

Myself (the researcher) and a local Te Atiawa kuia from Te Maunga Hauora Trust, as described above.

4.5 Where will the research procedures take place? 
4.6 If blood, tissue or body fluid samples are to be obtained, state type, use, access to, frequency, number of samples, total volume, means of storage and labelling, length of proposed storage and method of disposal.

N/A.

4.7 Will data or other information be stored for later use in a future study?

If yes, explain how

4.8 Will any samples go out of New Zealand? If so where, and for what purpose?

\section{Research Methods and Procedures}

5.1 Is the method of analysis quantitative or qualitative? QUL (If the method of analysis is qualitative, go to question 5.2)

If the method of analysis is wholly or partly quantitative, complete the following: 5.1.1 Describe the statistical method that will be used

5.1.2 Has specialist statistical advice been obtained? Yes No If yes, from whom?

(A brief statistical report should be included if appropriate)

5.1.3 Give a justification for the number of research participants proposed, using appropriate power calculations. 
5.2 If the method of analysis is wholly or partly qualitative, briefly describe the analysis. If interviews are to be used include the general areas around which they will be based. Copies of any questionnaires that will be used should be appended.

It is important that the research methods and analysis used are appropriate within a Kaupapa Maori framework. Focus group and one-to-one interviews fit such a theoretical and methodological stance (Bishop, 1996; Tomlins-Jahnke, 1996; Taylor, 1994). The method of data collection will be in focus group interviews, and one-to-one interviews, all of which will be audiotaped. Focus group interviews can bring out information that may not be surfaced in one-to-one interviews (Krueger, 1994). There will be 2-3 focus groups with 4 to 6 members in each, which is recommended by Krueger as the optimum group size. For reasons of confidentiality and to become familiar with the data, the researcher will transcribe the audiotapes.

The interviews will be audiotaped, transcribed and checked with the participants for accuracy, and changes made if necessary. Participants can choose, using a pseudonym, to partake in the discussion, raise points for discussion and agree or disagree with points raised without being singled out.

Data analysis will be in the form of narrative analysis of the full transcripts, explained by Taylor (1994, p. 369) as enabling "readers to focus on the experiences of the women in the primary context of their spoken words rather than on any...interpretation...provided".

Bishop (1996) explains narrative analysis as a method of data analysis which can successfully be used with Maori as long as the researcher and participants co-construct a mutual understanding which presents considerations and constructions made in the voices of all the participants. In generating explanations of participants' experiences, the research participants develop explanations in terms of the cultural contexts of the participants, rather than that of a researcher seeking themes and patterns (Bishop).

Ultimately, common threads woven through the interviews will be identified and discussed as research findings.

\section{Risks and benefits}

6.1 What are the benefits to research participants of taking part?

The participants will gain new knowledge from this study and potentially increased self-esteem through their involvement in Kaupapa Maori research (G. Smith, 1995). Also, there have been benefits identified from focus group interviews in terms of gaining information about services available, and meeting others in similar situations (Krueger, 1994).

\subsection{How do the research procedures differ from standard treatment procedures?} N/A.

6.3 What are the physical or psychological risks, or side effects to participants or third parties? Describe what action will be taken to minimise any such risks or side effects.

In the focus group interview method, the interviews are conducted with a group of participants together. Thus confidentiality within the group cannot be assured. This needs to be made clear to participants from the outset. Participants must be asked not to share what others in the group say with people outside the group. The participants at all stages in focus group and one-to-one interviews have the right to withdraw and to have any information concerning their participation deleted.

6.4 What arrangements will be made for monitoring and detecting adverse outcomes?

A common concern in focus group interviews is that participants may divulge too much within the group. This is something that participants will be made aware of before any group session commences. Participants will establish the confidentiality of information shared in the group, and they will be reminded of their right to withdraw at any time and to have information concerning them deleted.

6.5 Will any potential toxins, mutagens or teratogens be used? Yes No No If yes, specify and outline the justification for their use 
6.6 Will any radiation or radioactive substances be used? $\quad \square$ Yes No No

Note: If any form of radiation is being used please answer the following. If no, go to question 6.8

6.6.1 Under whose license is the radiation being used?

6.6.2 Has the National Radiation Laboratory (NRL) risk assessment been completed?

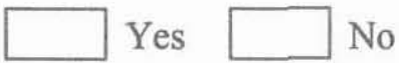
If yes, please enclose a copy of the risk assessment, and the contact name and phone number If no, please explain why

6.7 What facilities/procedures and personnel are there for dealing with emergencies?

6.8 Will any drugs be administered for the purposes of this study?

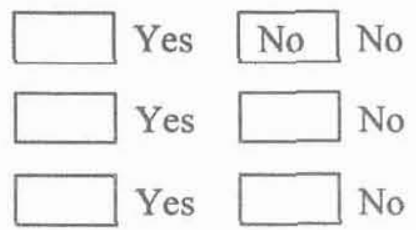

Has SCOTT approval been given? (please attach) 


\section{Expected outcomes or impacts of research}

7.1 What is the potential significance of this project for improved health care for Maori and non Maori, and for the advancement of knowledge?

The potential significance of this project is the outcome of this study, which will contribute new knowledge to the discussion on Taranaki Te Atiawa child health and give insights into Maori child health through the expectations, perceptions and voices of female caregivers. The research findings may be used to help in future development of iwi based health care initiatives, and will be used to acknowledge the value of participant contribution.

\subsection{What steps will be taken to disseminate the research results?}

The dissemination of results by the researcher will take two forms, as advised by the Health Research Council (1998). Initially, community dissemination will take place via a brief report presented at a local hui. This report will also be written as a document for participants and other interested parties. Secondly, there will be a thesis written based on the research results, and some publications, and possibly conference papers will arise from this document. However, any potential publications will be vetted by iwi first. No results will be disseminated without the informed consent of the research participants. 


\section{Budget}

\section{PART IV: BUDGET AND USE OF RESOURCES}

8.1 How will the project be funded?

The researcher has taken out a student loan and is receiving a student allowance for the eleven-month research period. Some research funding will be sought after ethical approval is received, to assist in covering some of the on going costs of the research.

8.2 Does the researcher, the host department or the host institution, have any financial interest in the outcome of this research? Please give details.

N/A.

8.3 Will the researcher personally receive payment according to the number of participants recruited, or a lump sum payment, or any other benefit to conduct the study? If so, please specify:

No.

8.4 What other research studies is the lead investigator currently involved with? None.

\section{Resource Implications}

9.1 Does the study involve the use of healthcare resources?

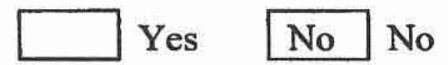
If yes, please specify:

9.2 What effect will this use of resources have on waiting list times for patients ie., for diagnostic tests or for standard treatments?

N/A.

10. Financial Costs and Payments to Participants

10.1 Will there be any financial cost to the participant? Give examples including travel.

There may be a cost if childcare in necessary while participants attend focus group interviews. Travel costs should be minimal, as participants will probably reside within a few kilometres of the interview venue/venues. 
10.2 Will the study drug/treatment continue to be available to the participant after the study ends?

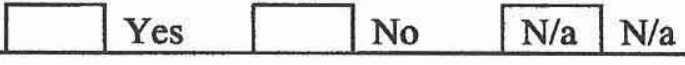
If yes, will there be a cost, and how will this be met?

10.3 Will any payments be made to participants or will they gain materially in other ways from participating in this project? If yes, please supply details

\section{Compensation for Harm Suffered by Participants}

Is this a clinical trial under Accident Rehabilitation and Compensation Insurance Corporation Guidelines? (see form guidelines)

If yes, please answer the following:

11.1 Is the trial being carried out principally for the benefit of a manufacturer or distributor of the drug or item in respect of which the trial is taking place?

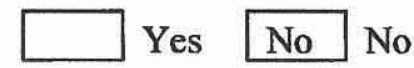

(a) If the answer to 11.1 is yes, please complete Statutory Declaration Form B and answer questions $11.2,11.3$ and 11.4

(b) If the answer to 11.1 is no please complete Statutory Declaration Form $\mathbf{A}$

11.2 What type of injury/adverse consequence resulting from participation in the trial has the manufacturer or distributor undertaken to cover? (please tick the appropriate box/es)

a) any injury (mental or physical)

b) only serious or disabling injuries.

c) only physical injuries

d) only physical injuries resulting from the trial drug or item, but not from any other aspect of the trial

e) physical and mental injury resulting from the trial drug or item, but not from any other aspect of the trial.

f) any other qualification (explain)

11.3 What type of compensation has the manufacturer or distributor agreed to pay?

a) medical expenses

b) pain and suffering

c) loss of earnings

d) loss of earning capacity

e) loss of potential earnings

f) any other financial loss or expenses

g) funeral costs

h) dependants' allowances

11.4 Exclusion clauses:

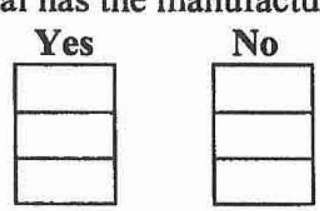

a) Has the manufacturer or distributor limited or excluded liability if the injury is attributable to the negligence of someone other than the manufacturer or distributor? (such as negligence by the investigator, research staff, the hospital or institution, or the participant).

b) Has the manufacturer or distributor limited or excluded liability

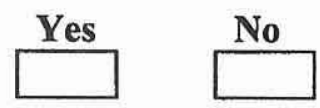
If yes, please specify
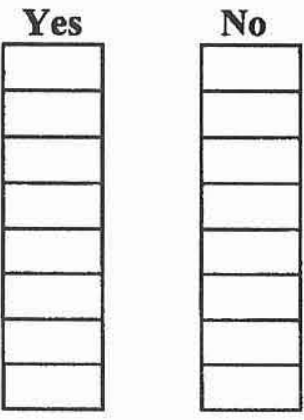 if the injury resulted from a deviation from the study protocol by someone other than the manufacturer or distributor?
c) Is company liability limited in any other way?




\section{Information and Consent}

Consent should be obtained in writing, unless there are good reasons to the contrary. If consent is not to be obtained in writing the justification should be given and the circumstances under which consent is obtained should be recorded. Attach a copy of the information sheet and consent form.

12.1By whom, and how, will the project be explained to potential participants?

12.2 When and where will the explanation be given?

12.3Will a competent interpreter be available, if required?

12.4 How much time will be allowed for the potential participant to decide about taking part?

12.5 Will the participants be capable of giving consent themselves? - if not, to whom will the project be explained and who will give consent?

12.6 In what form (written, or oral) will consent be obtained? If oral consent only, state reasons.

12.7 Are participants in clinical trials to be provided with a card confirming their participation, medication and contact phone number of the principal investigator?

13. Confidentiality and Use of Results

13.1 How will data including audio and video tapes, be handled and stored to safeguard confidentiality (both during and after completion of the research project)?

13.2 What will be done with the raw data when the study is finished?

13.3 How long will the data from the study be kept and who will be responsible for its safe keeping?

13.4 Who will have access to the raw data and/or clinical records during, or after, the study?

13.5 Describe any arrangements to make results available to participants, including whether they will be offered their audio tapes or videos.

13.6 If recordings are made, will participants be offered the opportunity to edit the transcripts of the recordings?

Orally, by the researcher.

At hui to be held in the local community and at any time an interest is expressed in the community or by an intending participant. Yes.

Hui to inform potential participants about the research will take place approximately one month before the research commences.

Yes.

Oral, as this is the most culturally appropriate format. A written "rolling" consent form will be utilised in order to ethically address issues that may arise over the course of the research, particularly with regard to ownership of data. (Please see appendix.)

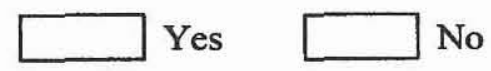

Once the tapes have been transcribed and the research is complete, the transcriptions will be given to the research participants or wiped. Transcriptions will be stored in a locked cabinet owned by the researcher.

Kept for 5 years in a locked cabinet, as above.

The researcher is responsible for keeping data safe for 5 years after the project finishes.

The researcher.

They will be offered these, but confidentiality cannot then be assured. Each focus group will need to reach an agreement on this issue. The local Te Atiawa community advisers will advise the researcher on this point.

13.7 Is it intended to inform the participant's GP of individual

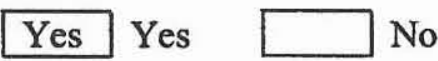
results of the investigations, and their participation, if the participant consents? If no, outline the reasons N/A.

13.8 Will any restriction be placed on publication of results? Yes Yes $\square$ No If yes, please supply details supporting this research will receive a copy of the results. Informed 


\section{Treaty of Waitangi}

14.1 Have you read the HRC booklet, "Guidelines for Researchers on Health Research involving Maori"?

14.2 Does the proposed research project impact on Maori people in any way?

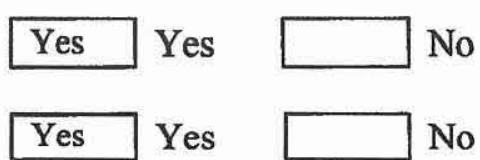

Yes Yes No

14.3 Explain how the intended research process is consistent with the provisions of the Treaty of Waitangi Treaty Articles $2 \& 3$ are of particular relevance to this study. In terms of health research, Article 2
of the Treaty provides for Maori control of their own health, and the authority that iwi and hapu have over their peoples' involvement in research. Initially, this research was discussed with Mina Timutimu, a local Te Atiawa health professional at Te Maunga Hauora Trust (a Maori health initiative in Waitara) and with Hayden Wano and Pam Ritai at Tui Ora Ltd. (a regional Maori health provider). Mina Timutimu will organise hui relating to the research and will be present during the interviews, with the participants' permission. Kura Taylor is the local Te Atiawa research adviser for this study. Article 3 of the Treaty prescribes both expectations for an equivalent state of health between Maori and pakeha, and an equitable share of the benefits of any government expenditure. The NZ Health Research Council (1998) recognises the need for collaborative research between Maori communities and non-Maori researchers that contributes to Maori health development.

The theoretical and methodological framework of this research is that of Kaupapa Maori. Local Maori health providers have identified the method of focus group interviews as being culturally appropriate for this study. Study findings will be disseminated through both hui and written material. Findings will also be useful in future development of iwi based health care initiatives.

14.4 Identify the group(s) with whom consultation has taken place, and attach evidence of their support Consultation has taken place with Te Roopu Wahine Maori Toko I Te Ora, Tui Ora Limited and Te Maunga Hauora. Please find letters of support in the appendix.

14.5 Describe the consultation process that has been undertaken prior to the project's development Initially, an idea for this research was discussed with Mina Timutimu, a local Te Atiawa health professional based at Te Maunga Hauora Trust (a Maori health initiative in Waitara), and with Hayden Wano and Pam Ritai at Tui Ora Ltd. (a regional Maori health provider). Informal discussions were held with these health providers around the direction this project would take, and the researcher's suitability to embark on the planned project. The methodology and method of data collection were also discussed in depth, as was the size and composition of the research sample. The rights of the research participants were considered by all to be of the utmost importance.

A hui was held with the local branch of Te Roopu Wahine Maori Toko I Te Ora, at which a summary of the proposed study was presented, and from which positive feedback was received.

14.6 Describe any ongoing involvement the group consulted has in the project

Kura Taylor will continue to act as the researcher's local Te Atiawa adviser. Mina Timutimu, Hayden Wano and Pam Ritai will advise and support the project and wish to be kept informed throughout the research. 
14.7 Describe how information will be disseminated to participants and the group consulted at the end of the project

There will be an agreement amongst members of each focus group that transcription will happen as a group transcription, with the use of pseudonyms for the participants. The participants will be given a transcription in order to comment on the accuracy of the content, and appropriate changes will be made as and if requested. Each participant will be given a letter thanking them for the value of their participation; this letter will assure them of the confidentiality of the information discussed and will reiterate issues of intellectual property rights.

The dissemination of results will take two forms, as advised by the Health Research Council (1998). Initially, community dissemination will take place via a brief report presented at a local hui. This report will also be written as a document for participants and other interested parties. Secondly, there will be a thesis written based on the research results and some publications will arise from this document. However, any potential publications will be vetted by iwi first. No results will be disseminated without the informed consent of the research participants.

\section{Other Issues}

15.1 Are there any aspects of the research which might raise specific cultural issues?

If yes, please explain The theoretical framework and study design of Kaupapa Maori research.

15.1.1 What ethnic or cultural group(s) does your research involve?

Te Atiawa living in Taranaki.

Describe what consultation has taken place with the group prior to the project's development Initially, an idea for this research was discussed with Mina Timutimu, a local Te Atiawa health professional based at Te Maunga Hauora Trust (a Maori health initiative in Waitara), and with Hayden Wano and Pam Ritai at Tui Ora Ltd. (a regional Maori health provider). Informal discussions were held with these health providers around the direction this project would take, and the researcher's suitability to embark on the planned project. The methodology and method of data collection were also discussed in depth, as was the size and composition of the research sample. The rights of the research participants were considered by all to be of the utmost importance.

A hui was held with the local branch of Te Roopu Wahine Maori Toko I Te Ora, at which a summary of the proposed study was presented, and from which positive feedback was received.

15.1.2 Identify the group(s) with whom consultation has taken place and attach evidence of their support

Consultation has taken place with Te Roopu Wahine Maori Toko I Te Ora, Tui Ora Limited and Te Maunga Hauora. Please find letters of support in the appendix. 
15.1.3 Describe any ongoing involvement the group consulted has in the project

Kura Taylor will continue to act as the researcher's local Te Atiawa adviser. Mina Timutimu, Hayden Wano and Pam Ritai will advise and support the project and wish to be kept informed throughout the research.

15.1.4 Describe how you intend to disseminate information to participants and the group consulted at the end of the project

There will be an agreement amongst members of each focus group that transcription will happen as a group transcription, with the use of pseudonyms for the participants. The participants will be given a transcription in order to comment on the accuracy of the content, and appropriate changes will be made as and if requested. Each participant will be given a letter thanking them for the value of their participation; this letter will assure them of the confidentiality of the information discussed and will reiterate issues of intellectual property rights.

The dissemination of results will take two forms, as advised by the Health Research Council (1998). Initially, community dissemination will take place via a brief report presented at a local hui. This report will also be written as a document for participants and other interested parties. Secondly, there will be a thesis written based on the research results and some publications will arise from this document. However, any potential publications will be vetted by iwi first. No results will be disseminated without the informed consent of the research participants.

\section{Ethical Issues}

16.1 Describe and discuss any ethical issues arising from this project, other than those already dealt with in your answers?

$$
\text { N/A. }
$$

Thank you for your assistance in helping us assess your project fully

Please now complete:

- the declarations (Part V)

- a drug administration form (if applicable)

- an Accident Rehabilitation and Compensation Insurance Corporation form $\mathbf{A}$ or $\mathbf{B}$ 


\section{DECLARATION BY PRINCIPAL INVESTIGATOR}

The information supplied in this application is, to the best of my knowledge and belief, accurate. I have considered the ethical issues involved in this research and believe that I have adequately addressed them in this application. I understand that if the protocol for this research changes in any way I must inform the Ethics Committee.

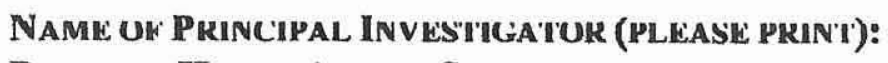

Patricia Helen AdAMS-SMitTh

Signature of PRINCipal INVESTigator/

DATE:<smiles>CC=CNCC(C)(C)C</smiles>

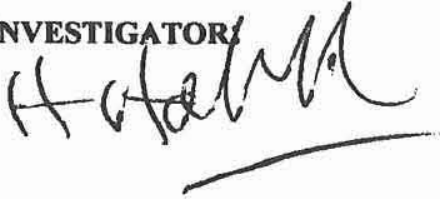

MARCH 13, 2000.

2. DECLARATION BY THE HEAD OF THE DEPARTMENT IN WHICH THE PRINCIPAL INVESTIGATOR IS LOCATED OI APPROPRIATE DEAN OR OTHER SENIOR MANAGER * *

I have read the application and it is appropriate for this research to be conducted in this department I giv my consent for the application to be forwarded to the Ethics Committee.

NAME AND DESignation (PLEASE PRINT): ir of. A 4 son w WON

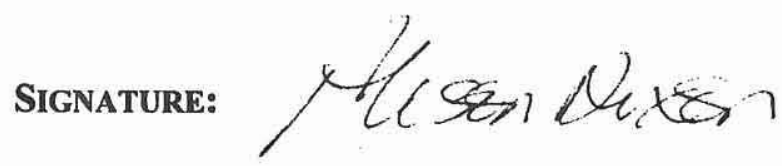
DATE:
2113100
Designation: 1 tob

(NOTE: WHERE THE HEAD OF DEPARTMENT IS ALSO ONE OF THE INVESTIGATORS, THE HEAD OF DEPARTMENT DECLARATION MUST BE SIGNED BY THE APPROPRIATE DEAN, OR OTHER SENIOR MANAGER.

IF THE APPLICATION IS FOR A STUDENT PROJECT, THE SUPERVISOR SHOULD SIGN HERE).

3. DECLARATION BY THE GENERAL MANAGER OF THE HEALTH SERVICE IN WHICH THE RESEARCH IS BEING UNDERTAKEN (IF APPLICABLE)

I have reviewed the proposal for cost, resources, and administrative aspects and issues regarding patient participation and staff involvement. The proposal has my approval subject to the consent of the Ethics Committee.

Name of General Manager (Please Print):

N/A.

SIGNATURE: 
References in the order they appear on the National Ethics Application form $6 / 99$.

From page 3:

Durie, M. (1994). Whaiora. Maori health development. Auckland: Oxford University Press.

Ministry of Health (N) (1998). Our children's health. Key findings on the health of New Zealand children. Wellington: Ministry of Health.

Pomare, E. (1995). Hauora. Maori standards of health III. Wellington: Huia Publishers.

Ratima, M., Allan, G., Durie, M., Edwards, A., Gillies, Te K., Waldon, J. (1996). Oranga Whanau. Maori health and well-being, and whanau. A report prepared by Te Pumanawa Hauora. Palmerston North: Massey University.

From page 4:

Durie, M. (1983). Culture and health. An address to the Royal Society of New Zealand (Manawatu branch). Paimerston North.

Talbot, L. (Ed.). (1995). Principles and practice of nursing research. St. Louis: Mosby.

Taylor, K.M. (1994). 'Conversations' with Maori women. Nga kupu paake a nga wahine Maori. Unpublished MPhil, Auckland University, Auckland.

Tomlins-Jahnke, H. (1996). Whaia te iti kahurangi. Contemporary perspectives of Maori women educators. Unpublished MA in Education, Massey University, Palmerston North.

Durie, M. (1997). Identity, access and Maori advancement. New Zealand Journal of Educational Administration, 12, 41-45.

From page 5:

Durie, M. (1994). Whanau, family and the promotion of health. Palmerston North: Massey University.

Ministry of Health (NZ). (1998). Whaia te whanaungatanga: Oranga whanau. The wellbeing of whanau. Wellington: Ministry of Health. 
Statistics New Zealand. (1996). New Zealand census of population and dwelling. Statistics New Zealand.

\section{From page 6 :}

Bishop, R. (1996). Collaborative research stories. Whakawhanaungatanga.

Palmerston North: the Dunmore Press.

Pihama, L.E. (1993). Tungia te ururua, kia tupu whakaritorito te tupu o te harakeke: A critical analysis of parents as first teachers. MA in Education, The University of Auckland, Auckland.

Smith, G.H. (1995). Whakaoho Whanau. Now formations of whanau as an innovative intervention into Maori cultural and educational crises. He Pukenga Korero, Koanga (Spring): 1(1): 18-36.

Smith, L. (1999). Decolonizing Methodologies. Research and Indigenous Peoples. Dunedin: University of Otago press.

Morse, J. (1989). Qualitative nursing research, a contemporary dialogue. Massachusetts: Aspin Publications Incorporated.

Krueger, R. (1994). Focus groups: A practical guide for applied research ( $2^{\text {nd }}$ ed.). Thousand Oaks: Sage Publications.

From page 10:

Health Research Council of New Zealand. (1998). Guidelines for researchers on health research involving Maori. Auckland: Health Research Council of New Zealand. 


\section{Appendix Three}

\section{Interview Questions}

1. What do you think is important about your mokopuna / children's health?

2. What do you do when your mokopuna / children are sick?

3. Who is most helpful when your mokopuna / children are sick?

4. How do you feel about the access that you have to public health services?

5. What else would be helpful for you when your mokopuna / children are sick? 


\section{Appendix Four}

\section{Information sheet.}

Tena Koe

\section{What is this project about?}

We are researching how you feel about local health care services for your children.

We will have conversations so that you can share feelings about your children's health and what you do when they are sick, and what you want for them.

I hope that we can tape record our conversations.

The information you share will only be used for my thesis and will not be published unless you agree.

Yours and your children's names will not be used unless you agree.

You will receive a brief report on the study when it is completed and a hui will be held at which time I will share the results of the study with you.

\section{What are the benefits of this research?}

The information shared by participants will give a clearer picture of how well the health needs of some local Te Atiawa children are met under the current health system. This information may be used if changes are needed. 
Any issues that arise at any time during the course of this research project will be discussed and agreed by you and us both.

Thank you for consenting to be part of this study and sharing your time with us.

A petrol voucher will be given to all participants.

You may withdraw at any time if you wish.

This project is being supported by Te Whare Punanga Korero, Te Atiawa Iwi Health Forum, Tui Ora Ltd. and the Waitara branch of Te Roopu Wahine Toko i te Ora.

If you have any questions about our study you may ask any of these people:

Tricia Adams-Smith at 754 4219, 24 Hutchins Street, Waitara.

Mina Timutimu, at Te Maunga Hauora Trust: 7547787.

Hayden Wano and Pam Ritai at Tui Ora Limited at 7594064.

The Health and Disability Commissioner's Advocates, Karen Eagles or Puti Rowe at 0800112233. 


\title{
Appendix Five
}

\section{CONSENT FORM}

\author{
EXPLORATION OF ISSUES OF PRIMARY HEALTH FOR TE \\ AT1AWA CHILDREN IN TARANAKI
}

I have read the information sheet for this study and have had the details of the study explained to me. My questions about the study have been answered to my satisfaction, and I understand that I may ask more questions at any time.

I also understand that I am free to withdraw from the study at any time, or to decline to answer any particular question in the study. I agree to provide information within the focus group on the understanding that it is completely confidential within the group.

I agree to participate in this study under the conditions set out on the information sheet. Issues arising over the course of the research will be documented and jointly signed by myself and the researcher as part of an on going informed consent process.

Participant Sign:

Participant Name:

Date:

Researcher Sign and Date: 
Consent form page 2: Added on November 3, 2000.

I consent to the transcript of my interview to be used for this project as it is, or with any alterations I have requested.

Date:

Participant sign:

Researcher sign:

I consent to the transcript of my interview being read by Kura Taylor, who is Te Atiawa from Waitara, to make sure that the focus of the project remains Kaupapa Maori.

I understand that my name will not be on the copy of the transcript that she receives \& that she will not know who I am. She will send the copies of the transcripts back to the researcher when she has read them, \& she will not keep any copies of them.

I understand that Kura Taylor will keep all the information in my transcript strictly confidential.

Date:

Participant sign:

Researcher sign: 


\section{REFERENCES}

Aboriginal health, a missing dimension. (1998). [Editorial]. The Lancet, 351(9105), 765.

Andrain, C.F. (1998). Public health policies and social inequality. New York: New York University Press.

Antezana, F. (1996). Health for all by the year 2000: WHO is spearheading global consultation to update policy on health for all [Letter]. British Medical Journal, 313(7068), 1331.

Asbury, J.-E. (1995). Overview of focus group research. Qualitative Health Research, 5(4), 414-420.

Barer, M., Getzen, T., \& Stoddart, G. (1998). Health, health care and health economics. Chichester: John Wiley \& Sons.

Barnsley, J. \& Ellis, D. (1992). Research for Change: Participatory Action Research for Community Groups. Vancouver: The Women's Research Centre.

BBC News. (Nov. 26, 1998). Health gap widens. BBC Online Network: Health. Available:

http://news.bbc.co.uk/hi/english/health/newsid 222000/222366.stm

BBC News. (June 30, 1999). Doctors call for child health action. BBC Online Network: Health. Available: http://news.bbc.co.uk/hi/english/health/newsid 381000/381354.stm Beanland, C., Schneider, Z., LoBiondo-Wood, G., \& Haber, J. (Eds.). (1999). 
Nursing research: methods, critical appraisal and utilisation (1st Australasian ed.). Sydney: Mosby.

Bishop, R. (1994). Initiating empowering research. New Zealand Journal of Educational Studies, 29(1), 175-188.

Bishop, R. (1996). Collaborative research stories. Whakawhanaungatanga. Palmerston North: The Dunmore Press.

Blackwell, N. \& Hayllar. J. (1998). Aboriginal health [correspondence]. The Lancet, 351(9112), 1363.

Bloom, G. \& McIntyre, D. (1998). Towards equity in health in an unequal society. Social Science and Medicine, 47(10), 1529-38.

Bottomore, T. (1984). The Frankfurt School. Chichester: Ellis Horwood Ltd.

Broughton, J., \& Koopu, P. (1996). Dental Health Services and Maori People. Dunedin: University of Otago.

Broughton, J., \& Lawrence, M. (1993). Nga Wahine Maori me te Kai Paipa: Maori Women and Smoking. Dunedin: University of Otago.

Buck, P. (1910). Medicine amongst the Maoris in ancient and modern times: A thesis for the degree Doctor of Medicine (NZ). University of New Zealand.

Bullock, A., Stallybrass, O., \& Trombley, S. (1988). The Fontana dictionary of modern thought ( $2^{\text {nd }}$ ed.). London: Fontana Press.

Burns, N., \& Grove, S. (1993). The practice of nursing research: Conduct, critique, and utilization (2 ${ }^{\text {nd }}$ ed.). Philadelphia: WB Saunders Co. 
Campbell, J., \& Bunting, S. (1991). Voices and paradigms: Perspectives on critical and feminist theory in nursing. Advances in Nursing Science, 13(3), $1-15$.

Carr, W., \& Kemmis, S. (1986). Becoming critical: Education, knowledge and action research. London: The Falmer Press.

Carryer, J. (1995). Feminist research: strengths and challenges. Contemporary Nurse, 4(4), 180-186.

Casey, H. (2002). Empowerment: What can nurse leaders do to encourage an empowering environment for nurses working in the mental health area? Unpublished MA Thesis in Nursing, Victoria University of Wellington, Wellington.

Coates, K., \& McHugh, P. (1998). Living Relationships / Kookiri Ngaatahi: The Treaty of Waitangi in the New Millennium. Victoria University Press: Wellington.

Cooney, C. (1994). A comparative analysis of transcultural nursing and cultural safety. Nursing Praxis in New Zealand, 9(1), 6-12.

Coup, A. (1996). Cultural safety and culturally congruent care: A comparative analysis of Irihapeti Ramsden's and Madeleine Leinininger's educational projects for practice. Nursing Praxis in New Zealand, 11(1), 4-11.

Cram, F. (1997). Developing partnerships in research: Pakeha researchers and Maori research. Sites, 35(Spring), 44-63.

de Koning, K. \& Martin, M. (Eds.). (1996). Participatory Research in 
Health: Issues and Experiences. London: Zed Books Ltd.

Diamond, P. (1998, July 28, Edition 3). Cost of reforms 'too high'. The Evening Post, p. 5. Wellington, New Zealand.

Dilorio, C., Hockenberry-Eaton, M., Maibach, E., \& Rivero, T. (1994). Focus groups: An interview method for nursing research. Journal of Neuroscience Nursing, 26(3), 175-180.

Dow, D. (1999). Maori Health and Government Policy 1840-1940. Victoria University Press: Wellington.

Durie, M. (1983). Culture and health. An address to the Royal Society of New Zealand (Manawatu Branch). Palmerston North.

Durie, M. (1995). Tino Rangatiratanga: Maori self determination. He pukenga korero: A journal of Maori studies, 1(1), 44-53.

Durie, M. (1997). Identity, access and Maori advancement. New Zealand Journal of Educational Administration, 12, 41-45.

Durie, M. (1998a). Whairora: Maori health development. (2 $2^{\text {nd }}$ ed.). Auckland: Oxford University Press.

Durie, M. (1998b). Te Mana, Te Kawanatanga. The Politics of Maori SelfDetermination. Auckland: Oxford University Press.

Ellison-Loschmann, L. (1997). Maori Women's Experiences of Breastfeeding. Unpublished Thesis: Master of Arts (Midwifery). Victoria 
University of Wellington, Wellington, New Zealand.

English, B. (1998). Hospital Services Plan. Wellington: New Zealand Ministry of Health.

Fay, B. (1987). Critical Social Science: Liberation and its Limits. Oxford: Polity Press.

Foller, M-L. (1995). Future health of indigenous peoples: A human ecology view and the case of the Amazonian Shipibo-Conibo. Futures, 27, 1105-23.

Foltin, G. (1995). The Institute of Medicine report on emergency medical services for children: Critical issues in urban emergency medical services for children. Pediatrics, 96(IS), 174-179.

Fook, J. (Ed.), (1996). The Reflective Researcher: Social Workers' Experience With Theories of Practice Research. St. Leonards, N.S.W.: Allen \& Unwin.

Foucault, M. (1980). Power / Knowledge. Selected interviews and other writings 1972-1977. Translated by C. Gordon, L. Marshall, J. Mepham, K. Soper. Brighton: The Harvester Press.

Fox, R. (1997). The Antenatal Education Needs of Maori Women (in the Tainui Region) and Implications for Midwifery Practice. Unpublished MA Thesis in Midwifery, Victoria University of Wellington: Wellington.

Freire, P. (1972). Pedagogy of the oppressed. Harmondsworth: Penquin. Friedman, E. (1994). Money isn't everything: Nonfinancial barriers to access. JAMA, 271, 1535-1538. 
Geertz, C. (1988). Work and Lives: The Anthropologist as Author. Cambridge: Polity Press.

Gibbs, A. (2001). Social work and empowerment-based research: Possibilities, process and questions. Australian Social Work, 54(1), 29-39.

Gulzar, L. (1999). Access to health care. Image: Journal of Nursing Scholarship, 31(1), 13-19.

Hall, J. (1999). Incremental change in the Australian health care system. Health Affairs, 18(3), 95-110.

Hall, J., Stevens, P.E., \& Meleis, A.I. (1994). Marginalization: A guiding concept for valuing diversity in nursing knowledge development. Advances in Nursing Science, 16(4). 23-41.

Health and Disability Commissioner. (1996). Code of health and disability services consumers' rights. Auckland: Health and Disability Commissioner.

Health Research Council of New Zealand. (1996). Health research council guidelines on ethics in health research: Guidelines and requirements for researchers. Wellington: Health Research Council.

Health Research Council of New Zealand. (1998). Guidelines for researchers on health research involving Maori. Wellington: Health Research Council. Henderson, D.J. (1995). Consciousness raising in participatory research: Method and methodology for emancipatory nursing inquiry. Advances in Nursing Science, 17(3), 58-69. 
Hertz, R. (Ed.). (1997). Reflexivity and Voice. Thousand Oaks: Sage Publications.

Hill, R. (2000). The Treaty of Waitangi Today. Occasional Papers Series (2). Wellington: Treaty of Waitangi Research Unit, Victoria University of Wellington.

Hill Bailey, P. (1997). Finding your way around qualitative methods in nursing research. Journal of Advanced Nursing, 25, 18-22.

Hill Cone, D. (2002). Respect list gives useful pick me up for the politicians. National Business Review, Jan. $25^{\text {th }}, 14$.

Holloway, I. \& Wheeler, S. (1996). Qualitative research for nurses. Oxford: Blackwell Science.

hooks, b. (1990). Yearning, race, gender and cultural politics. Boston: South End Press.

Hui Piri ki nga Tangaora; participants of. (1989). Standards of Kawa Whakaruruhau: Cultural Safety To Practice. November. In Kawa Whakaruruhau. Cultural Safety in Nursing Education in Aotearoa.

Irwin, K. (1994). Maori research methods and processes: An exploration. Sites, 28 (Autumn), 25-43.

Jackson, G., Kelsall, L., Parr, A., \& Papa, D. (1998). Socio-economic inequalities in health care. North Health: Auckland.

Jamieson, C. (1992). Many families built up an 'unpayable medical debt'. 
GP Weekly, June 24, 14, 36.

Jenkins, R. (1997). Issues of empowerment for nurses and clients. Nursing Standard, 11(46), 44-46.

Johnstone, P. \& McConnan, I. (1995). Primary health care led NHS: Learning from developing countries - many lessons. British Medical Journal, 311(7010), 891-892.

Kawharu, I. H. (Ed.). (1989). Waitangi: Maori \& Pakeha Perspectives of the Treaty of Waitangi. Auckland: Oxford University Press.

Keefe, V., Cram, F., Ormsby, C. \& Ormsby, W. (1999). Kaupapa Maori Health Research. Paper given at the Millennium World Conference in Critical Psychology, University of Western Sydney, 30 April-2 May, 1999. Published by Te Ropu Rangahau hauora a Eru Pomare, Wellington School of Medicine, University of Otago.

Kelsey, J. (1990). A Question of Honour? Labour and the Treaty 1984-1989. Allen \& Unwin: Wellington.

Kelsey, J. \& O'Brien, M. (1995). Setting The Record Straight: Social Developments in Aotearoa/New Zealand. Association of Non Government Organisations of Aotearoa: Wellington.

Kendall, J. (1992). Fighting back: Promoting emancipatory nursing actions. Advances in Nursing Science, 15(2), 1-15.

King, A. (1998). Access inequality in rurual New Zealand. New Zealand $G P$, July 1,12 . 
King, M. (2001). Nga Iwi O Te Motu: 1000 Years Of Maori History. (2 ${ }^{\text {nd }}$ ed.). Reed Publishing (NZ) Ltd.: Auckland.

King, M., King, F., Martodipoero, S. (1980). Primary Child Care: A Manual for Health Workers, Book One. (2 ${ }^{\text {nd }}$ ed.). Oxford Medical Publications: Oxford.

Kingry, M. J., Tiedje, L. B., \& Friedman, L. L. (1990). Focus groups: A research technique for nursing. Nursing Research, 39(2), 124-125.

Kiro, C. (1999). Broad determinants of health - Indigenous peoples perspective. World Health Organization Consultation On Indigenous Health, Geneva, 23-26 November, 1999. Available: www.healthsite.co.nz/hauora_maori/resources/feature/0001/001.htm

Koch, T. (1998). Story telling: is it really research? Journal of Advanced Nursing, 28(6), 1182-1190.

Koch, T. \& Harrington, A. (1998). Reconceptualizing rigour: the case for reflexivity. Journal of Advanced Nursing, 28(4), 882-890.

Krueger, R. A. (1994). Focus groups: A practical guide for applied research. (2nd ed.). Thousand Oaks: Sage Publications.

Kuokkanen, L., \& Leino-Kilpi, H. (2000). Power and empowerment in nursing: three theoretical approaches. Journal of Advanced Nursing, 31(1), 235-241.

Lamb, G., \& Huttlinger, K. (1989). Reflexivity in nursing research. Western 
Journal of Nursing Research, 11(6), 765-772.

Lane, P. (1995). Health care system on the sick list. Canadian Medical Association Journal, 152(4), 580-582.

Lange, R. (1999). May the people live: A history of Maori health development 1900-1920. Auckland: Auckland University Press.

Lather, P. (1986). Isues of validity in openly ideological research: Between a rock and a soft place. Interchange, 17(4), 63-84.

Lather, P. (1990). Reinscribing otherwise. In E. Guba (Ed.). The paradigm dialog (pp. 315-332). California: Sage Publications Inc.

Lather, P. (1991). Feminist research in education: With / against. Victoria: Deakin University Press.

Leininger, M. (1996). Response to Cooney article: A comparative analysis of transcultural nursing and cultural safety. Nursing Praxis in New Zealand, 11(2), 13-15.

Makereti; Pennimen, T.K. (1938). The Old-Time Maori. London: Gollanz.

Malcolm, L. (1996). Inequalities in access to and utilisation of primary medical care services for Maori and low income New Zealanders. New Zealand Medical Journal, 109(Issue 1030)), 356-358.

Maori Women's Welfare League. (1984). Rapuora: Health and Maori 
Women. Wellington: The Maori Women's Welfare League.

Maquire, P. (1987). Doing Participatory Research: A Feminist Approach. Amherst, Massachusetts: University of Massachusetts.

Marcus, G., \& Fischer, M. (1986). Anthropology as Cultural Critique. Chicago: The University of Chicago Press.

Massey University Human Ethics Committee. (1997). Code of ethical conduct for research and teaching involving human subjects. Palmerston North: Massey University.

Metge, J. (1995). New Growth From Old: The Whaanau in the Modern World. Wellington: Victoria University Press.

Midland Health. (1995). The People of the Midland Health Region. (Vol. 2, Part 1: Infants and Children). Midland Health.

Ministry of Health. (1994). Kia Whai te Maramatanga: The Effectiveness of Health Messages for Maori. Wellington: New Zealand Ministry of Health.

Ministry of Health. (1995). Policy guidelines for Maori health: Ngaa aratohu kaupapahere hauora Maaori. Wellington: Ministry of Health.

Ministry of Health. (1997). Progress on Health Outcome Targets. Wellington: Ministry of Health.

Ministry of Health. (1998a, May). Whaia Te Whanaungatanga: Oranga Whanau. The Wellbeing of Whanau. Wellington: New Zealand Ministry of Health. 
Ministry of Health. (1998b, December). Progress on Health Outcome Targets. Wellington: New Zealand Ministry of Health.

Ministry of Health. (2001a). He Korowai Oranga: Maori Health Strategy Discussion Document. Wellington: New Zealand Ministry of Health.

Ministry of Health. (2001b). Priorities for Maori and Pacific Health: Evidence from Epidemiology. Wellington: New Zealand Ministry of Health.

National Collective of Women's Refuge in New Zealand. (1990). Code of Ethics. National Collective of Women's Refuge in New Zealand: Wellington.

National Health Committee. (1998). The Social, Cultural and Economic Determinants of Health in New Zealand: Action to Improve Health. Wellington: The National Advisory Committee on Health and Disability.

Newacheck, P., Hughes, D., \& Stoddard, J. (1996). Children's access to primary care: Differences by race, income, and insurance status. Pediatrics, 97(1), 26-32.

New Zealand 1990. (1990). The Treaty of Waitangi. The symbol of our life together as a nation.

New Zealand Nurses' Organisation. (1996). Ethics of nursing research. Wellington: New Zealand Nurses Organisation.

Ngaati Hine Health Trust. (1996). Case study: The Ngaati Hine Health Trust. Health Manager, 3(3), 10-12. 
Northway, R. (2000). Disability, nursing research and the importance of reflexivity. Journal of Advanced Nursing, 32(2), 391-397.

Nursing Council of New Zealand. (1992). Standards for registration of comprehensive nurses from polytechnic courses. Wellington: NCNZ.

Nursing Council of New Zealand. (1996). Guidelines for Cultural Safety in Nursing and Midwifery. Nursing Council of NZ: Wellington.

Nyamathi, A., \& Shuler, P. (1990). Focus group interview: A research technique for informed nursing practice. Journal of Advanced Nursing, 15, 1281-1288.

O’Dowd, A., (1999). What is a HAZ? Nursing Times, 95(13), 17.

Omenn, G. (1998). Stunted lives, stagnant economies: Poverty, disease, and underdevelopment. JAMA, 280(24), 2131.

Orange, C. (1987). The Treaty of Waitangi. Allen \& Unwin New Zealand Limited: Wellington.

Palmer, A., Burns, S., \& Bulman, C. (Eds.) (1994). Reflective Practice in Nursing: The Growth of the Professional Practitioner. Blackwell Science: Oxford, England.

Polaschek, N. (1998). Cultural safety: A new concept in nursing people of different ethnicities. Journal of Advanced Nursing, 27, 452-457.

Parata, H., \& Durie, M. (1993). Maori Health Review: A Report for the Department of Health on How It Can Meet the Government's Maori health Objective. Wellington: New Zealand Department of Health. 
Peacock, D., Devlin, N., \& McGee, R. (1998). The horizontal equity of health care in New Zealand. Dunedin: University of Otago Press.

Pere, D. R. T. (1997). Te Wheke. A celebration of infinite wisdom. (2nd ed.). Gisborne, New Zealand: Ao Ako Global Learning New Zealand Ltd.

Pettis, D. (1997). Maori health in the Southern region: The state of the play and what we're doing about it. Primary Healthcare New Zealand, August, 64-68.

Pihama, L. E. (1993). Tungia te ururua, kia tupu whakaritorito te tupu o te harakeke: A critical analysis of parents as first teachers. Unpublished MA in Education, The University of Auckland, Auckland.

Pomare, E., Keefe-Ormsby, V., Ormsby, C., Pearce, N., Reid, P., Robson, B., \& Watene-Haydon, N. (1995). Hauora: Maori Standards of Health III. Wellington: Te Ropu Rangahau Hauora a Eru Pomare.

Ramsden, I. (1992). Kawa whakaruruhau: Guidelines for nursing and midwifery education. Wellington: NCNZ.

Ramsden, I. (1993). Kawa Whakaruruhau: Cultural Safety in Nursing Education in Aotearoa (New Zealand). Nursing Praxis in New Zealand, 8(3), 4-10.

Ramsden, I. (1996). The Treaty of Waitangi and cultural safety: The role of the Treaty in nursing and midwifery education. In Nursing Council of New Zealand Guidelines for cultural safety in nursing and midwifery education (pp. 21-35), Wellington: NCNZ. 
Ratima, K., Ratima, M., Durie, M., \& Potaka U. (1994). A comprehensive maternity service for Maori women: A pilot study of Maori women in the Palmerston North region. Palmerston North: Te Pumanawa Hauora, Massey University.

Ratima, M., Allan, G., Durie, M., Edwards, W., Gillies, A., Kingi, Te K., and Waldon, J. (1996). Oranga Whaanau: Maori health and well-being, and whanau. Palmerston North, N.Z.: Massey University, Te Puumanawa Hauora (Department of Maori Studies).

Ray, M. (1992). Critical theory as a framework to enhance nursing practice. Nursing Science Quarterly, 5(3), 98-101.

Reason, P. \& Rowan, J. (Eds.). (1981). Human inquiry: A sourcebook of new paradigm research. New York: J. Wiley.

Richardson, F. (2000). What is it like to teach cultural safety in a New Zealand nursing education programme? Unpublished Master of Arts (Nursing) thesis, Massey University, Palmerston North, New Zealand.

Ritchie, J. (1992). Becoming Bicultural. Wellington: Huia Publishers.

Rimene, C., Hassan, C., \& Broughton, J. (1998). Ukaipo: The Place of Nurturing. Maori Women and Childbirth. Dunedin, New Zealand: Te Roopu Rangahau Hauora Maori o Ngai Tahu (The Ngai Tahu Maori Health Research Unit).

Rosenbach, M., Irvin, C., \& Coulam, R. (1999). Access for low-income 
children: Is health insurance enough? Pediatrics, 103(6), 1167-1174.

Ryan, P.M. (1997). The Reed dictionary of modern Maori, (2 ${ }^{\text {nd }}$ ed.). Wellington: Wright and Carman (NZ) Ltd.

Sachdev, P. (1990). Behavioural factors affecting physical health of the New Zealand Maori. Social Science and Medicine, 30(4), 431-440.

Shipley, J. (1995). Policy Guidelines for Regional Health Authorities 1996/97. Wellington: New Zealand Ministry of Health.

Shirley, A. (1995). Special needs of vulnerable and underserved populations: Models, existing and proposed, to meet them. Pediatrics, 96(4), 858-863.

Smith, D. (1995). Les nouveaux miserables: Modern victims of social asphyxia. Pediatrics, 96(4), 851-857.

Smith, G. (1990). Research Issues in Maori Education. Paper presented at the NZARE Special Interests Conference. Auckland: Department of Education, University of Auckland.

Smith, G. H. (1995). Whakaoho Whanau. New formations of whanau as an innovative intervention into Maori cultural and educational crises. He Pukenga Korero, Koanga (Spring); Vol 1(No. 1), 18-36.

Smith, L. (1992). Te Raapunga I te Ao Marama: The search for the world of light. In University Of Auckland Research Unit for Maori Education [Ed.]. Te Tari Rangahau o te Matauranga Maori: The issue of research and Maori 
[Vol. Monograph Number 9]. Auckland: University of Auckland.

Smith, L. T. (1999). Decolonizing Methodologies. Research and Indigenous Peoples. Dunedin: University of Otago Press.

Statistics New Zealand. (1996). New Zealand Census of Population and Dwelling. Statistics New Zealand.

Stephens, R., Frater, P., \& Waldegrave, C. (2000). The GSBGM Working Paper Series. Working Paper 2/00: Below the line: An analysis of income poverty in New Zealand, 1984-1998. Robert Stephens, Paul Frater and Charles Waldegrave: Victoria University in Wellington.

Stevens, P. (1989). A critical social reconceptualization of environment in nursing: implications for methodology. Advances in Nursing Science, 11(4), 56-68.

Stokes, E. (1985). Maori Research and Development: A Discussion Paper. Wellington: National Research Advisory Council.

Survey highlights poverty hardship. (1999, Sept. 24). The Daily News, p. 3.

Sword, W. (1999). A socio-ecological approach to understanding barriers to prenatal care for women of low income. Journal of Advanced Nursing, 29(5), 1170-1177.

Taylor, K. M. (1994). 'Conversations' with Maori women. Nga kupu paake a nga wahine Maori. Unpublished MPhil. Thesis, Auckland University, Auckland. 
Teariki, C., Spoonley, P., \& Tomoana, N. (1992). Te Whakapakari Te Mana Tangata: The Politics and Process of Research for Maori. Palmerston North: Massey University.

Te Awekotuku, N. (1991). He Tikanga Whakaaro. Research Ethics in the Maori Community. Wellington: Manatu Maori.

Te Kete Hauora. (1995). Nga Matatini: Strategic Directions for Maori Health. Wellington: New Zealand Ministry of Health.

Te Puni Kokiri. (1993). He kakano: A handbook of Maori health data. Wellington: Te Puni Kokiri.

Te Puni Kokiri. (1998). Progress Towards Closing Social and Economic Gaps Between Maori and non-Maori: A Report to the Minister of Maori Affairs. Wellington: Te Puni Kokiri.

Te Puni Kokiri. (2000). Progress Towards closing Social and Economic Gaps Between Maori and non-Maori: A Report to the Minister of Maori Affairs. Wellington: Te Puni Kokiri.

Te Whaiti, P., McCarthy, M., \& Durie, A. (Eds.). (1997). Mai I Rangiatea. Auckland: Auckland University Press.

The Maori Health Commission. (1998). Tihei Mauri Ora! Wellington: The Maori Health Commission.

The Public Health Commission. (1995). He Matariki: A Strategic Plan for Maori Public Health. Wellington: Public Health Commission. 
The Royal Commission on Social Policy. (1988). The Treaty of Waitangi and Social Policy, Discussion Booklet No 1. ( $2^{\text {nd }}$ ed.). The Office of the Race Relations Conciliator: Auckland.

Timutimu, M. (2001). Health and Treaty Issues. Unpublished paper.

Thompson, J. (1987). Critical scholarship: The critique of domination in nursing. Advances in Nursing Science, 10(1), 27-38.

Tomlins-Jahnke, H. (1996). Whaia te iti kahurangi. Contemporary perspectives of Maori women educators. Unpublished Masters Thesis in Education, Massey University, Palmerston North.

Tulloch, S. (Ed.). (1996). The Oxford dictionary and thesaurus (Rev. ed.). Oxford: Oxford University Press.

United Kingdom Department of Health. (1999, July 6). Reducing health inequalities: An action report. Available: http://www.doh.gov.uk/ohn/inequalities.htm

Urmson, J., \& Ree, J. (Eds.). (1989). The concise encyclopedia of Western philosophy and philosophers (Rev. ed.). London: Routledge.

Visser, L., Thurmond, L., \& Stinson, N. (1998). Health education: A 'primary' component to the delivery of comprehensive primary care. Journal of Health Education, 29(5), S10-14.

Waldegrave, C., \& Coventry, R. (1987). Poor New Zealand: An Open Letter on Poverty. Platform Publishing: Wellington. 
Walker, R. (1990). Ka Whawhai Tonu Matou: Struggle Without End. Auckland: Penguin Books (NZ) Ltd.

Walker, R. (1995). Physical access to health services in Northland. Auckland: North Health.

Waterman, H. (1998). Embracing ambiguities and valuing ourselves: issues of validity in action research. Journal of Advanced Nursing, 28(1), 101-105.

Werner, D. (1980). Where There Is No Doctor: A Village Health Care Handbook. (2 ${ }^{\text {nd }}$ ed.). Macmillan Publishers Ltd: London.

White, G., \& Thomson, A. (1995). 'As every good mother should'. Childhood immunization in New Zealand: A qualitative study. Health And Social Care In The Community, 3, 73-82.

Wilkinson, G. (1999). Theories of power. In G. Wilkinson \& M. Mier (Eds.), Power and Nursing Practice (pp. 7-23). London: MacMillan.

Women's Health Action Trust. (1999). How the health system works. Inform New Zealand.

Wood, P. \& Schwass, M. (1993). Cultural safety: A framework for changing attitudes. Nursing Praxis in New Zealand, 8(1), 4-15.

Yelland, J., \& Gifford, S. M. (1995). Problems of focus group methods in cross-cultural research: A case study of beliefs about sudden infant death syndrome. Australian Journal of Public Health, 19(3), 257-263. 
Yon, D. (1999). The discursive power of schooling: On the theories of power and empowerment in multiculturalism and anti racism. In A. Cheater (Ed.), The anthropology of power (pp. 28-41). London: Routledge.

Zakrison, T. (1999). Room for a view: Chiapas: a state of health in a state of siege. Canadian Medical Association Journal, 160(4), 538-539. 